\title{
THE IMPACT OF LEARNING ON THE SELECTION OF COST-EFFECTIVE MACHINING AND PRODUCTION PROCESS
}

\author{
By \\ Mohammad Irtiza Hossain \\ Bachelor of Science in Business Administration,
}

State University of New York at Buffalo, New York, United States, 2014

\author{
A thesis \\ presented to Ryerson University \\ Ted Rogers School of Management \\ in partial fulfillment of the \\ requirements for the degree of \\ Master of Science in Management \\ in the Program of \\ Master of Science in Management \\ Toronto, Ontario, Canada, 2020 \\ CC (Mohammad Irtiza Hossain) 2020
}




\section{AUTHOR'S DECLARATION}

I hereby declare that I am the sole author of this thesis. This is a true copy of the thesis, including any required final revisions, as accepted by my examiners.

I authorize Ryerson University to lend this thesis to other institutions or individuals for the purpose of scholarly research

I further authorize Ryerson University to reproduce this thesis by photocopying or by other means, in total or in part, at the request of other institutions or individuals for the purpose of scholarly research.

I understand that my thesis may be made electronically available to the public. 


\title{
The impact of learning on the selection of cost-effective machining and production process
}

\author{
Mohammad Irtiza Hossain \\ Master of Science in Management \\ Ted Rogers School of Management \\ Ryerson University, 2020
}

\begin{abstract}
Informed production decision-making requires a structured understanding of the production process and costs associated. This research proposes a decision support system incorporating the learning effects on selecting cost-effective machining production process. The approach is applied to the case on manufacturing wind turbine blades. The machining industry has experienced a surge in demand for complex machining applications and an availability of a wide range of new machining technologies. Producing complex structures requires experienced CNC programmers that perform extensive strategy planning, design and optimization. The system developed considers the production processes, cost items, power learning curve and experience of the programmers. This enables managers to evaluate between various production processes and select the most cost-efficient process. An analytical approach to evaluate cost efficiency between 3-axis $\mathrm{CNC}$ and 5-axis $\mathrm{CNC}$ machines. The result is a user-friendly planning and selection tool aiding in answering critical managerial questions related to cost-effectiveness.
\end{abstract}

Keywords: Learning effects, Decision Support System, Cost Modelling, Cost Efficiency, CNC Machining, Analytical Modelling, Managerial Question 


\section{Acknowledgements}

I would like to express my deep gratitude to Dr. Margaret Plaza, my research supervisor, for her patient guidance, enthusiastic encouragement and valuable feedback of this research work. Working with Dr. Plaza has been a great honour and privilege. She continually challenged my problem-solving strategies and ensured my readiness for completing the program and also prepared me for corporate life. Thank you for believing in me.

I cannot thank Dr. Franklyn Prescod enough for all his support and guidance throughout my journey at Ryerson University. From the first day of school till the last Dr. Prescod opened opportunities for me and always inspired me to work harder. I would also like to thank Professor Bharat Shah and Professor Robert Hudyma for their advice, opportunities, continued support and mentorship.

Special thanks to Dr. Wojciech Zębala and Dr. Andrzej Matras from Cracow University of Technology, Poland, for facilitating my visit to their beautiful country and letting me use the university's state of the art machining laboratories. I am deeply grateful to Dr. Matras for preparing teaching materials catered to my needs and for performing several experimental demonstrations. My experience at the lab played a huge part in enabling me to carry out this research.

I would also like to thank the Ted Rogers School of Management, Ryerson University and the incredible team that works tirelessly to enrich every student's experience and career opportunities. I would like to thank the MScM program for providing me with the resources to carry out the research and for the employment opportunities that created relief towards the financial burdens over the course of my program. 
Finally, I wish to thank my parents and sister for their support and encouragement throughout my studies 
Table of Contents

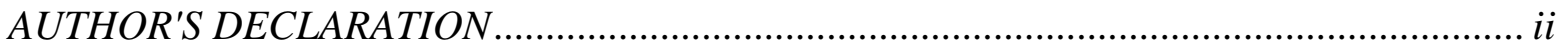

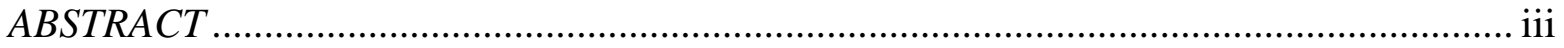

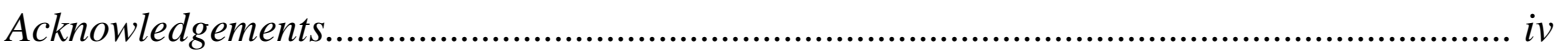

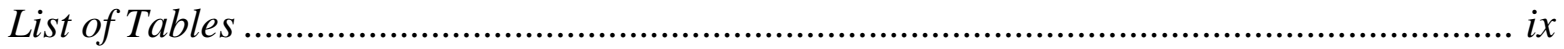

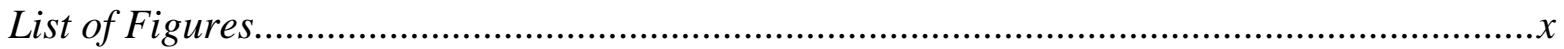

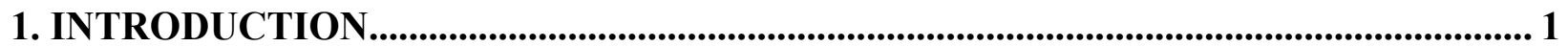

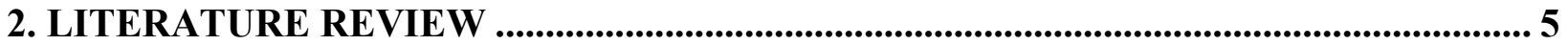

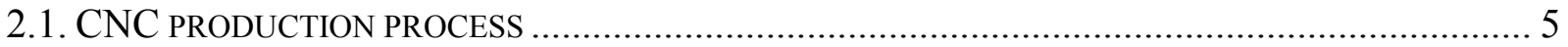

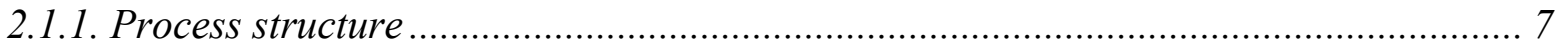

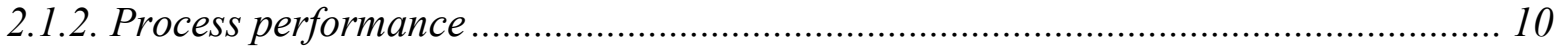

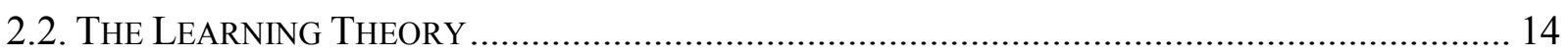

2.2.1. Application of Learning Curve .......................................................................... 15

2.2.2. Application in Strategic Decision-making....................................................... 17

2.2.3. Application in Operational Decision-making ................................................. 18

2.2.4. Application in the machining industry .................................................................. 19

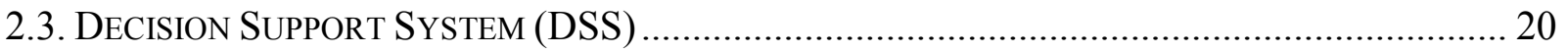

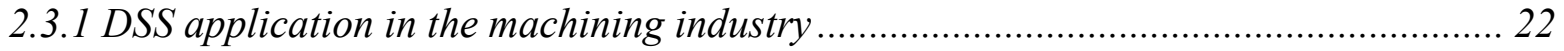

2.3.2. Design Science Methodology ..................................................................... 25

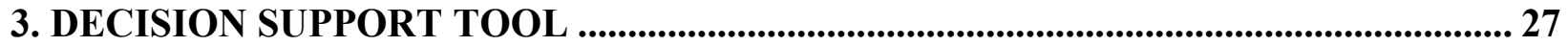

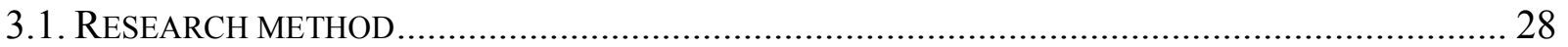




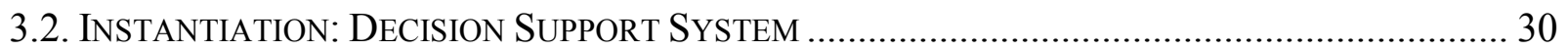

3.2.1. The decision support system flow of information ................................................. 31

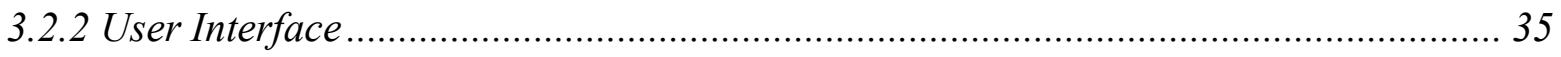

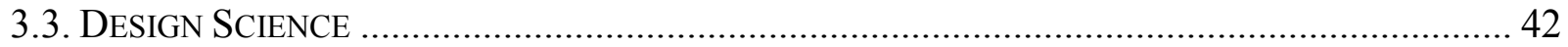

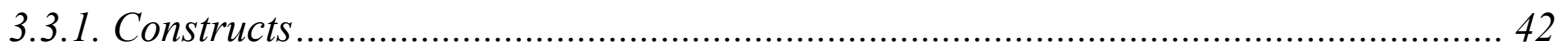

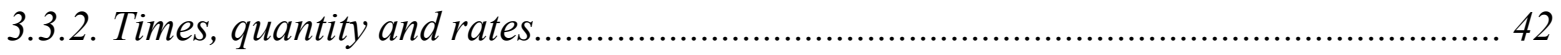

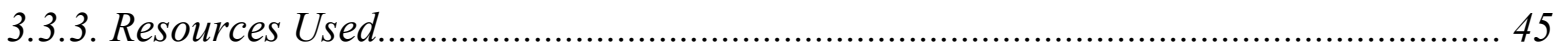

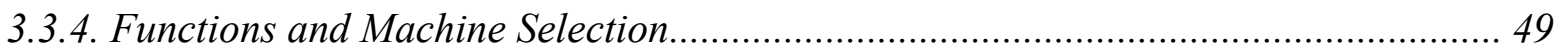

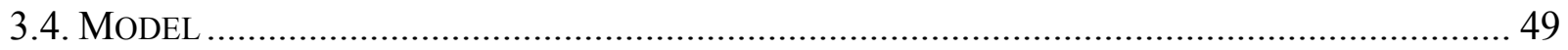

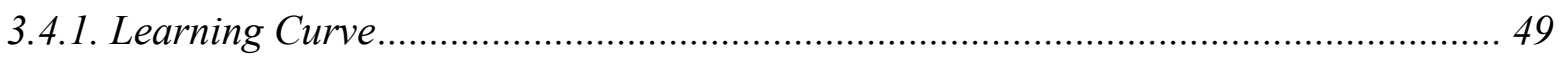

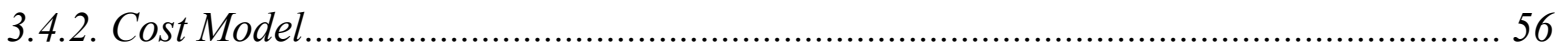

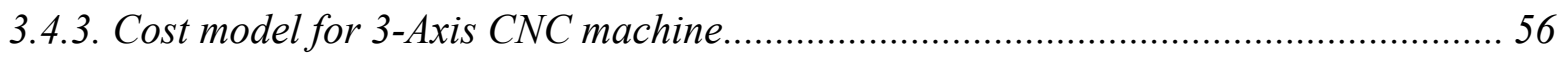

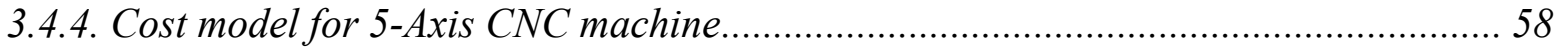

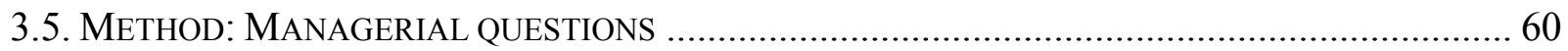

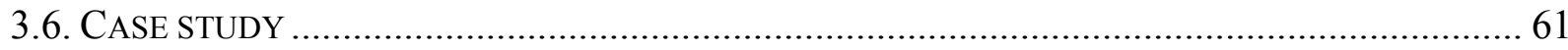

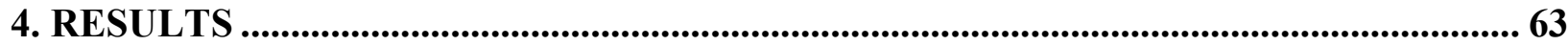

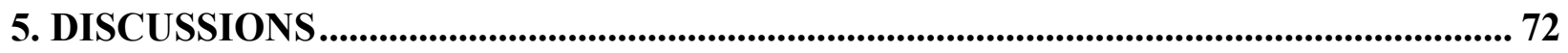

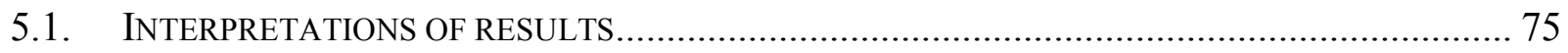

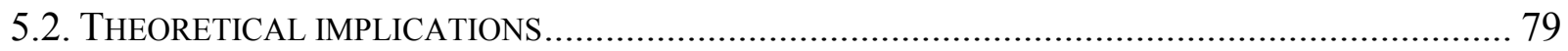

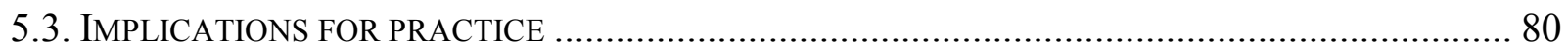

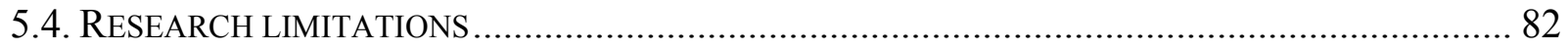

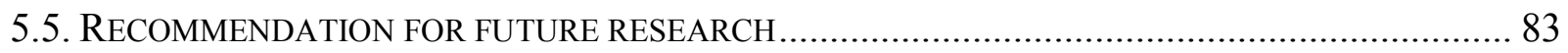

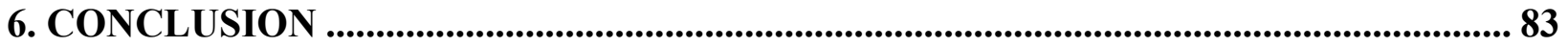




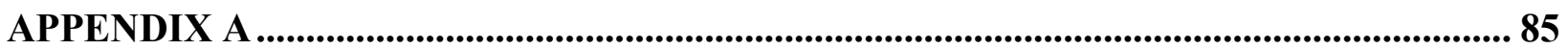

FIGURE A1 DECISION SUPPORT SYSTEM REPORT FOR 3-AXIS COMPETENT .............................. 85

FIGURE A2 DECISION SUPPORT SYSTEM REPORT FOR 3-AXIS PROFICIENT............................... 85

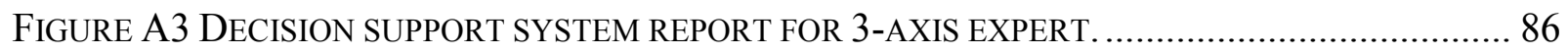

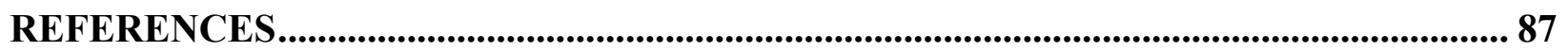




\section{List of Tables}

Table 2. 1 Categorization of Decision Support System (Power, 2016).................................. 21

Table 2. 2 Framework for Decision Support Systems (Power, 2016) ..................................... 22

Table 3. 1 Programmer Experience Level ..................................................................... 51

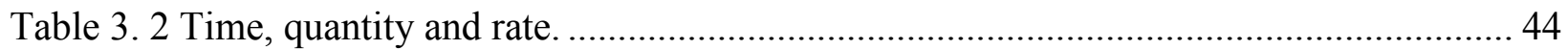

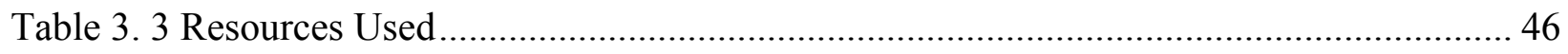

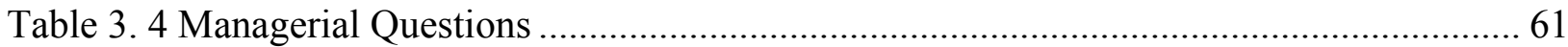




\section{List of Figures}

Figure 2. 1 The types and components of $\mathrm{CNC}$ machine.

Figure 3. 1 Theoretical model for factors determining the impact of learning on the selection of

cost-effective machining and production process... 29

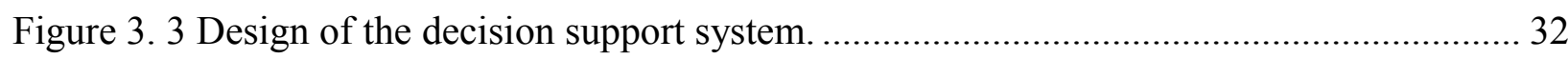

Figure 3. 4 The decision support system data entry form....................................................... 36

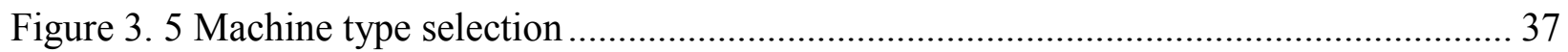

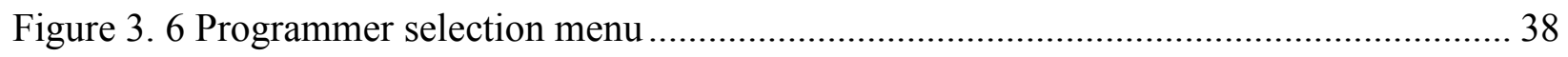

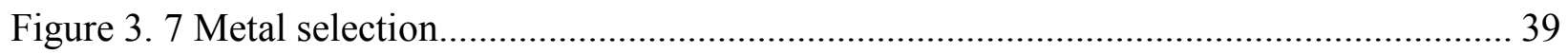

Figure 3. 8 Experimental Verification selection menu ............................................................ 40

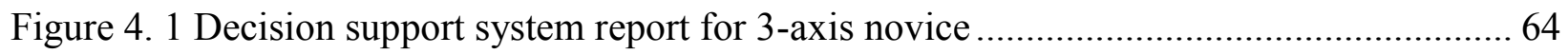

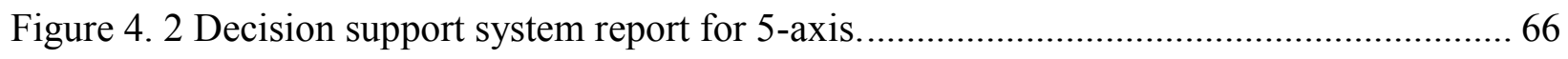

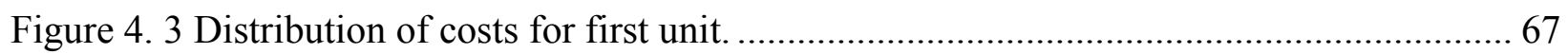

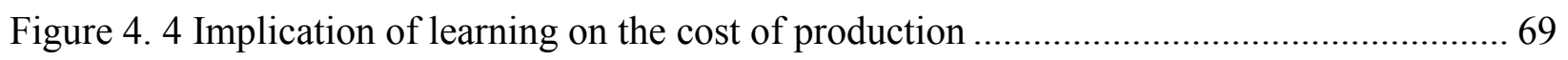

Figure 4. 5 Optimal Batch Size ............................................................................................... 71

Figure A1 Decision support system report for 3-axis competent ……………………............. 85

Figure A2 Decision support system report for 3-axis proficient ……......................................... 85

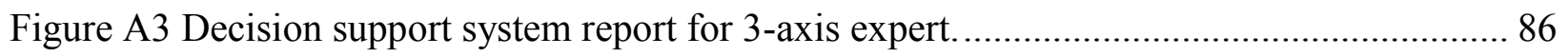




\section{Introduction}

The globalized and highly competitive steel industry requires manufacturers to minimize cost of production and manufacture high-quality complex structures from hard to cut materials. The industry has also experienced a surge in new technology like 3D Printing, 4-axis and 5-axis CNC machines along with software programs Computer-integrated manufacturing (CIM), Computer-aided design (CAD) and SIM (Simulation). The technological advancements have created a wide variety of options to manufacture high quality complex structures (Zębala \& Plaza, 2014a).

To remain competitive, achieving the most cost-effective method of machining can be equally important to achieving the accurate surface finish, quality and precision of the finished product. It is crucial for machining companies to select the appropriate machine for production, frequently upgrade or optimize their manufacturing equipment, use specialized CNC programmers and apply cost effective methods of production. However, implementing a new method of production requires significant upfront investments, training of $\mathrm{CNC}$ programmers, consideration of the programmer experience level and a meticulous examination of the short term and long-term production implications (Gopalakrishnan, Yoshii, \& Dappili, 2004). This study proposes a static decision support system to identify and streamline the variables crucial to the decision-making process and elevate efficiency.

Today China dominates the global steel industry by producing $49 \%$ of the 1.7 billion metric tons steel production per year (Petroff, 2018). Factors responsible for the globalization of the steel industry include a country's surplus capacity of steel, consolidation between major 
steelmakers through vertically and horizontal integration, customer demand and shifting cost curves across the regions (EY global steel, 2016). Elements of the manufacturing strategy such as labour assignments, product quality, process efficiency, time saving and costs must be accurately controlled in order to remain competitive in the dynamic steel industry. Furthermore, effective transition of strategy in changing infrastructure or selecting production process requires extensive design activity in the organization planning process and IT systems (Hevner, March, Park, \& Ram, 2004). Selecting a machining methods without considering alternative methods can lead to inefficiencies as different production cycles can have varying product mix and batch sizes (Seo \& Egbelu, 1996). Moreover, repeating the same manufacturing technique for an extended period of time can be detrimental to achieving efficiency as newer methods are not being evaluated and implemented to improve production processes (Hancock, 1988), (Hancock, 1989).

A decision is a choice made by evaluating two or more alternatives. Effective decisionmaking process can significantly reduce uncertainty and create efficiency. Ayag and Özdemir, (2012) and Arslan, et al., (2004) revealed that only 6\% of machining tool selection is carried out by programmers and $94 \%$ of the times, the selection is made by the operation managers or csuite members in a business. Therefore, a simplified user-friendly approach to the selection process is necessary (Stam \& Kuula, 1991).

The machining design phase requires extensive manual input from the $\mathrm{CNC}$ programmer in conjunction with software technology like CAM. The programmer's ability to write highquality streamlined $\mathrm{NC}$ code, under a time constraint, vastly depends on their experience, skill and aptitude to learn. These factors are crucial to achieving production cost-effectiveness along with programmers' rate per hour, production condition and selected production strategies. 
It is assumed that a programmer performing a task in repetition will follow the production manuals- before and during the production process. The time spent in reading, processing and acquiring knowledge from manuals will be added to the machining time. Furthermore, $\mathrm{CNC}$ centers often produce custom-made products. Variability in the product and the production process make it difficult to fully observe the implications of learning effects. When a programmer switches from one product type to the next, they refer back to the manual for reference on how to complete the new task. However, after a programmer has performed production of a wide variety of products they have acquired experience and have new knowledge. Eventually the programmer requires less time to look at the production manual due to cognitive learning and their production speed increases due to motor learning (Jaber \& Glock, 2013a). It has been observed that the performance improvements are significant during the early stages of the task, followed by improvements continuing to occur at a diminishing rate (Heathcote, Brown, \& Mewhort, 2000). This phenomenon is theorized by Logan (Logan, 1988) as the power law of practice and is mathematical represented as the equation $y_{n}=\mathrm{ax}^{-b}$ (Myung, Kim, \& Pitt, 2000). Where $y_{n}$ is the is the time required to produce the $\mathrm{n}^{\text {th }}$ unit in the batch, expressed in hours. a is the amount of time required to produce the first unit of the batch and is dependent of the learning effects, $\mathrm{x}$ is the number of units in the batch and $\mathrm{b}$ represents the slope of the learning curve. Where $0<\mathrm{b}<1$ (Plaza \& Zebala, 2019a).

Jaber and Glock, (2013b) applied the learning curve into experimental data of a nonspecific repetitive manual assembly task to investigate the economic production quantity, but due to the increasing availability of newer technology and different methods of production, there is a need for another study focusing on the cost implications. Hamade, et al., (2009a) proposed a power curve to observe performance based on the procedural and cognitive performance data 
obtained from novice programmers training with CAD. Brookfield, (2005), Jaber and Glock, (2013a) focused on the phenomena of the power learning curve model on production processes. However, the application of the power curve in a decision support system on the CNC machining production process and its cost implications are have not been explored yet.

This research proposes a decision support system that applied a modified power curve algorithm to describe the learning effects exhibited by the CNC programmer and detected costreductions. Changes are made to the $\alpha$ (Alfa) coefficient to indicate seniority/experience of programmer. The programmers are categorized into groups novice, competent, proficient, expert and 5-axis. The comparison is made between 3 -axis and 5-axis computer numerical control (CNC) machining methods. The 5-axis CNC machines have two additional rotary axes than 3axis $\mathrm{CNC}$ machines, enabling it to machine complex surfaces in one setup with minimal adjustments. This leads to increased time saving and precision. However, the 5-axis machines are more expensive to acquire, service and operate. The 3-axis machines on the other hand are widely available, inexpensive to operate and maintain. Zębala \& Plaza, (2014a) applied a feedrate optimization algorithm called the experimental verification to enhance machining capabilities of 3-axis CNC machine. They concluded that the optimization enhanced 3-axis machines capabilities, increased machining speed by $17 \%$ and produced free-form structures with quality and precision on par to 5-axis CNC machines. This study adopts the Zębala \& Plaza, (2014a) case-study and aims to develop a methodical, accurate, fast-processing, and practical decision-making tool for $\mathrm{CNC}$ machining process selection, to enable managers to analyze different methods of production and select the most cost-effective method. The main objective of this research is to integrate information technology and workforce capabilities to enable the comparison between different methods of production, select the most cost-effective method and 
fill in the knowledge gap on how factors, related to $\mathrm{CNC}$ programmer learning and experience level in combination with choosing the suitable method of production can impact the cost effectiveness of production.

This research explores the following question: What are the implications of learning on the selection of cost-effective machining and production process?

\section{Literature Review}

\subsection{CNC production process}

The computer numerical control $(\mathrm{CNC})$ production process can be segregated into two main segments: planning and machining (Ben-Arieh \& Qian, 2003). CNC planning phase relies heavily on programmer input in software programs like CAD to generate the NC code. Numerically controlled (NC) machining or g-code is the programming language that provide instructions to the CNC machine controller about motors movements and force (ISO 6983, 2009). The accuracy of machining tools depends on quality of the NC code (Fu, Fu, Shen, Yao, $\&$ Chen, 2015). The code is manually written, making the process labour intensive and susceptible to errors. Additional steps like corrections to the code structure, compression of code lines and debugging are also needed to be performed (Plaza \& Zebala, 2019 p.5).

The free-form structures are designed in CAD (Zębala \& Plaza, 2014a) or through 3D scanning (Srinivasan, Harrysson, \& Wysk, 2015). The programmer then examines the work piece material 
and selects the right machining type. Figure 2.1 provides an overview of the different types of CNC cutting techniques and the components associated with the techniques when cutting metal.

\begin{tabular}{|c|c|c|c|c|c|}
\hline CNC Lathe & $\begin{array}{c}\text { CNC } \\
\text { Milling } \\
\text { Machine }\end{array}$ & $\begin{array}{c}\text { CNC } \\
\text { Grinding } \\
\text { Machine }\end{array}$ & $\begin{array}{c}\text { CNC } \\
\text { Boring } \\
\text { Machine }\end{array}$ & $\begin{array}{c}\text { CNC } \\
\text { Drilling } \\
\text { Machine }\end{array}$ & $\begin{array}{c}\text { Machining } \\
\text { Centre }\end{array}$ \\
\hline \multicolumn{6}{|c|}{ CNC Machine Tool } \\
\hline \multirow[t]{8}{*}{$\begin{array}{l}\text { Protective } \\
\text { System }\end{array}$} & $\begin{array}{l}\text { Spindle } \\
\text { Unit } \\
\text { System }\end{array}$ & $\begin{array}{l}\text { Feed-Drive } \\
\text { Unit } \\
\text { system }\end{array}$ & $\begin{array}{l}\text { Manipulator } \\
\text { System }\end{array}$ & $\begin{array}{c}\text { Large } \\
\text { Structural } \\
\text { Component } \\
\text { System }\end{array}$ & $\begin{array}{l}\text { Assist } \\
\text { System }\end{array}$ \\
\hline & Motor & Screw & & $\begin{array}{l}\text { Machining } \\
\text { Surface }\end{array}$ & $\begin{array}{l}\text { Electric } \\
\text { System }\end{array}$ \\
\hline & Bearing & Guide & & Column & $\begin{array}{c}\text { Swarf } \\
\text { Removal }\end{array}$ \\
\hline & & Motor & & & \\
\hline & Axis & Bearing & & Workbench & $\begin{array}{l}\text { Pneumatic } \\
\text { System }\end{array}$ \\
\hline & & Coupling & & & $\begin{array}{l}\text { Lubricant } \\
\text { System }\end{array}$ \\
\hline & & & & & $\begin{array}{l}\text { Hydromantic } \\
\text { system }\end{array}$ \\
\hline & & & & & $\begin{array}{l}\text { Cooling } \\
\text { System }\end{array}$ \\
\hline
\end{tabular}

Figure 2. 1 The types and components of CNC machine.

After selecting the correct machining method, the programmer then maps the surface of the structure with insertion points. The most efficient tool-path through each insertion points are 
selected in conjunction to machining parameters for each of the insertion points. The machining parameters typically consists of several data points such as measurements of material feed-rate, cutting depth, cutting force, cutting speed, tool- angle/inclination, deflection and spindle rotation speed. The success of the machining operation depends on the selection of accurate machining parameters for each insertion points and designing the most efficient tool-path. The programmer responsible for the planning and machining phases, relies heavily on their knowledge, past production data and production manuals to select the parameters suitable for the machine tool being used in production. The manuals consist of base-line parameters such as technical specification of the machine, structure geometry and material properties. These parameters do not always derive optimal result. therefore, adjustments and optimization techniques are applied to the parameters to increase efficiency, precision and eliminate discrepancies in production.

\subsubsection{Process structure}

A wide number of studies have been made to determine the efficiency, cost saving and precision in production through selecting the right process planning. Strategy development and optimization is carried out during the planning phase. Both functions are highly cost intensive. However, by applying innovative techniques to perform strategy development and optimization can create cost savings.

Liu, et al., (2014), Gao, et al., (2019) and Zhou, et al., (2019) provided various data driven process planning techniques to achieve efficiency. Liu et al., (2014) created a knowledgebased model on different types of CNC machines that can be used in production of particular structures. The model considered a database with different combination of process simulations and existing process data to allow the programmer to select the most efficient method of 
production. Gao et al., (2019) experimented with a cloud-based intelligent CNC controller system to automate process planning, minimize manual programmer input and increase efficiency. However, the system requires building an opensource machining database through collaboration and sharing which might be difficult to accomplish in a highly competitive industry. Zhou et al., (2019) proposes a model where data generated from machining are collected and analysed to detect discrepancies (i.e. imperfections on the structure surface) and used the data to make corrections for the next production cycle.

The tool positioning in relation to the cutting surface is vital to achieving the right cutting force and dimensions. The tool-path is the best route through the surface of the structure that the tip of the cutting tool travels through (Layegh, Erdim; et al. 2012). During process planning, the position of the tool in relation to the cutting surface and the continuous shift in position of the tool, as it travels through various insertion points placed on the tool-path must be predetermined precisely (Baskar, et al., (2005), (Fontaine, et al., (2006). Zhiwei, et al., (2012, p.1192) proposed an algorithm to achieve efficiency during planning and to generate a "collision-free" tool path. They concluded that the algorithm improved machining precision, generated faster production time and was versatile enough to be used with a wide-range of cutting tools and achieve different surface finishes.

Skillfulness, experience and learning abilities of the operator are crucial factors in the process planning stage (Plaza, et al., (2019). The programmer ability to write error-free, streamlined NC code under time constraint can substantially improve efficiency in production and cut production costs. The programmer cost per hour is the second highest variable cost after raw materials. Many authors Hamade, et al., (2009b), Ngai \& Cheng, (2001) and Hamade, et al., (2007) provided evidence that programmer capabilities vary during the production process. 
Generally, the programmer performance decline (i.e. causing more errors, lower productivity and added time taken to produce) when new technology, process or task is introduced. However, the decline is quickly reversed after the completion of the first batch. Improvements in performance were also observed after programmers received training or demonstrations. Furthermore, research on learning effects showed that programmer productivity continues to increases after the optimal level is reached when compared to the production of previous batches. Therefore, the recurring costs associated with process planning will continue to decline, after every consecutive batch are manufactured.

The rapid advancements in the CNC machining technology has transformed the way $\mathrm{CNC}$ programmers operate at their work stations. Programmers generally perform demanding cognitive tasks like design, planning and production observation. For example programmers constantly monitor and minimize rapid tool-head deterioration, prevent work-piece surface damage from high-speed cutting, monitor the tool tip temperature and maintain production parameters within the volumetric capacity of the $\mathrm{CNC}$ machine (Thakur, Ramamoorthy, \& Vijayaraghavan, 2009). Any lapse in their ability to perform their tasks properly can lead to significant monetary losses and can even cause injuries. Therefore, the crucial first step is to assign programmer with the right skill and experience Hamade, Jaber, \& Sikstrom, (2009). (I, A, et al., (2012) further emphasized on the need to ergonomically design work-station and create environment for programmers to work more efficiently with minimal effort.

Newman, et al., (2012) focused on achieving efficiency through energy saving process planning. They performed experiments that illustrated using different combinations of energy efficient process planning can lead to $6 \%$ to $40 \%$ less energy usage. Xiong, et al., (2016) identified inconspicuous variables like energy consumption and compressed air usage to derive 
accurate machining parameters in relation to the current running state of the machines, cutting tool and production condition. Substantial heat is generated when machining hard to cut metals. Compensating for the thermal energy can play a critical role in process planning. In practice, testing, modeling and compensation of thermal error are performed, when the $\mathrm{CNC}$ machine is at idling state and the spindle is rotating free with no contact with the work price. Miao et al., 2017) measured the impact of machining parameters like spindle rotation speed, temperature, cooling liquid levels, feed-rate, depth of cut and cutting forces between actual machining condition and in idle condition. They concluded that the distribution of heat and the transfer of heat varied. Furthermore, they highlighted that the accurate calculation of thermal energy can increase production precision and efficiency.

\subsubsection{Process performance}

In the aforementioned literature focused on machining process structure. However, optimizations of parameters play an important role in achieving efficiency and improving the process performance. A vast array of research in manufacturing like Tolouei-Rad \& Bidhendi, (1996), Yildiz, (2013), Al-Ahmari, (2001) and Ganesan \& Mohankumar, (2013a) has been applied to finding optimal machining parameters and creating cost saving. Optimization is applied in the form of algorithms or enhanced NC code to constraints like feed-rate, tool life, cutting force, etc. For example Baskar, et al., (2006) applied three different algorithm based optimization methods to a production process and observed significant improvements in production efficiency from each algorithm. 
Structural properties like thin-walled metal in combination with varying cutting forces can create vibrations. Uncontrolled vibrations can lead to loss of precision, deformation on the structure surface, accelerate tool wear and reduce efficiency. Various optimization methods have been applied to control vibration, create stability and achieve efficiency. Ratava \& Lohtander, (2018a) and Altintaş \& Budak, (1995) applied a data driven approach to analyse production data, isolate forces that caused vibration and optimized cutting forces with parameters that caused less vibration, ultimately increasing machining precision. Chen, et al., (2009) used a similar analysis to create a vibration prediction model. Altintaş \& Budak, (1995) examined various cutting forces and proposed a combination of cutting depth and cross-coupling to reduce vibration and increase stability. Chen, et al., (2009) and Dépincé \& Hascoët, (2006) evaluated the link between the cutting force and deformation on the surface of the structure. They proposed a deformation prediction and error compensation model to optimize machining parameters. Grabec, (1988), Hanna \& Tobias, (1969) factored in the stiffness of the metal and variations in cutting force, to achieved stability. Similarly Plaza et al., 2019), Roman, et al., (2006) proposed an optimized machining parameter in the form of enhanced $\mathrm{NC}$ code to increase machining stability and reduce structure surface deformations. Kabaldin, et al., (2018) proposed the use of neural networks for optimization of the machining process and improving stability of cutting forces.

Optimization of material feed-rate can create multifaceted efficiency in production. Generally the feed-rate parameter impacts quality of output and cutting tool longevity (Choi, 2015). Lower feed-rate increases stability, precision and reduces tool-wear but increases production time and cost. Higher feed-rate on the other hand increases production speed, but creates stress and vibrations on the cutting surface that can lead to deformations (Dong, Ferreira, \& Stori, 2007), (Tansel et al., 2006). In practice the feed-rate is set conservatively for safety and 
reliability reasons. Furthermore, the feed-rate generated through CAD is only a baseline and needs to be optimized for every production process to maximize machine usage. Hence, inaccurate material feed-rate parameter commonly leads to inefficiency and underutilization of resources (J. K. Rai \& Xirouchakis, 2008).

The feed rate is the most relevant cutting parameter affecting tool longevity (Kose, Kurt, \& Seker, 2008) and cutting speed (Razak, Chen, \& Pasang, 2017). Ibrahim et al., (2017) measured surface deformations and tool wear to evaluate the optimum feed rate parameter. Badrinathan \& Karunamoorthy, (2014) performed statistical analysis on the effects of the feedrate optimization and illustrated significant reduction in expenses resulting from reduced tool wear and production time. Oral, et al., (2016) used a combination of variable feed-rate to reduce tool wear by $32 \%$. Whereas (Hajian, et al., (2017), Xu \& Tang, (2014) examined the correlation between tool-bending and feed-rate to minimize deformations occurring on the cutting surface.

Joshi, et al., (2018), Bosetti \& Bertolazzi, (2014) focused on achieving efficiency through reducing tool-path deviations and by using feed-rate optimization. (Zhang, et al., (2018) developed off-line feed-rate optimization techniques. While (Liang, et al., (2017), (Ridwan, et al., (2012b) focused on feed-rate scheduling to improve processing efficiency. Numerous studies (Lie Tang \& Landers, 2012), (Karunakaran \& Shringi, 2008), (Ratava \& Lohtander, 2018b) and (Ridwan, Xu, \& Ho, 2012a) proposed various adaptive feed-rate methods to achieve efficiency and precision.

The lapse between machining parameters generated through CAD, simulation or 3D scanning versus the real-world performance, capability and condition of the $\mathrm{CNC}$ machine, lead to inaccuracies and imperfections on the structure surface. The lapse in machining parameters 
must be considered in the planning phase. Hence optimization techniques are adopted to prevent issues like over-loading of the spindle, excessive cutting force, vibrations, excessive tool wear, etc. to improve machining precision Ganesan \& Mohankumar, (2013b) and capabilities Zębala \& Plaza, (2014a). Yeh \& Su, (2009) proposed the non-uniform rational basis spline (NURBS) curves fitting technique to bridge the gap between machining parameters generated in CAD software and real production condition. Their optimized parameters demonstrated improvements in time, quality and efficiency in production.

Ridwan \& Xu, (2013), (Oliveira, et al., (2008) proposed smart monitoring systems equipped with sensors to collect real-time data from the machines. The data is used to automatically analyze, perform optimization and finetune the parameters to gain accuracy. This technique resulted in shorter machining time, minimized programmer input and increased quality. Nee, et al., (2018) performed experiments to observe the correlation between the best possible feed-rate, spindle rotational speed, depth of cut and tool-tip radius with the amount of surface roughness in the structure. They reduced the surface roughness to the lowest levels, inorder to derive the optimal cutting parameters.

The issues effecting machining parameters are often addressed through data modelling, simulation (Wan, Zhang, Tan, \& Qin, 2008), offline optimization and experimental cuts (Ratchev, Liu, Huang, \& Becker, 2004). Lange, et al., (2012) utilized simulation, to generate data on large-scale machining process. The data was analysed to extract machining parameters like optimal tool usage and control strategies like feed-rate. However, this process proved labour intensive and required additional machining hours. Simulations are performed in two dimensions environment, which can result in discrepancies when machining free-form three dimensional structures. New three dimensional simulation technology like virtual reality (VR) and augmented 
reality (AR) can provide more accurate results (Mao, Liu, \& Gao, 2011). But implementation often requires purchasing costly hardware, computer processing power and training of programmers (Abdul Kadir, Xu, \& Hämmerle, 2011).

\subsection{The Learning Theory}

The learning curve occurs as a natural phenomenon when human capital is involved. The correlation between task repetition and reduction in time taken to complete each repeated task is termed as the learning effect. It was first discovered in 1925 by an aircraft manufacturer at the Wright-Patterson Air Force Base in Ohio, United States (Wright, 1936, p.124). An observation was made that during the assembly of aircrafts, manufacturing the fourth aircraft required $20 \%$ less labour hours then the second plane and manufacturing the eight plane required $20 \%$ less labour hours then the fourth aircraft (Norsworthy \& Tsai, 2012). Ever since Wright's discovery the benefits of the learning curves have been widely recognized, accepted and integrated into production, capacity and workforce planning (Cantamessa \& Valentini, 2000), (Z. X. Guo, Yang, Wang, \& Yang, 2015). Extensive research, applications and literature have been produced on the learning curves. There are numerous iterations of the learning curves, enabling its application to a wide range of production economic decisions (Castellano, Gallo, Grassi, \& Santillo, 2019). Review the study by Jaber, (2016) for an comprehensive description of the different learning curves and applications. The implications of learning curve depend on variables like the nature and complexity of the task, the operator's prior experiences, machines, tools and systems being used, interruptions to the production time and process and training/manuals provided for the task, etc. In practice learning curve provide a mathematical representation of the value created from 
programmers learning ability while performing a repetitive task, as a result efficiency and cost saving can occur.

Alamri \& Balkhi, (2007) rejected Wright's original hypothesis that knowledge once gained is not lost or diminished. Jaber \& Sikström, (2004), Jaber \& Bonney, (1996), Nembhard \& Uzumeri, (2000) examined the forgetting models and provided correlations between time when learning took place and knowledge was retained followed by forgetting of the skill. Globerson, et al., (1989) further illustrated the relationship between the length of the absence, performance time before the absence and the degree of forgetting that took place during the absence. They derived a correlation between forgetting and absence length by recording the workers experience gained before the absence. Introduced an absence period that ranged from one to eighty-two days. Furthermore, they proposed a power curve to illustrate the forgetting model and concluded that the decline in performance was marginal for a one-day absence, but substantial for long term absences. This demonstrated that the production environment, time and process have a significant role in the programmers learning abilities, knowledge retention and performance.

\subsubsection{Application of Learning Curve}

Lerch \& Buck, (1975) presented various forms of learning curves and classified them into two principal groups: an exponential model and power-form model. Each group can be described in a discrete or continuous form. Furthermore, the performance is measured based on time and rate. The log-linear model was developed by Gruber, (1998), who considered production strategy dimensions like duration of task, production rates and product life-cycle. Smunt, (1999) further 
modified the log-linear model to include time and rate parameters. Several studies observed the positive implications arising from the workers previous experiences, skills and performance. These variables are factored it into learning models like Stanford-B, Dejong and S-Curve (Z. X. Guo, Yang, Wang, \& Yang, 2015).

Anzanello \& Fogliatto, (2011) studied existing learning curves and addressed how learning curves are used to estimate/forecast time-required to complete a task, monitor performance and aid in assigning workers to tasks based on their performance profile and skill sets. This method ultimately reduced costs and created efficiency in production. They compared multivariate and univariate learning curve models and enforced the idea that multivariate models are more effective in measuring the learning effects taking place in manufacturing processes, compared to the univariate models. Because multivariate models can factor in multiple independent variables. Grosse, Glock, \& Müller, (2015) conducted an analysis of a large set of empirical data on existing learning curves. They derived the best application for each type of learning curve and highlighted the importance of selecting the right curve in relation to the production situations. Jaber \& Glock, (2013b) proposed a new learning curve model that considered the cognitive and motor components of a worker while performing a repetitive task. They concluded that programmers cognitive and motor factors were an effective measure. The findings matched the results of two renowned journals in the field (Dar-El, Ayas, \& Gilad, 1995), (Bailey, 1989). 


\subsubsection{Application in Strategic Decision-making}

The S-curve and the simpler exponential curve are frequently used to track cost estimations and performance measurements in technology based projects (Plaza \& Zebala, 2019a). For example Yang, Wang, \& Pai, (2009) used the exponential curve to keep track of reduction in process cost and Koltai \& Kalló, (2017) applied an exponential learning curve to determine the throughput-time in a production process of a pre-set quantity of goods in a simple assembly line. Ngwenyama, Guergachi, \& McLaren, (2007) utilized the S-curve to calculate the ideal time for software upgrades and enterprise resource planning implementations. Plaza, (2016a) applied the S-Curve to demonstrate the importance of the operator's performance when new enterprise resource planning (ERP) technology is introduced. The model highlighted the multiskilled nature of individual workers and performed a data driven task scheduling technique to create efficiency.

Gagnon \& Sheu, (2000) utilized learning and forgetting curves for selecting new technology in labour intensive production process. Similarly, Lamar \& Lee, (1999) incorporated learning effects along with variables like setup costs, economies of scale, and work place congestion effects into a model to aid in capital investment decisions. Dardan, Busch, \& Sward, (2006) analysed the impact of learning when investing in technology using a 3-parameters exponential model. Whereas Plaza, (2016b) used a 2-parameter logistic curve to analyze the cost benefit effects obtained through training operators when implementing a new ERP system. Guo \& Fan, (2017) studied adoption of optimal abatement technology. They showed that accumulated experience amongst the workers can lower technology adoption cost and create a positive spillover effect because of learning that took place from the use of other technologies. Plaza \& Rohlf, (2008) utilized the S-curve to measure the performance improvements during an ERP 
software implementation process. They observed significant performance improvements that occurred during the initial stages of implementation and concluded that providing training to workers can significantly increase their performance.

\subsubsection{Application in Operational Decision-making.}

Grosse \& Glock, (2013) applied empirical data from an order picking process to six different learning curves. They performed a regression analysis of the data set and demonstrated that, learning curves can effectively be used in planning in the order picking process. However, they concluded that it is imperative to apply the right learning curve, since the Wright, De Jong, Dar-El et al. and the three-parameter hyperbolic learning curves provided realistic results while; the Stanford B model and the time constant learning curve derived improbable results.

Anzanello \& Fogliatto, (2007) presented a method where learning curves were used to assign products to workers in groups that are working in a fast-changing assembly-line process. They based the allocation of task on similarities in the product's manufacturing process. Whereas Małachowski \& Korytkowski, (2016) took an individualistic approach to appraise each worker's competence. They analysed tasks completed by each worker, recorded workers experience and learning to enable managers to make accurate worker allocation decisions.

The Dejong curve was used by (Ji, et al., (2015) to derive accurate scheduling results from a single and multiple machining units. Biskup, (2008), (1999), (Azzouz, et al., (2018) emphasized on the usefulness of learning curves in scheduling environments.

Jennings \& Shah, (2014) analysed large scale workforce planning issues when implementing a new technology. They focused on key production implications like the learning 
rate of the workforce when new technology is introduced, used an uncertainty analysis that provided descriptive statistics of their model. They concluded that by considering manufacturing costs during the design phase and finding the right procedure can have immense cost benefits to the manufacturing process. Jin, Thomas, \& Hewit, (2016) addressed the workforce assignment problems arising from nonlinearity of the learning curves. They developed a model to eliminate the nonlinearity of the learning curve and observed that nonlinearity of the curves caused several optimization costs to be excluded, leading to inaccurate calculation of the cost of production.

\subsubsection{Application in the machining industry}

Hamade et al., (2009) presented experimental data of an inexperienced programmers working with CAD software. The performance of the programmer was analysed using univariate, multivariate and aggregate learning curve models. They correlated the time taken to complete a task with the time taken to actually perform the: task, accumulate experience and gain knowledge. Furthermore, they measured performance gained by the programmer, by counting the number of CAD features used. The lower number of CAD features used indicated higher progress and higher number of CAD features indicated lower progress. They observed that the univariate learning curve model showed a decline in learning when performing similar tasks and an optimal level is reached. However, there was no relationship between performance and cognition of the worker. Therefore, they concluded that a worker's performance does increase when performing a repetitive task, as long as the worker is being challenged to work more efficiently and by using fewer features. The aggregate learning curve model suggested inexperienced workers typically used more CAD software features, but had a higher learning rate. The research concluded that the multivariate model was the most effective tool to measure 
performance. However, it is not widely used due to its complex mathematical and data requirements. (Hamade, Jaber, \& Sikström, 2009b, p.1518). Castellano et al., (2019) emphasized on the trend of mass-customization and variations in products. Since variability in the production can make it difficult to apply learning curves and quantify improvements accurately. They used batching policies to group customized orders with similar production characteristics like the tool used and then analysed the performance measurements arising from learning effect.

\subsection{Decision Support System (DSS)}

The dynamic machining industry is presented with developments in advanced machining technologies, innovative methods of production and at the same time facing a surge of demand for manufacturing complex structures. There is a need for a reconfigurable decision support system, that can accommodate and compare new methods of machining. Numerous studies have provided evidence that decision support systems can improve decision quality and positively alter the structure and operations of organizations (Power, 2016). Rao, (2007) stated that the selection of accurate machining technology and production method can significantly increase production efficiency and create cost savings. While Gupta \& Dutta, (2016) emphasized on the need to create a user-friendly decision support system that can serve various personnel in a business as an effective planning tool.

Generally, a decision support system is a technology product that is created to link hardware and software components in a business through networks. It provides a user interface that can be accessed on devices like computers and smartphones. A model-driven decision support system consists of a small to mid-sized data sets and can be operated on popular 
applications like Microsoft Excel and Microsoft Access that requires minimal computer processing power. The managers manually enter the data. The data is processed using a widerange of techniques like the analytic hierarchy process (AHP) by Saaty, (1980), including: algorithms, fuzzy multiple-attribute decision-making model, linear programming models, etc. to derive the information on planning, machining tool selection, worker assignment, etc. Table 2.1. provide an overview of the categorization of the decision support system.

Table 2. 1 Categorization of Decision Support System (Power, 2016).

\begin{tabular}{|r|l|}
\hline 1 & What is the functionality of the decision support system? \\
\hline 2 & Who are the targeted users? \\
\hline 3 & What is the purpose of the decision support system? \\
\hline 4 & What technology is used to deploy the decision support system? \\
\hline
\end{tabular}

Mirchandani \& Pakath, (1999) analysed various forms of decision support systems and categorized them into two types- static and dynamic. Their categorization was based on data management and problem-solving functions of the system. Whereas Renowned research performed in the field by Power, (2008) identified five variants of decision support systems like data-driven, knowledge-driven, communications-driven, document-driven, model-driven systems and presented a framework for creating decision support systems. The framework is summarised in the table 2.2 
Table 2. 2 Framework for Decision Support Systems (Power, 2016)

\begin{tabular}{|l|c|c|c|}
\hline \multicolumn{1}{|c|}{ DSS Type } & Technology & Targeted User & Purpose \\
\hline Communication & Video Conferencing, bulletin boards & Internal teams, suppliers & $\begin{array}{c}\text { Conduct meetings, help } \\
\text { users collaborate }\end{array}$ \\
\hline Data-driven DSS & Relational database & $\begin{array}{c}\text { Managers, staff and } \\
\text { suppliers }\end{array}$ & Query a data warehouse \\
\hline Document-driven DSS & Search engines & Operators, programmers & Search Web \\
\hline Knowledge-driven DSS & $\begin{array}{c}\text { Expert Systems for example Tableau, IBM } \\
\text { SPSS }\end{array}$ & Managers and staff & Data Analytics \\
\hline Model-driven DSS & Linear & Programming, & Quantitative \\
& Microsoft Excel and Access & programmers & $\begin{array}{c}\text { Models, scheduling, } \\
\text { forecasting }\end{array}$ \\
\hline
\end{tabular}

Clark, Jones, \& Armstrong, (2007) analysed the dynamic nature of management support systems and proposed four types of management support systems, the decision support systems, knowledge management systems, business intelligence and executive information systems.

\subsubsection{DSS application in the machining industry}

Ayağ \& Özdemir, (2006), Çimren, Çatay, \& Budak, (2007) used an analytic hierarchy process (AHP) to build a decision support system that solve issues related to machining tool selection. Sun, et al., (2008) also used the AHP in conjunction with an algorithm to aid in machining tool selection.

Arslan et al., (2004) rated and ranked machining systems on several different standards and proposed a multi-criterion weighted average model, that will assist in production decisionmaking process. Stam \& Kuula, (1991) used a similar multi-criteria approach to create a visually 
interactive, simplified decision support system for non-technical decision makers, that would allow them to select appropriate technology and design in manufacturing.

Abdel-Malek \& Resare, (2000) focused on several CNC machining parameters such as structure geometry, designed and proposed a support system built with analytical algorithms that can be instrumental in the selection process. Likewise Moon, et al., (2002) recommended a genetic algorithm based decision model that can be integrated with the machining tool, evaluate its performance and be used to choose between methods. Seo \& Egbelu, (1996) focused on production process that produced a wide variety of products and proposed a decision model that can determine cost efficiency in production.

Alberti, et al., (2011) proposed to calculate costs accurately, evaluate production dimensional precision and machining parameters with the aid of a decision support system. Whereas Morgan \& O'Donnell, (2017) created an interactive algorithm, deployed it on a cloudbased/online collaborative support system that can be accessed and used by businesses. Their system facilitated the share of designs, ideas and machining parameters to assist in production control, quality, and management.

Vichare, Nassehi, \& Newman, (2011) identified the problem arising from the lack of a standardized information system in the marketplace. Generally, CNC equipment manufacturers promote their own proprietary models, resulting in an incoherent set of models. Therefore, they proposed a unified machining resource support system, that can help the managers to compare and choose between various $\mathrm{CNC}$ machining systems and auxiliary devices like cutting tool, bar feeders, robotic arm, etc. Similarly (Plaza \& Zebala, (2019b) proposed a decision model that help investigate and determine accurate business condition for investing in $\mathrm{CNC}$ machining 
technology.

Zhao, Li, \& Tian, (2017) introduced a decision support system that utilized current and past $\mathrm{CNC}$ production data, eliminate faulty diagnostics and deliver an advanced diagnostic system. Ahmad, Tichadou, \& Hascoet, (2017) presented a knowledge-based decision support system that collected data through vision sensors installed in the machines. The system automatically detects collisions and recalibrated the machining parameters to avoid them. Qader \& Elbadawi, (2019) carried out a study on selecting the ideal CAD, CAM software and CNC machines. However, their study was performed for academic training purposes and cannot be directly applied to industrial use. Taha \& Rostam, (2012) presented a decision support model that assessed the best alternative CNC machines. They used a combination of fuzzy AHP created in a MATLAB software and assigned different weights to the selected criteria. lastly, they implemented a preference based ranking system to evaluate the most-effective machining process. Similarly, Yurdakul \& İç, (2009) used fuzzy AHP and multi-criteria decision-making model to rank the feasible machining tools. A similar approach has also been applied by Ayağ \& Özdemir, (2011), Wang, Shaw, \& Chen, (2000), Önüt, Kara, \& Efendigil, (2008) to solve the machining tool selection problem using different iterations of decision support systems.

Chan \& Swarnkar, (2006) utilized ant-colony optimization and Rai, Kameshwaran, \& Tiwari, (2002) utilized GA algorithm optimization in correlation with fuzzy-goal programming approach to model a decision support system that can determine the optimal combinations of machine and tool that will be most cost-effective. Furthermore, Rai et al., (2002) included constraints like capacity of machines and tool life to estimate cost of machining accurately.

Karsak \& Kuzgunkaya, (2002), (Mishra, et al., (2006) used fuzzy multiple-objective programming approach to minimize production uncertainties like market demand and supply. 
They assigned priorities for production components based on importance. They intended to increase the businesses ability to respond to market trends more efficiently.

Aly \& Subramaniam, (1993) presented a decision support system focused on simulation data and Keung, et al., (2000) on the other hand focused on the programmer scheduling with a genetic algorithm (GA) based decision support system. They aimed to minimize the need to switch between tools during production and observed substantial time and cost savings.

The static, Mirchandani \& Pakath, (1999) data-driven, reconfigurable decision support system Power, (2008), Clark et al., (2007) with a user-friendly Gupta \& Dutta, (2016) interface is proposed in this research. Which the managers can use to evaluate between machining methods and achieve cost efficiency.

\subsubsection{Design Science Methodology}

Information technology (IT) is used to collect and analyze information from a combination of: hardware, software, procedures and the user to support business processes. IT systems are classified into two segments: descriptive and perspective (March \& Smith, 1995a). Descriptive research falls under the umbrella of natural science or behavioral-science and is used to produce knowledge by developing and analysing theories (Hevner et al., 2004). Prescriptive research falls under the umbrella of technology-oriented design science that are intended to create innovation and present a new approach to solving the problem (March \& Smith, 1995b). The design science research methodology consists of two basic activities: building an artifact and evaluating its performance towards its objective, whereas natural science focuses on discovering and justifying (March \& Smith, 1995a). Design science is widely used in academic fields and 
have contributed to the creation of a new paradigm for research in science, art and engineering. It provided a platform for scientific objects and models, enabled the unification of different fields of study, uncovered theoretical details and expanded the scope of knowledge (Hatchuel, Le Masson, Reich, \& Subrahmanian, 2018). Furthermore, design science is used to evaluate information technology artefacts, aid in finding solutions to problems faced by businesses and extend managers decision making capabilities, making it the ideal theoretical framework for this research objective (Hevner et al., 2004).

Peffers, et al., (2007) proposed a six-step design science research methodology to facilitate the creating of conceptual models. The first step is defining the problem, second step is to define the object in the research, the third phase is design and development of the research model and the final stage is to demonstrate the usefulness of the model, evaluate the results produced by the model and communicate the findings to the user.

Carlsson \& Turban, (2001), Zulkafli et al., (2017) described design science methodology used to create decision support systems. Such systems are instrumental in solving unstructured problems, providing a user interface (UI) and concealing the complications of the model, algorithms and data. Furthermore, the simplicity of the system, allowed managers to solve problems using their knowledge, experience and without having to learn advanced modelling. Carlsson \& Turban, (2001) further recognized that the traditional models were too simple and outdated to accommodate the current surge in IT applications encountered by businesses. They proposed an updated model that can include and differentiate between declarative i.e. a programming model that provides the logic of a program without describing its control flow and imperative i.e. a programming model that uses statements to change a program's process. They concluded by defining four aspects of design science i.e. designing an interactive constraint- 
based model that can rejects biases arising from the managers preferences, evaluates several methods, the system must be intelligent and adaptive to learn from the user's feedback and finetune the parameters automatically and lastly the system must be able to deliver optimal solutions quickly. Design science methodology has been widely used to create instantiations like the decision support system (Arnott \& Pervan, 2014). Design theories provide the instructions used to build decision support systems (Gregor \& Jones, 2007).

A plethora of research has been made independently on implications of learning curves, achieving cost-efficiency in machining and using different variants of decision support systems to solve business problems. However, there is a gap in existing literature on implementing decision support systems to the machining industry, that considers implications of the learning curve and aids in selecting between methods of production.

This research applies the design science- prescriptive research approach to deliver an innovative machining method selection tool, known as the decision support system that considers implications arising from the programmer learning effects, unify and display all the cost items in one coherent application and provides a platform for managers to perform a high-level comparison and selecting cost-effective method for production.

\section{Decision Support Tool}




\subsection{Research method}

This research seeks to streamline the abstract managerial selection process of finding the cost-effective machining and production methods. The machining process is first segregated into two phases: planning and machining. All the cost items are correlated to the phase where they occur. For example, cost incurred during strategy development and optimization are placed under the planning phase. Whereas cost of rough and finish machining, cutting tools and raw materials are placed in the machining phase. To present all the components in a logical manner a decisionsupport tool is presented that connects all the components and enables the direct comparison between machining methods.

Due to the scope of the research and limited availability of CNC production data, the comparison is applied to two machining method: the 3-axis and 5-axis CNC machines. The research method presented in Figure 3.1. provide a road map on how the research is structured, provide an overview of the organization of data, define the relationship between the theoretical framework and conceptual framework. Lastly it illustrates how the model managerial questions and instantiation (i.e. the decision support system) aid in answering the research question. 


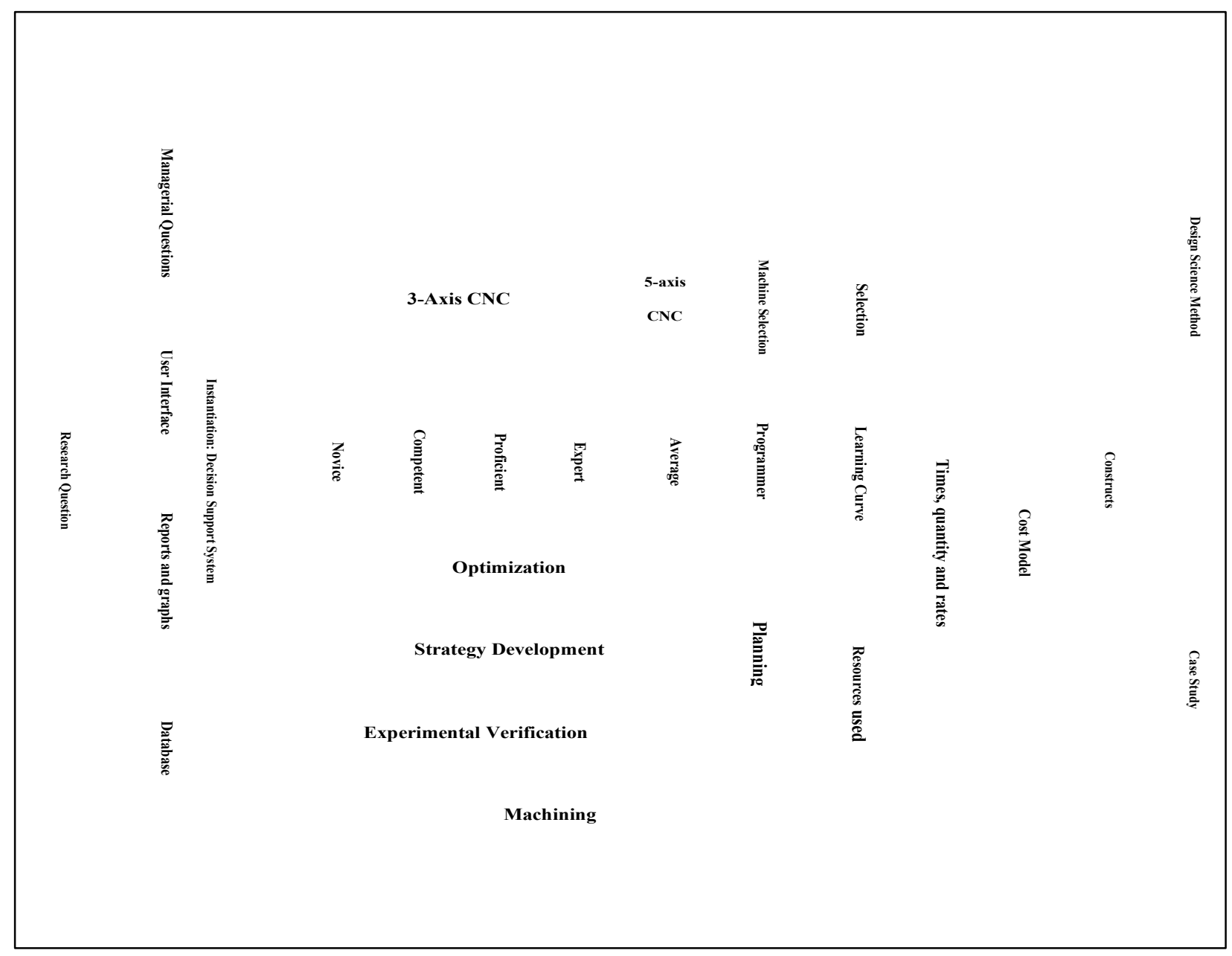

Figure 3. 1 Theoretical model for factors determining the impact of learning on the selection of cost-effective machining and production process.

The theoretical framework is based on the application of design science methodology. It facilitated the use of both the process and the instantiation design. The design science methodology connects the different subject matters i.e. the industrial engineering processes, accounting and theories like the learning curve. The artefacts represent each aspect of the process. It comprises of the constructs, the model, method and the instantiation.

The conceptual framework is obtained through studying CNC machining industry and the case-study that describes the 5-axis and 3-axis CNC machining procedure. This research builds 
on the findings of Zębala \& Plaza, (2014a), applies the power learning curve to evaluate cost implications arising from different experience levels of programmers.

\subsection{Instantiation: Decision Support System}

The instantiation created this research is an object-oriented static decision support system built using Microsoft Excel spreadsheet application and the user interface is built using Microsoft Access database management system. The use of the instantiation/decision support system enabled the implementation and validation of the constructs, the model and the method. Microsoft Excel and Microsoft Access were used to build the decision support system because they are widely available, easy to use and popular software applications (Katz, 2010). The decision support system is intended to be used by nontechnical managers. Therefore, it is vital to create a simplified system that is easy to use and can be adopted by managers with minimal training.

Selected machining data and procedures has been extracted from the case-study and used to evaluate the feasibility of the system, enable the high-level comparison between machining methods and answer the managerial question posed in this research. The decision support system is built with two set of algorithms. The cost model and the power learning curve algorithm. The algorithms enabled the system to obtain accurate repeatable results. Figure 3.2. provide an overview of the design of the system.

The decision support system consists of five components:

1. The base-line quantity and rates presented in the time, quantity and rate construct. 
2. The machining parameters are required to be entered by the manager using the decision support system data entry form. For the purpose of this research the system is tested using values listed in the resources used construct.

3. The machine and functions selection construct used to select between the various production components.

4. Processing contains the application of the base-line quantity and rates with the resources used values to the cost model and power learning curve to obtain costs of production.

5. The output phase consists of answering to the managerial questions in the form of graphs and reports.

\subsubsection{The decision support system flow of information}

Figure 3.2 illustrated the selection process and the flow of information of the decision support system to the manager, the programmer and the $\mathrm{CNC}$ machine. 


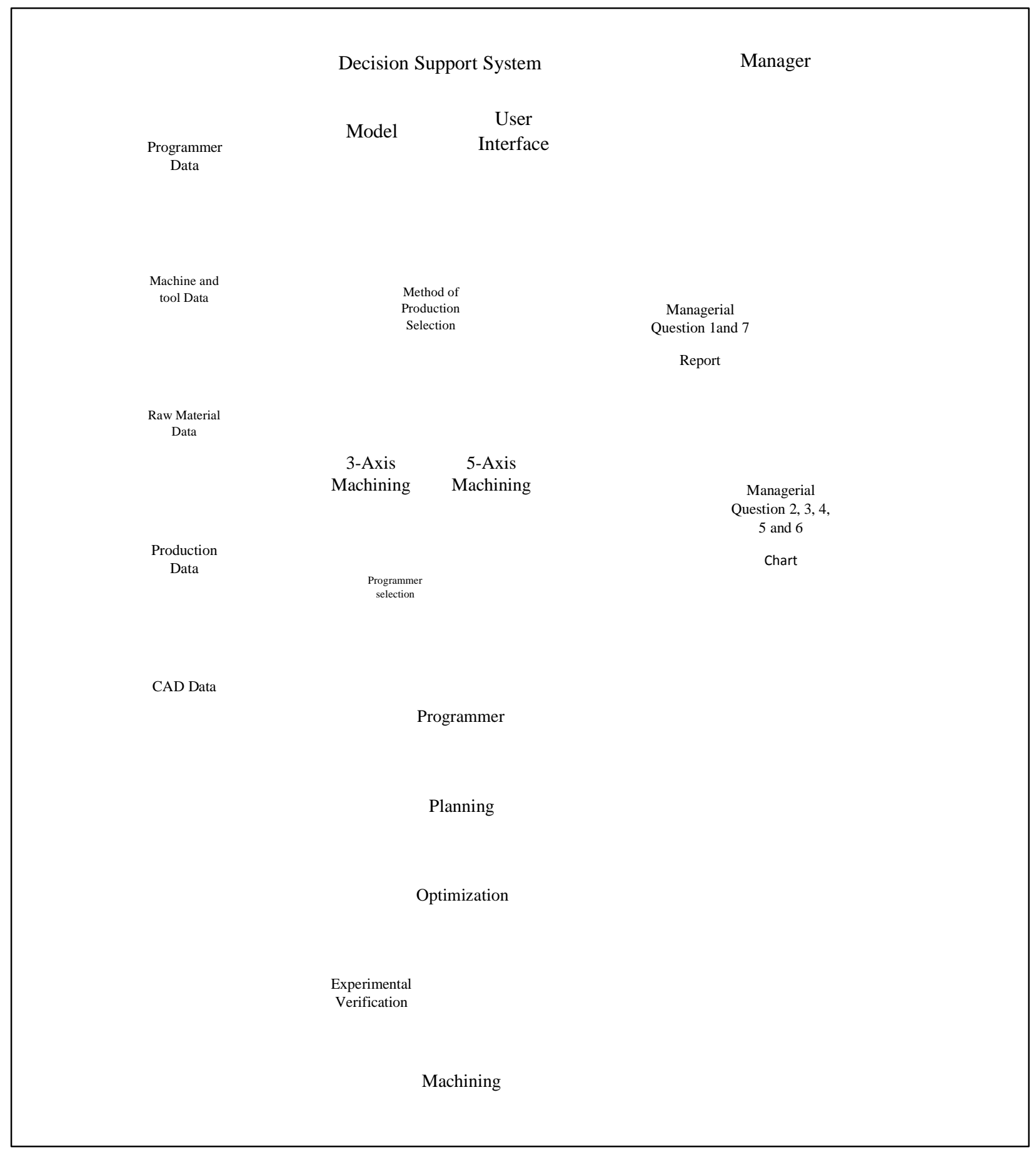

Figure 3. 2 Design of the decision support system. 
Input: The manager consults with the customer to determine the structure parameters, the supplier to determine the raw material and cutting tools needed in the machining process. The data is entered manually into the system; hence it is the input phase.

Processing: The processing stage consists of the application of the cost-model and the power learning curve to the machining parameters i.e. the baseline time, rates and quantity and the resources used table and the rates associated with the selected programmers. The processing phase uses both manually entered data and data stored in the databases. Table 3.1. describes the databases used by the decision support system. For the purpose of this research the data is stored in Microsoft Excel spreadsheets

Table 3. 1 List of databases

\begin{tabular}{|c|c|l|}
\hline Number & Database & \multicolumn{1}{c|}{ Function } \\
\hline 1 & Machine and Tool & $\begin{array}{l}\text { Stores machine and tool specifications like machine capacity, } \\
\text { availability, condition, precision, cost, etc. } \\
\text { Contains stock information of the materials available for production } \\
\text { and the dimensional properties like length, width, height, volume, } \\
\text { density, costs, etc. } \\
\text { Stores structure parameters, machining data, process planning, } \\
\text { strategy development, optimization, experimental verification, etc. } \\
\text { Stores data generated from production processes. } \\
\text { Stores details about the programmer's rate per hour, experience } \\
\text { levels, availability, etc. }\end{array}$ \\
\hline 5 & CAD & Production
\end{tabular}

Output: After the manager entered the parameters, the decision support system calculates the cost of production for each process, provides reports and graphs to answers the managerial questions.

The manager can easily obtain the information displayed by the system, make the selection of the most cost-effective method and assigns the task the group of programmers that can complete the task most cost-effectively. 
The selection of the 5-axis machine triggers the calculation for the planning and machining phases. 5-axis planning phase consists of strategy development and optimization. The machining phase consists of rough machining, finish machining and includes costs associated with programmer performing the machining, the raw materials used in production, the cost of 5axis machines and the cost of cutting tools.

The selection of the 3 -axis machine also triggers the calculation for the planning and machining phases. 3-axis planning phase consists of strategy development, optimization and experimental verification. 3-axis machines require experimental verification in order to machine complex structures. It is additional optimization process that consists of a feed-rate adjustments algorithm and requires additional programmer input and equipment. The machining phase consists of rough machining, finish machining and includes costs associated with programmer performing the machining, the raw materials used in production, the cost of 3-axis machines and the cost of cutting tools.

During the planning phase the programmer can fine-tune the machining parameters using the user interface built into the decision support system. Fine-tuning might be required to factor in production environment and the machine tool condition. Once all the parameters are set accurately, the programmer can send the instructions in the form of NC code to the CNC machine controller for the machining process to be executed. The decision support system automatically stores the production data to the corresponding databases. The data can be easily accessed and used for future production cycles, keep production record and can be quickly retrieved, analysed and debugged if are any faults are detected on the structure surface. 


\subsubsection{User Interface}

The first step of the decision support system is to provide the managers with a user interface (UI) with which they can interact with the system. The UI conceals the complications of the model, algorithms and data. It is built with the principles that it must be quick in processing the information, simple and easy to understand UI that can answer the managerial questions accurately. It allows the manager to enter the machining parameters and select the components critical to the production process. The managers and programmers can enter, edit and fine-tune the machining parameters. They can select the components numerous times to evaluate different processes by clicking the next button.

The user input form has been created using Microsoft Access database software, because of the application's ability to sync and update data from multiple databases and spreadsheets simultaneously. Figure 3.3. provide an illustration of the managerial data input form and provides clarification on the decision support system proposed. 


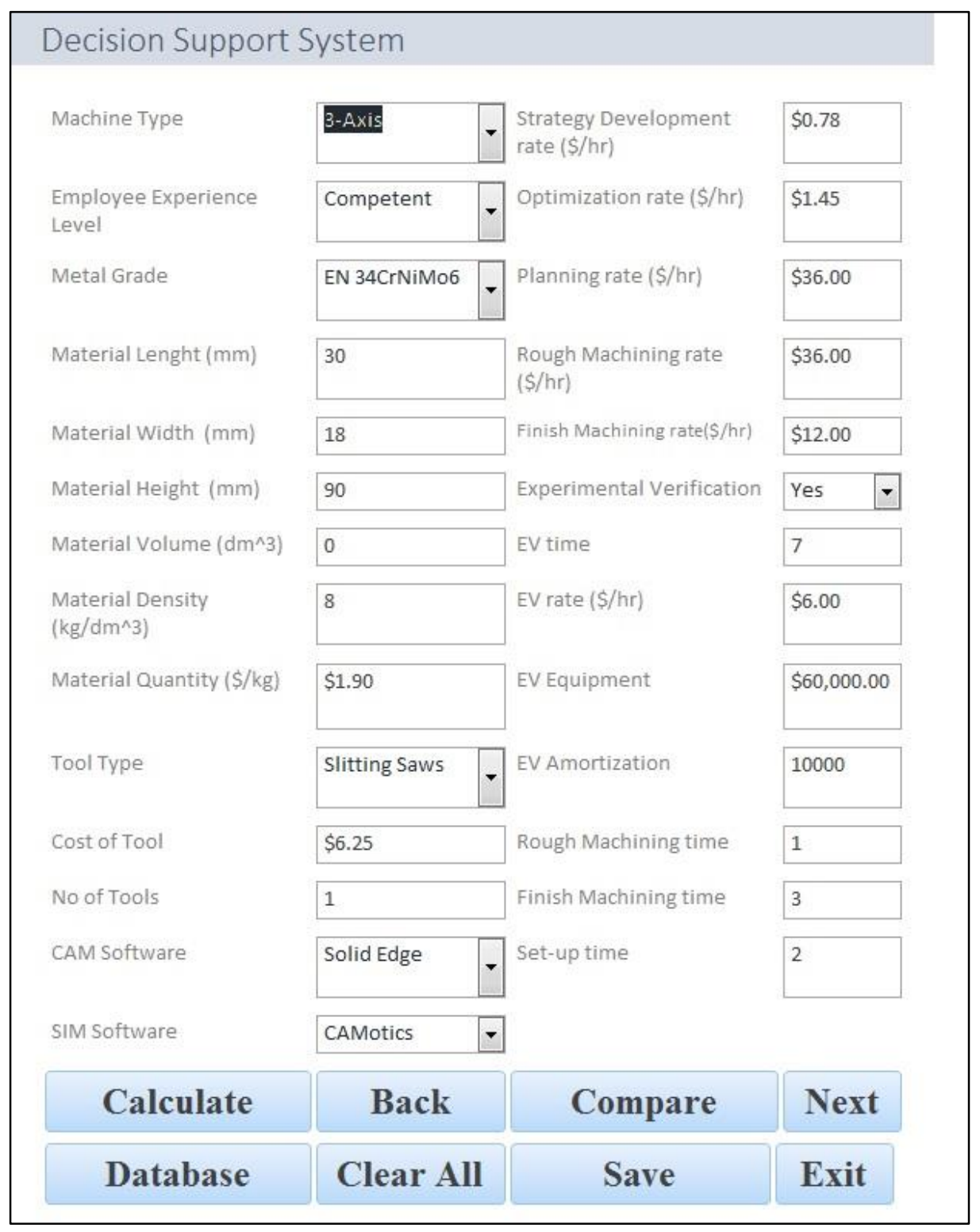

Figure 3. 3 The decision support system data entry form.

The first item in the form is machine type. It allows the user to choose the machining method for which the parameters are being entered. The field is displayed as a drop-down menu that contains the various machines available on the production floor. After a machining method is selected, the interactive form automatically populates items associated with the machine, some manual entry fields are activated and fields not applicable to the particular machine are 
deactivated. For example, when the 5-axis machine option is selected, the fields associated with experimental verification become deactivated. Furthermore, multiple fields are automatically calculated and displayed in the decision support system form i.e. the machinery amortization per hour cost is automatically calculated once a machine is selected. Figure 3.4 illustrates the dropdown function of the machine selection menu, for the purpose of this research the menu consists of 3-axis and 5-axis CNC machine options.

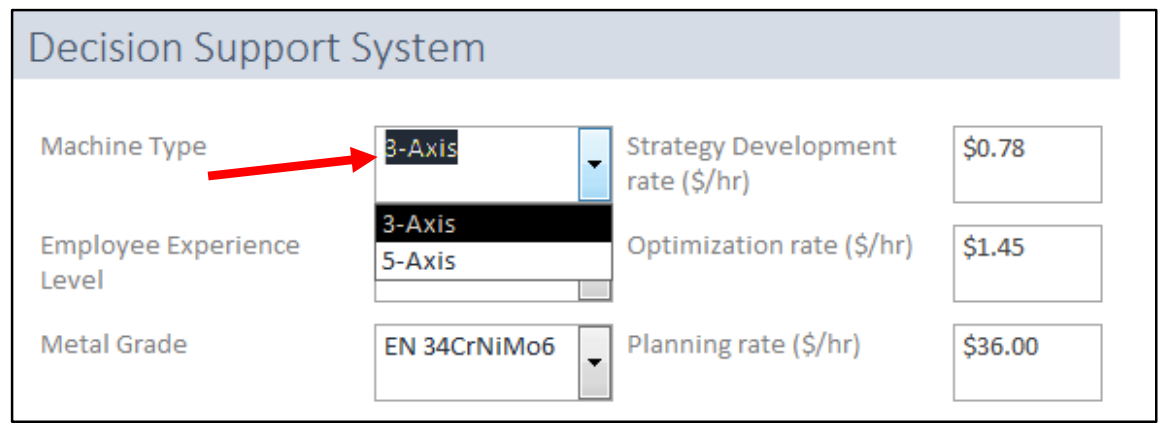

Figure 3. 4 Machine type selection

Assigning the right programmer to a task is an important part of the selection process to accomplish cost-efficiency through learning implications. Machining complex free-form structures requires specialized programmers. The selection of programmer can impact most cost items i.e. the programmer rate per hour, the machining and planning time and rates. Therefore, the second item in the form is the employee experience level field. The managers can choose between the various experience levels of programmers available to perform the task. The programmers have been grouped into four categories for 3-axis: novice, competent, proficient, expert and one category for 5-axis. The selection of a particular level of programmer initiates the calculation of the total programmer costs and the cost of production based on their rates. Figure 3.5. illustrates the drop-down menu of the programmer selection function. 


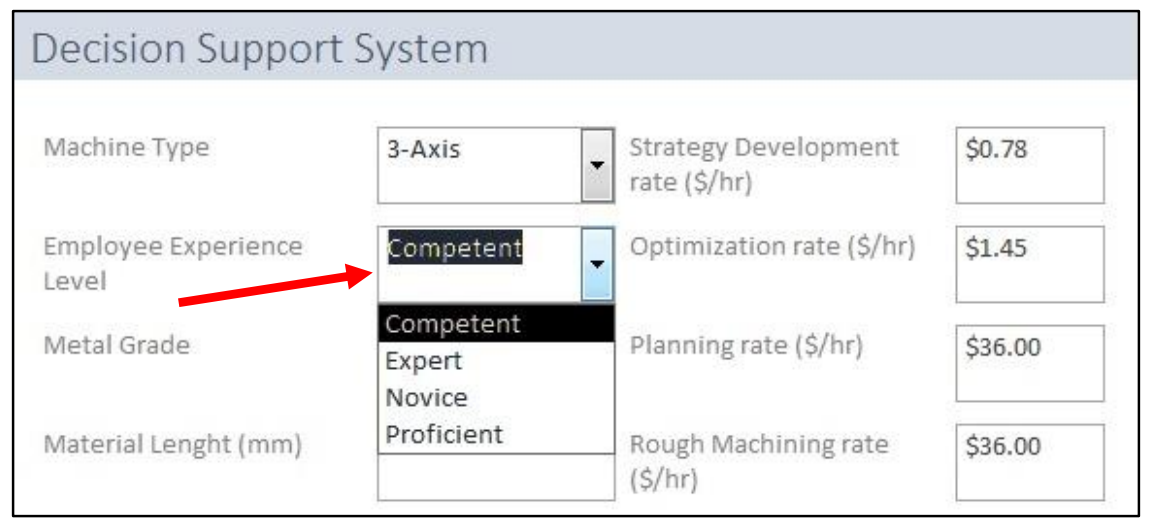

Figure 3. 5 Programmer selection menu

The manager then can proceed to select the metal grade in the next field. The field has a drop-down menu option and also can be manually entered. This layout allows the manager to select between materials already stored in the system or enter new material being used for the first time. The selection of metal grade is followed by the manual-entry of the metal's properties i.e. length, width and height. These fields are created with validation rules. For example, measurements are pre-set in millimetres $(\mathrm{mm})$ in-order to minimize data-entry errors and to create consistency in units in the system. The next field is volume, it is measured in cubic decimetre. Followed by the field to enter density, which is measured in cubic decimetre per kilogram (kg). Figure 3.6. illustrates the metal grade selection process. 


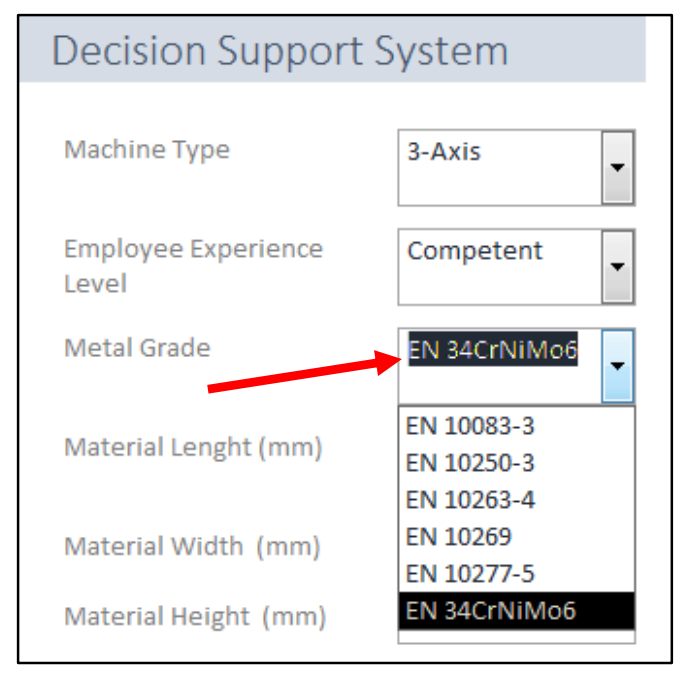

Figure 3. 6 Metal selection

This metal grade and properties fields enable the accurate calculation of the material cost needed for production. By being aware of the cost generated from material and programmers, before the production process has begun, managers can tightly control variable costs, fine-tune the process by selecting different combinations of material and assign different groups of programmers to achieve the most cost-effective production process.

After selecting the machine, programmer and cutting material, the manager can review the cutting tool, CAM and SIM software being used in the production. The amortization cost of CAM and SIM software are automatically factored into the cost of production.

The following three items encompass the rate and time associated with the planning phase i.e. the rate per hour for strategy development, rate per hour for optimization and the overall rate per hour for planning. The four items associated with the machining phase are the following: rate and time needed rough followed by the rate and time needed for finish machining. These items need to be manually entered as they represent current order 
requirements. Currency validation rule is set to fields containing rates and values to prevent bad data being saved in the system.

For the purpose of this research experimental verification has only been applied to the 3axis CNC machines. Therefore, when 3-axis is selected, the decision support system automatically activates the experimental verification field and displays the "yes" option. The field also contains a "no" option to turn off experimental verification. This function is useful, when machining simple structures that can be produced with 3-axis machines without the need for the additional level of optimization and prevent any additional costs incurred from experimental verification.

The manager needs to manually enter the amount of time and rate needed for experimental verification as they represent current costs. The set-up time for the machining process field is also manually entered based on current machining environment. Figure 3.7. illustrate the experimental verification selection menu.

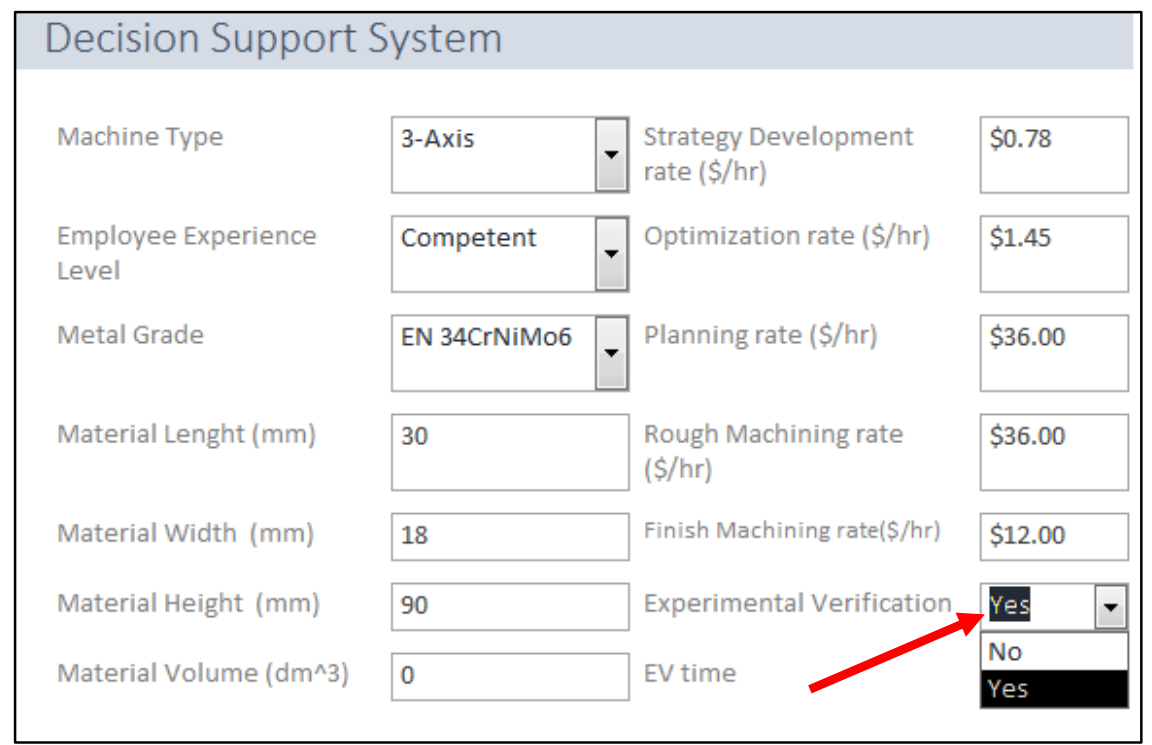

Figure 3. 7 Experimental Verification selection menu 
The form has been designed centred on the idea to create user friendliness. The managers can enter data into the system, edit the data, retrieve data from the various databases, save the newly entered data and evaluate machining processes by using the group of buttons placed at the bottom of the decision support system form illustrated in figure 3.3. To enter multiple machining methods the manager can first enter data for one process and click the "next" button to open a new data entry form and enter the data for subsequent methods for comparison. The "back" button can be used to go back to the previous form to make changes.

The "calculate" button allows the manager to calculate total costs incurred for a single method. Whereas the "compare" button can derive total costs calculations for multiple methods and allow a direct comparison. Both the calculate and compare buttons implement the power learning curve and the cost model. When the "back", "next", "save" and "exit" buttons are clicked after a new process is entered, a "save as" dialogue box prompts to remind the user to save the data entered and assign a name to the method. This will ensure the data is saved and can be retrieved easily for future use.

The "database" button allows the user to retrieve and manipulate data from multiple database linked to the system. The "clear all" buttons allows the user to quickly reset the form, the "save" buttons allows the data fields entered to be saved into the corresponding databases. The "exit" button allows the application to be closed.

The following section provides an overview of the design science methodology and describes the constructs that provide the semantics for this research. 


\subsection{Design Science}

Researchers Hevner et al., (2004), March \& Smith, (1995a) defined four fundamental artifacts needed in design science methodology. The first artefact is to develop the constructs, followed by building the model, applying a method and the final component is creating an instantiation that enables the implementation of the constructs, model, method and is the output of the research. Their framework has been used to create the instantiation (i.e. decision support system) proposed in this research.

\subsubsection{Constructs}

Constructs represent the vocabulary of the data, aid in defining the task, creates the design framework and facilitate the delivery of information. For this research the constructs are selected to accurately define all the activities in CNC machining. Furthermore, enable the creation of the instantiation (i.e. the decision support system). The important criteria for construct selection was to provide a logical structure of the data, define the activities, describe the process and ensure simplicity. The following sections categorize and explain the constructs used in this research (Hevner et al., 2004), (March \& Smith, 1995a).

\subsubsection{Times, quantity and rates}

All activities occurring in the production process with cost implications fall under the time, quantity and rate construct. Selected data points are extracted from the case study (Zębala \& Plaza, 2014a). Resource consumption accounting (RCA) is used to provide monetary values to 
resources used. All cost items are aligned with the baseline time, rates and quantity to facilitate the comparison between 3-axis and 5-axis CNC machining methods. Both methods are presented with a set rates and quantity. Rates are measured on a per hour basis and differs between 3-axis and 5-axis CNC machines.

The variation in rates occur due to the following reasons:

1. Machinery, cutting tool and software cost

2. Application of the experiential verification to 3-axis.

3. Rate of CNC center for each method.

4. Rate of rough and finish machining.

5. Programmer rate and application learning curve application.

Table 3.2 provide the baseline time, quantity and rate per unit used in this research and is critical to the total cost of production calculation performed by the decision support system. 
Table 3. 2 Time, quantity and rate.

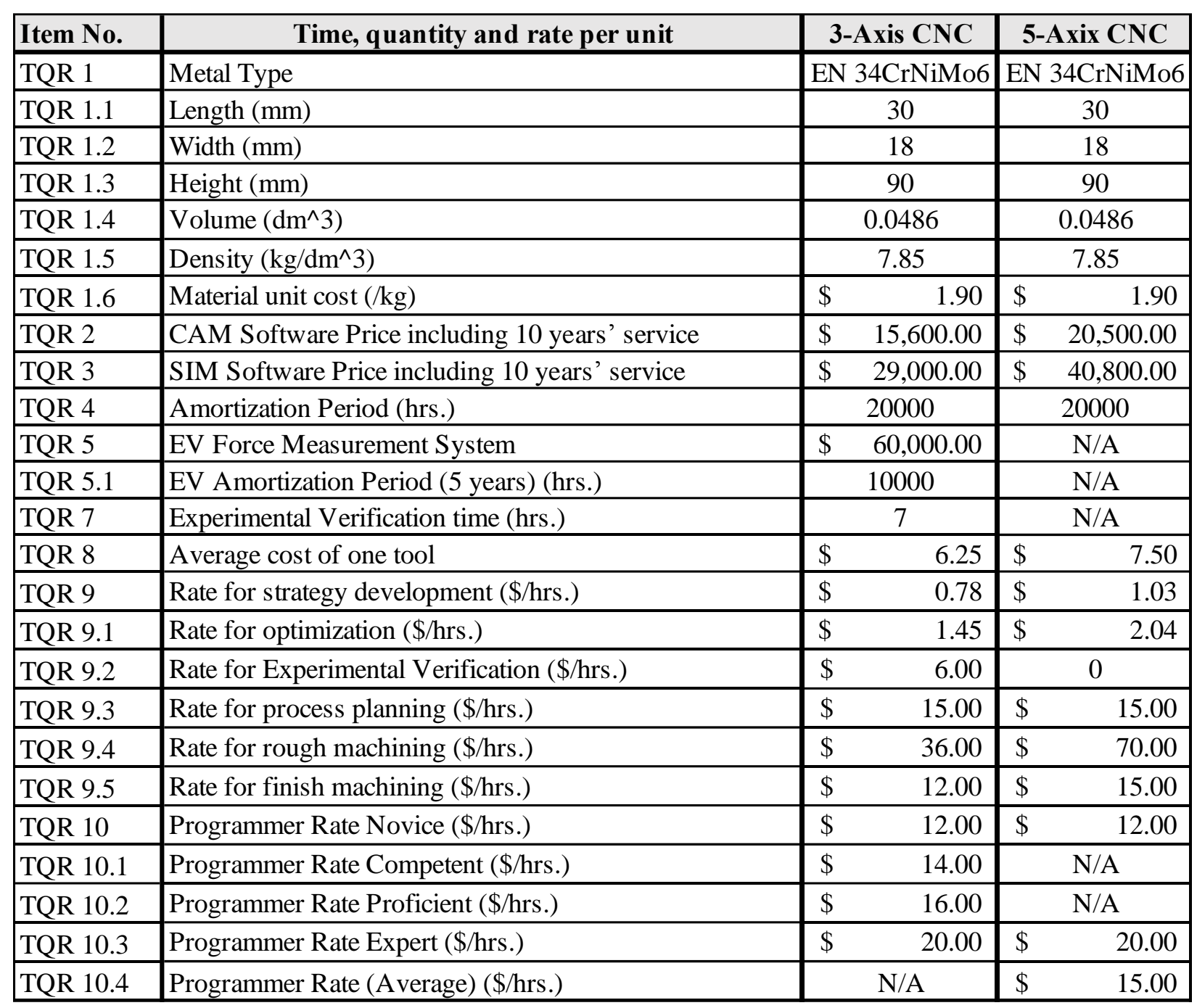

The item numbers TQR 1 to TQR 1.6. and TQR 4 to TQR 9.5. are data extracted from the case study (Zębala \& Plaza, 2014a). The dimensional properties i.e. metal type, length, width, height, volume and density of the cuboidal shaped metal blank selected for the manufacturing process are mentioned under item numbers TQR 1 to TQR 1.6.

The CAM software price includes the ten years software servicing fee and is listed under item no. TQR 2. The cost of the SIM Software including the ten years' software servicing fee is listed under item no. TQR 3. 
The five-year amortization rate for 3-Axis and 5-Axis CNC machines is included in the cost calculation and are listed under TQR 4. Item no. For the purpose of this research, experimental verification has only been applied to 3-axis machining and is not applicable to 5axis. The seven hours required for experimental verification is listed under item no. TQR 7. Rate for experimental verification is listed under TQR 9.2. Experimental verification requires additional equipment for force measurement. Therefore, the cost of the equipment and its amortization rate is presented under item no TQR 5. and TQR 5.1.

TQR 8. lists the average cost of cutting tool. TQR 9 to TQR 9.5 lists the various rates of the CNC center. The rate for strategy development is listed under TQR 9, the rate for optimization is listed under TQR 9.1 and the rate for the planning phase is listed under TQR 9.3. The machining phases consists of rough machining and finish machining. The rate for rough machining is listed under TQR 9.4 and the rate for finish machining is listed under TQR 9.5.

The different categories of programmer are each assigned a rate per hour. The rate for novice programmers is listed under TQR 10 and the rate of expert programmers is listed under TQR 10.3. The same rate for novice and expert has been applied to 3-axis and 5-axis for the purpose of the analysis. The average programmer rate is presented under TRQ 10.4 and has only been applied to 5-axis and not applicable to 3-axis. TQR 10.1 and 10.2 list the rate per hour for proficient and competent programmers.

\subsubsection{Resources Used}

The resources used construct in conjunction with the time, quantity and rate construct enable the production cost calculation. Resources used account for all the resources that will be 
utilized in the machining process. It consists of the parameters manually entered by the manager into the decision support system user interface form. For the purpose of this research values are assigned to the system and are displayed in table 3.3. All the values are listed in time except for the number of tools, weight of blank material, scrap rate and quality constant.

Table 3. 3 Resources Used

\begin{tabular}{|l|l|c|c|}
\hline Item No. & \multicolumn{1}{|c|}{ Resources } & 3-Axis CNC & 5-Axix CNC \\
\hline R 1 & Task Duration for Planning- Average (hrs.) & 2 & 2.5 \\
\hline R 2 & Task Duration for Planning- Expert (hrs.) & 1.6 & 2 \\
\hline R 3 & Task Duration for Planning- Novice (hrs.) & 2.4 & 3 \\
\hline R 4 & Task Duration for Optimization- Average (hrs.) & 1 & 1.3 \\
\hline R 5 & Task Duration for Optimization- Expert (hrs.) & 0.8 & 1.04 \\
\hline R 6 & Task Duration for Optimization- Novice (hrs.) & 1.2 & 1.56 \\
\hline R 7 & Task Duration Experimental Verification Average (hrs.) & 7 & 0 \\
\hline R 8 & Task Duration Experimental Verification- Expert (hrs.) & 5.6 & 0 \\
\hline R 9 & Task Duration Experimental Verification- Novice (hrs.) & 8.4 & 0 \\
\hline R 10 & Task Duration Rough Machining (hrs.) & 0.73 & 0.6 \\
\hline R 11 & Task Duration Finish Machining (hrs.) & 2.85 & 2.26 \\
\hline R 12 & Set-up (hrs.) & 0.2 & 0.17 \\
\hline R 13 & Weight of cuboidal shaped cutting metal blank required for one blade (kg) & 0.38 & 0.38 \\
\hline R 14 & Number of Tools & 1 & 1 \\
\hline R 15 & Scrap Rate (\%) & 0.12 & 0.04 \\
\hline R 16 & k-quality efficiency \& sensitivity constant & 0.3 & 0 \\
\hline
\end{tabular}

Selected data has been obtained from the case-study (Zębala \& Plaza, 2014a) and accounts for all the direct and indirect resource usage, for example material, labour-hours, machining-hours, and metal scrap-rate. The data was collected from a sample of ten CNC machining companies. Zębala \& Plaza, (2014a) found evidence that 3-axis CNC machines optimized with the experimental verification algorithm perform tasks $17 \%$ faster and achieve the quality of structure surface similar to the more advanced 5-axis CNC machines. The data sample size is sufficient for this research because 
(i) It demonstrated that the selected machining approach (i.e. the optimization 3-axis $\mathrm{CNC}$ machine with experimental verification and the 5-axis $\mathrm{CNC}$ machine) are comparable and produce similar quality product.

(ii) The data is sufficient to illustrate the cost efficiency obtained from the learning effects.

(iii) The data synchronizes with the time, quantity and rate per unit mentioned in table 3.2. and the resources used table 3.3.

The planning phase consists of strategy development and optimization. The average value for strategy development listed under R 1, has been used to evaluate both the methods and answer the managerial questions posed in this research. The strategy development expert listed under $\mathrm{R}$ 2. and strategy development novice listed under R.3 has been applied to the dataset to analyze the implications of learning effecting 3 -axis and 5 -axis methods. Similarly, the average value for optimization is listed under R 4 . This value has been used to evaluate both the 5 -axis and 3-axis to answer the managerial questions posed in this research. The optimization expert listed under $\mathrm{R}$ 5. and optimization novice listed under R.6 has been applied to the dataset to analyze the implications of learning effecting 3-axis and 5-axis methods in order to perform a fair comparative analysis.

The 3-axis method require the additional experimental verification phase during the planning phase. The average time needed for experimental verification is listed under $\mathrm{R} 7$ and has been applied to obtain the cost of production for 3-axis. Although experimental verification is not applied for 5-axis. The task duration for experimental verification expert and novice mentioned under item number R 8 and R 9 has been used to perform an analysis to observe the application of the learning curve on both 3-axis and 5-axis. These values in conjunction to the 
strategy development expert, strategy development novice, optimization expert and optimization novice were used to obtain production costs for 3-axis and compared to 5-axis.

The machining phase is segregated onto two segments, the first is to perform rough cuts followed by finish cuts. The rough-cuts main objective is to remove larger amount of material in the most efficient manner. Subsequently finish cuts are performed to achieve the desired surface finish accurately (Yin, 2004). Rough machining and finish machining represent the two segments of the machining process and are listed under R 10 and R 11. Item no. R 12 lists the amount of time taken by the programmer to set-up the machinery and tools.

The items listed in the resources used table are instrumental in finding and displaying the cost of producing, followed by finding product cost per unit. For example, R 13 lists the weight of cuboidal shaped cutting metal blank required to manufacture the wind turbine blade measured in kilograms, it is multiplied with TQR 1.6 - material unit cost per kilograms stated in the time, quantity and rate table 3.2.- to find the total cost of the work-piece material that will be required for machining. Similarly, item no. R 14- the number of tools used in the machining process is multiplied with TQR 8- average cost of one tool to find the overheads arising from cutting tools usage.

CNC centers often use expensive materials to produce structures. R 16 list the quality constant that ensures that desired surface finish is being achieved. Item no. R 15 list the percentage of scrap material generated from the machining process. (i.e. the material that is discarded or recycled). In order to ensure efficiency in production, the manager must keep track of the amount of scrap material generated, and attempt to minimize scrap rate during the planning phase. 


\subsubsection{Functions and Machine Selection}

The numerous components that make up the machining process are identified and examined by reviewing available research performed on $\mathrm{CNC}$ machining and from the case study. The micro-planning and selection activities crucial to the machining process are encompassed in the functions and machine selection construct. It is used to define the various

production components. For example, it includes the managers selection of the set of NC code to be used for production, deciding on how many repeatable simulations and experimental cuts are needed to be performed and selecting the parameters obtained from the simulations.

The structure can be manufactured using multiple combinations of machining parameters. Each parameter like the feed-rate, spindle rotational speed, depth of cuts, tool-tip, radius of the tool-tip, tool paths etc. has alternatives. Therefore, the selection between the variants fall under this construct. Consideration the scope of the research, the machining parameter and process components have been adopted from the case study (Zębala \& Plaza, 2014a).

\subsection{Model}

This section describes the power learning curve and the cost model algorithms used to create the decision support system.

\subsubsection{Learning Curve}

The programmer cost per hour is the second largest cost of production item after the cost of raw materials. Therefore, accurately selecting programmers based on experience, skill and 
knowledge can lead to achieving significant cost effectiveness in production. The power learning curve is applied to measure the time-saving arising from the learning effects exhibited by the programmers (Bill Brookfield, 2005), (Hatcher, 1980). The increasing amount of time spent on a task in conjunction to the number of task repetition leads to significant quantifiable performance improvements (Newell \& Rosenbloom, 1980). The increased performance and shorter period of time taken to complete the task can be placed in a highly predictable function known as the power function (i.e. the average performance measured from a group of participants). On the other hand the performance measurements obtained from an individual participant is called the exponential function (Schmidt, De Houwer, \& Rothermund, 2016).

Logan, (1988) originally proposed the power law of practice and mathematical represented it as the equation $y_{n}=\mathrm{ax}^{-b}$. This research applied a modified version of the power curve to quantify performance improvements exhibited by the following groups of programmers: novice, competent, proficient, expert and 5-axis performing a repetitive machining task.

The first step was to assign an $\alpha$ learning curve coefficient to each category of programmers to indicate their learning abilities. Changes are made to the $\alpha$ (Alfa) coefficient to indicate seniority/experience. The programmer group performing the task fastest is assigned the lowest $\alpha$ value, whereas the programmer group taking the longest time to finish the task is assigned the highest $\alpha$ value. The 5-axis programmers are assigned an average $\alpha$ value to serve as the benchmark. Table 3.4. provide an overview of the learning curve coefficients and the rate (\$) per hour assigned to each group of programmers. 
Table 3. 4. Programmer Experience Level

\begin{tabular}{|c|c|c|c|c|c|}
\hline Programmer level & Novice & Competent & Proficient & Expert & $\begin{array}{c}\text { 5-axis } \\
\text { (Average) }\end{array}$ \\
\hline$\alpha($ alpha $)$ & 0.9 & 0.8 & 0.7 & 0.6 & 0.75 \\
\hline$r=\log (\alpha) / \log (2)$ & -0.15 & -0.32 & -0.51 & -0.74 & -0.42 \\
\hline Rate & $\$ 12.00$ & $\$ 14.00$ & $\$ 16.00$ & $\$ 20.00$ & $\$ 15.00$ \\
\hline
\end{tabular}

Novice programmers are assigned the highest $\alpha$ value of 0.9 as they are the most inexperienced group and is estimated to take the longest to complete the task. However, they are the most inexpensive group of programmers as their pay rate is the lowest at $\$ 12$ per hour. Competent programmers are assigned an $\alpha$ value of 0.8 and a pay rate of $\$ 14$ per hour, similarly proficient programmers are assigned a mid-ranged $\alpha$ value of 0.7 and a pay rate per hour of $\$ 16$, expert programmers are placed with the smallest $\alpha$ value of 0.6 as they are the group that are assumed to have performed similar tasks in the past, have gained experience and are expected to complete the task with the least amount of time and resources. However, they are the most expensive group of programmers with the highest pay rate of $\$ 20$ per hour. 5-axis programmers are assigned the average $\alpha$ value of 0.75 and an average rate of $\$ 15$. The average value will serve as the benchmark and aid in determining the performance of the other groups of programmers.

Heathcote et al., (2000) has observed that programmer of all experience levels demonstrates a decline in performance i.e. longer time to complete the task, when a new task is introduced. As a result, producing the initial batches take substantially longer. However, the decline in performance is quickly reversed, after the first few batches are produced. As the programmer becomes fluent, performance improvements like shorter time needed for production is detected. The improvements continue to occur throughout the production process but at a 
diminishing rate. Therefore, time is used as an important measure to evaluate learning and performance improvements.

The machining process of 5-axis and 3-axis has been segregated into two groups: planning and machining phases. Planning phase for 3-axis machining consists of strategy development, optimization and experimental verification i.e. enhanced optimization using algorithm. Machining phase for 3-axis consists of costs associated with rough and finish machining, programmer wages, raw material and cutting tool.

The planning phase for 5-axis machining consists of strategy development and optimization. The 5-axis machining phase is similar to 3-axis and consists of costs associated with rough and finish machining, programmer wages, raw material and cutting tool.

The cumulative durations for planning and machining equal to the total time required for production. The cumulative durations are depicted as the function of time required to complete the first batch presented in equation 6 .

A learning curve is geometric with the general form $y_{n}=\mathrm{ax}^{-b}$ (Logan, 1988). The form has been modified to accommodate the requirements for this research.

$t_{S D(M M)}=$ Average time needed for strategy development for $M M^{t h}$ batch

$t_{O P(M M)}=$ Average time needed for optimization for $M M^{t h}$ batch

$t_{E V(M M)}=$ Average time needed for experimental verification for $M M^{t h}$ batch

$M M=$ Cumulative number of batches.

$t_{S D(1)}=$ Time taken for strategy development for the $1^{\text {st }}$ batch 
$t_{O P(1)}=$ Time taken for optimization for the $1^{\text {st }}$ batch

$t_{E V(1)}=$ Time taken for experimental verification for the $1^{\text {st }}$ batch

$\mathrm{r}=$ the learning curve coefficient

$r$ is calculated as log learning curve percentage/ log (2)

$r=\frac{\log \alpha}{\log 2}$

Equation 1

Strategy development:

Time taken for strategy development for the $1^{\text {st }}$ batch:

$$
\begin{gathered}
t_{S D(M M)}=t_{S D(1)} * M M^{r} \\
t_{S D(M M-1)}=t_{S D(1)} *(M M-1)^{r}
\end{gathered}
$$

Total time required for planning of $M M^{\text {th }}$ batch:

$$
\begin{gathered}
t_{S D(M M)}=t_{S D(M M)}-t_{S D(M M-1)} \\
t_{S D(M M)}=t_{S D(1)} * M M^{r}-t_{(1)} *(M M-1)^{r} \\
t_{S D(M M)}=t_{S D}\left(M M^{r}-(M M-1)^{2}\right) \\
t_{S D(M M)}=t_{S D(1)} *\left(M M^{(r+1)}-(M M-1)^{r+1}\right)
\end{gathered}
$$

Equation 2

Optimization:

Time taken for optimization for the $1^{\text {st }}$ batch: 


$$
\begin{aligned}
& t_{O P(M M)}=t_{O P(1)} * M M^{r} \\
& t_{O P(M M)}=t_{O P(1)} * M M^{r}
\end{aligned}
$$

$t_{O P(M M-1)}=t_{O P(1)} *(M M-1)^{r}$

Equation 3

Total time required for optimization of $M M^{\text {th }}$ batch:

$$
\begin{gathered}
t_{O P(M M)}=t_{O P(M M)}-t_{O P(M M-1)} \\
t_{O P(M M)}=t_{O P(1)} * M M^{r}-t_{(1)} *(M M-1)^{r} \\
t_{O P(M M)}=t_{O P}\left(M M^{r}-(M M-1)^{2}\right) \\
t_{O P(M M)}=t_{O P(1)} *\left(M M^{(r+1)}-(M M-1)^{r+1}\right)
\end{gathered}
$$

Equation 4

Experimental Verification:

Time required for experimental verification for $1^{\text {st }}$ batch:

$$
\begin{gathered}
t_{E V(M M)}=t_{E V(1)} * M M^{r} \\
t_{E V(M M-1)}=t_{E V(1)} *(M M-1)^{r}
\end{gathered}
$$

Total time required for experimental verification of $M M^{\text {th }}$ batch:

$$
\begin{gathered}
t_{E V(M M)}=t_{E V(M M)}-t_{E V(M M-1)} \\
t_{E V(M M)}=t_{E V(1)} * M M^{r}-t_{(1)} *(M M-1)^{r}
\end{gathered}
$$


$t_{E V(M M)}=t_{E V}\left(M M^{r}-(M M-1)^{2}\right)$
$t_{E V(M M)}=t_{E V(1)} *\left(M M^{(r+1)}-(M M-1)^{r+1}\right) \quad$ Equation 5

The sum of total time needed to complete Strategy development (SD), Optimization (OP) and Experimental Verification (EV) stages.

Cumulative average time per batch spent by programmer $=t_{E V(1)} * M M^{(r+1)}-t_{E V(1)} *(M M-1)^{r+1}+$

$t_{O P(1)} * M M^{(r+1)}-t_{O P(1)} *(M M-1)^{r+1}+t_{S D(1)} * M M^{(r+1)}-t_{S D(1)} *(M M-1)^{r+1} \quad$ Equation 6

Equation 6 is used to find the costs related to activities involving the programmers. The equation is applied to all categories of programmers i.e. novice, competent, proficient, expert and 5 -axis. For the purpose of analysis, the power learning curve has been applied to the 5-axis. The highest learning curve coefficient group (i.e. novice) and the lowest learning curve coefficient group (i.e. expert) has been applied to the 5 -axis cost calculation. When equation 6 was applied to 5-axis the time $t$ for the experimental verification was entered as zero. This effectively removed the cost implications arising from experimental verification being applied to 5-axis. 


\subsubsection{Cost Model}

The cost models consist of a set of algorithms used in the decision support system to calculate the cost of production. The cost model is applied to the constructs mentioned above. The decision support system is formed mathematically, using the cost model, allowing the research to evaluate cost-efficiency (March \& Smith, 1995a). Selected components of the cost model has been adopted from the research (Zębala \& Plaza, 2014b), 30/04/2020 11:26:00 PM, (Plaza \& Zebala, (2019b). This research expands the cost model by adding the power learning curve.

Total cost $(\mathrm{MM})=$ Cost of Planning $(\mathrm{MM})+\mathrm{N} *$ Cost of machining $(\mathrm{MM})$

\subsubsection{Cost model for 3-Axis CNC machine}

The cost of planning for 3-Axis CNC machine is the cumulative total of the cost of strategy development, optimization and experimental verification.

Cost of Planning per unit $=\left[\operatorname{Cost}_{S D}+\operatorname{Cost}_{O P}+\left(t_{E V(1)}\left(M M^{r+1}-(M M-1)^{r+1}\right)\right] / \mathrm{N}\right.$

Equation 7

Equation for experimental verification is $t_{E V(M M)}=t_{E V(1)}\left(M M^{r+1}-(M M-1)^{r+1}\right)$ it is obtained from equation 5

Where:

$$
\begin{aligned}
& \operatorname{Cost}_{S D}=\left(R R_{E S D}+R R_{O \text { Plan }}\right) t_{S D} \\
& \operatorname{Cost}_{P O}=\left(R R_{E P O}+R R_{O \text { Plan }}\right) t_{P O}
\end{aligned}
$$


$N$ : Number of units

$M M=$ Cumulative number of batches

$r=$ the learning curve coefficient

$R R_{E S D}=$ Rate of equipment used for strategy development

$R R_{E O P}=$ Rate of equipment used for optimization

$R R_{O \text { Plan }}=$ Rate of planning

$t_{S D}=$ Average time needed for strategy development

$t_{O P}=$ Average time needed for optimization

$t_{E V(M M)}=$ Average time needed for experimental verification per $M M^{\text {th }}$ batch

$t_{E V(1)}=$ Time taken for experimental verification for the $1^{\text {st }}$ batch

Cost of Machining 3-Axis CNC per unit $=\left[\left[\left(R M * W+\left(R R_{P \text { Machining }}+R R_{E V \text { Machining }}\right)\left(t_{\text {Rough Machining }}+\right.\right.\right.\right.$ $\left.\left.\left.\left.t_{\text {Finish Machining }}+2 t_{\text {Setup }}\right)+C T * N T\right)\right]\left(1+R S C_{3-a x i s}\right)\right] / \mathrm{N}$

Equation 8

Where:

$N$ : Number of units

$R M=$ Raw material coefficient obtained from material length, width, height, volume and density of raw material.

$W$ : Weight of one unit in $\mathrm{kg}$ 


$$
\begin{aligned}
& C T \text { : Average cost of one tool } \\
& N T=\text { Number of tools } \\
& R S C_{3-\text { axis }}=\text { Average quantity of scrap produced } \\
& R R_{P \text { Machining }}=\text { Rate of planning for machining } \\
& R R_{E V \text { Machining }}=\text { Rate of experimental verification for machining } \\
& t_{R o u g h \text { Machining }}=\text { Time required for rough machining } \\
& t_{\text {Finish Machining }}=\text { Time required for finish machining } \\
& t_{\text {Setup }}=\text { Average time needed for setup }
\end{aligned}
$$

\subsubsection{Cost model for 5-Axis CNC machine}

The cost of planning for 5-Axis CNC machine are the sum of strategy development and optimization.

Cost of Planning per unit $=\left(\operatorname{Cost}_{S D}+\operatorname{Cost}_{O P}\right) / \mathrm{N}$

Where:

$$
\begin{aligned}
& \operatorname{Cost}_{S D}=\left(R R_{E S D}+R R_{\text {OPlan }}\right) t_{S D} \\
& \operatorname{Cost}_{O P}=\left(R R_{E O P}+R R_{O \text { Plan }}\right) t_{P O}
\end{aligned}
$$

$N$ : Number of units

$M M=$ Cumulative number of batches

$r=$ the learning curve coefficient 
$R R_{E S D}=$ Rate of equipment used for strategy development

$R R_{E O P}=$ Rate of equipment used for optimization

$R R_{O \text { Plan }}=$ Rate of planning

$t_{S D}=$ Average time needed for strategy development

$t_{O P}=$ Average time needed for optimization

Cost of Machining 5-Axis CNC per unit $=[[(R M * W+$

$\left.\left.\left(R R_{P \text { Machining }}\right)\left(t_{\text {Rough Machining }}+t_{\text {Finish Machining }}+2 t_{\text {Setup }}\right)+C T * N T\right)\right](1+$

$\left.\left.R S C_{5-\text { axis }}\right)\right] / \mathrm{N}$

Equation 10

Where:

$N$ : Number of units

$R M=$ Raw material coefficient obtained from material length, width, height, volume and density of raw material.

$W$ : Weight of one unit in $\mathrm{kg}$

$C T$ : Average cost of one tool

$N T=$ Number of tools

$R S C_{5-a x i s}=$ Average quantity of scrap produced by 5 -axis CNC

$R R_{P \text { Machining }}=$ Rate of planning for machining 
$t_{\text {Rough Machining }}=$ Time required for rough machining

$t_{\text {Finish Machining }}=$ Time required for finish machining

$t_{\text {Setup }}=$ Average time needed for setup

\subsection{Method: Managerial questions}

The questions posed to assist in managerial decision making can encompass a large number of issues faced by a business. For example, decisions relating to the volumetric capacity of the business, where if the capacity is too low, the business can lose customers due to their inability to produce large batch sizes. Whereas if the capacity is too high, it indicates that the business has excess machines that are being underutilized. Therefore, having the right capacity can be key to achieving competitive advantage (Persson, 1991). The selection of cost-effective machining and production process also has broader implication. For instance, the strategies used to select machines can affect the business's flexibility to switching between producing different products. For the purpose of this research the managerial questions have been based on the $\mathrm{CNC}$ production data extracted from the case-study. Table 3.4. outline the managerial questions, narrow the scope of the research and facilitate to answer the basic research question. 
Table 3. 5 Managerial Questions

\section{Managerial Questions}

\begin{tabular}{l|l}
\hline MQ 1 & What is the cost of the planning phase development? \\
MQ 2 & What is the cost of the machining phase? \\
MQ 3 & What is the cost per unit? \\
MQ 4 & What is the costs implication of each resources used to produce the first unit? \\
MQ 5 & What is the distribution of cost? \\
MQ 6 & Which group of programmers should be assigned to complete the task? \\
MQ 7 & What is the optimal batch size? \\
\hline
\end{tabular}

\subsection{Case study}

The case study provides the observational environment that enables the study of the artifacts in depth. This research used the case study to analyze managers selection techniques, the 5-axis and 3-axis machining procedures and parameters. The complications faced by managers in selecting between methods are identified and an innovative tool is proposed that will be instrumental in the selection process and enable the managers to select the cost-effective method.

The level of complexity in the shape of the structure dictates the selection of procedures needed to digitize and map the structure. The physical dimensions of the wind-turbine mentioned in the case study was digitized and mapped using scanning technology. This step enabled the programmer to gather structural parameters. The parameter data points are then organized and imported into CATIA v5R16, CAD software developed by Dassault Systems. The tool path parameters are created using Esprit, CAM software from developer DP Technology.

Based on the machining parameters the $12 \mathrm{~mm}$ ball-end mill with the optimal tool inclination of $12^{\circ}$, the cuboidal shaped cutting metal blank and the removal of redundant material 
using roughing operation were selected at this stage. Multiple prospective cutting parameters and cutting strategies were evaluated in $\mathrm{CAD}$, with the selection criterion- being able to achieve the shortest machining time. The following strategies have been evaluated in the case study: Circle, ellipse, square, level-z, spiral, zigzag-1 and zigzag-2. Among the strategies Ellipse and level-z were selected for rough machining, as they derived the shortest machining time.

The following machining parameters were selected in the case study based on recommended industry standard and acceptable ranges suggested by the machine and tool manufacturers. Cutting speed $70 \mathrm{~m} / \mathrm{min}$, feed $-0.06 \mathrm{~mm} /$ edge. The cutting-speed for 3 -axis CNC machines varied from $0 \mathrm{~m} / \mathrm{min}$ to $70 \mathrm{~m} / \mathrm{min}$ whereas the 5 -axis $\mathrm{CNC}$ machines cutting-speed variation was insignificant and remained around $70 \mathrm{~m} / \mathrm{min}$. The variation in feed-rate was in the range of $0.02 \mathrm{~mm} /$ edge to $0.12 \mathrm{~mm} /$ edge. The rough machining axial depth of $3 \mathrm{~mm}$ and radial depth of $2 \mathrm{~mm}$ were applied. Followed by the finish machining axial depth of $0.5 \mathrm{~mm}$ to $1.3 \mathrm{~mm}$ and radial depth of $0.25 \mathrm{~mm}$ to $0.35 \mathrm{~mm}$ were applied.

Experimental cuts were performed for six feed-rate values and three simulations were performed to optimize the model for experimental verification (EV). The total time needed for experimental cuts and simulations for EV was 7 hours. The optimized model utilized the physical process simulation software to create the baseline EV parameters. Simulation were carried out in CAM software to evaluate the cutting forces applied to the complete modeled tool path. Lastly the optimal cutting force and feed-rate was set as the parameters for EV. The adjustments in the feed-rate and the cutting force improved the performance of 3-axis $\mathrm{CNC}$ machines. Complex three-dimensional structures could now be machined and achieve the same surface quality as 5 -axis. The 3 -axis machining speed also increased by $17 \%$. 
EV provided several benefits to 3-axis machining. However, its application required additional equipment like the Kistler piezoelectric-multicomponent dynamometer to measure the cutting force, it increased the machining time and cost of planning. The higher accumulated cost for 3-axis machining with the application of EV still remained lower than the 5-axis method.

The workpiece material used in the case study was the hardened alloy steel EN 34CrNiMo6. The steel has properties like high strength, corrosion resistance and resistance to overheating (Media, 2015). It is commonly used to manufacture industrial devices like wind turbines. Final optimization of the workpiece model was carried out in CAM software. The cutting force coefficient is set at 0.1 , allowing a $10 \%$ discrepancy in between estimated and observed cutting force.

\section{Results}

Reports and graphs for each machining methods are generated to answer the managerial questions. The report consists of the calculation used to evaluate the cost of producing each unit in correlation to the batch and the number of units in the batch. The calculation is performed by considering all the base-line rates presented in table 3.2. and the resources used table 3.3. The following reports and graphs are displayed to the manager consecutively in the order presented in this section. The managerial questions relating to cost-efficiency are equally important in helping the managers to determine which machining process should be used to complete the task.

The decision support system calculates and displays reports for each of the machining methods evaluated in this research. The reports for 3-axis machining performed by novice programmers is presented in figure 4.1. and the 5-axis is presented in figure 4.2. The reports for 
3-axis competent, 3-axis proficient and 3-axis expert have identical format as the 3-axis novice and are presented in Appendix A. The reports aid in answering the following managerial questions:

MQ 1. What is the cost of the planning phase?

MQ 2. What is the cost of the machining phase?

MQ 3. What is the cost per unit?

Report 4.1. provides an overview of all the costs incurred for producing the structure on 3-axis using novice programmers.

\begin{tabular}{|c|c|c|c|c|c|c|c|c|}
\hline \multicolumn{9}{|c|}{ 3-Axis Novice } \\
\hline Programmer & 42.96 & & & & & & & \\
\hline Raw Materials & 0.72 & & & & & & & \\
\hline CNC Machine & 128.88 & & & & & & & \\
\hline Cutting Tools & 6.25 & & & & & & & \\
\hline Machining Total & 178.81 & & & & & & & \\
\hline Scrap & 200.71 & & & & & & & \\
\hline Batch Number & Batch Size & Strategy Development & & & Experimental Verification & Total Cost for Planning Phase & Production Cost & Cost Per Unit \\
\hline 1 & 1 & $1 \$ \quad 27.12$ & $\$$ & 13.45 & $\$ \quad 378.00$ & $\$ \quad 418.57$ & $\$ \quad 619.28$ & $\$ \quad 619.28$ \\
\hline & 2 & 1.00 & $\$$ & 0.50 & 3.50 & 5.00 & 205.71 & 102.85 \\
\hline & 3 & 0.67 & $\$$ & 0.33 & 2.33 & 3.33 & 204.04 & 68.01 \\
\hline & 4 & 0.50 & $\$$ & 0.25 & 1.75 & 2.50 & 203.21 & 50.80 \\
\hline & 5 & 0.40 & $\$$ & 0.20 & 1.40 & 2.00 & 202.71 & 40.54 \\
\hline & 6 & 0.33 & $\$$ & 0.17 & 1.17 & 1.67 & 202.38 & 33.73 \\
\hline & 7 & 0.29 & $\$$ & 0.14 & 1.00 & 1.43 & 202.14 & 28.88 \\
\hline 2 & 8 & 0.20 & $\$$ & 0.10 & 0.70 & 1.00 & 201.71 & 25.21 \\
\hline & 9 & 0.18 & $\$$ & 0.09 & 0.62 & 0.89 & 201.60 & 22.40 \\
\hline & 10 & 0.16 & $\$$ & 0.08 & 0.56 & 0.80 & 201.51 & 20.15 \\
\hline & 11 & 0.15 & $\$$ & 0.07 & 0.51 & 0.73 & 201.44 & 18.31 \\
\hline & 12 & 0.13 & $\$$ & 0.07 & 0.47 & 0.67 & 201.38 & 16.78 \\
\hline & 13 & 0.12 & $\$$ & 0.06 & 0.43 & 0.62 & 201.32 & 15.49 \\
\hline & 14 & 0.11 & $\$$ & 0.06 & 0.40 & 0.57 & 201.28 & 14.38 \\
\hline
\end{tabular}

Figure 4. 1 Decision support system report for 3-axis novice

The costs are correlation to the number of units produced and number of batches presented in the first and second columns. For the purpose of this research, batch size is displayed up to seven units and reports are presented for two consecutive batches. The next three columns, display the costs associated with the planning phase that consists of strategy development, optimization and experimental verification. The total cost needed for planning is displayed in the fourth column. 
The cost incurred during the planning phase is vital for the managers to consider when selecting the machining method. The information enables them to closely review cost incurred during the design of the process when strategy development and optimization takes place. Finetuning of machining parameters and changing to the machining method can be made in this phase which can lead to significant cost-saving. A large portion of these costs will transition into sunk cost (i.e. costs that can no longer be recovered once the production has been initialized). Therefore, these reports provide a set of vital decision-making information, enabling the managers to reflect on their decision to continue with further investments.

The four items presented at the top of the report are costs incurred during the machining phase, the fifth item provides the total of the costs incurred during machining and the cost of the scrap material generated from the process is presented as the sixth item.

The machining phase includes the cost of the programmer operating the machine, the cost of raw materials being utilized in production, the flat rate arising from the $\mathrm{CNC}$ machine's amortization and the cost of cutting tool used for machining. The total machining field provide the fundamental decision-making information on how much will it cost to carry out the machining process. The total cost incurred during planning and machining add up to provide the total cost of production. Subsequently, the production cost is divided by the correlated number of units $(\mathrm{N})$ to find the per unit cost.

Figure 4.2. illustrate the report generated for 5-axis machines. The format of the report is similar to the 3-axis report with the exception in the planning phase which includes the cost of strategy development, cost of optimization and excludes experimental verification. 


\begin{tabular}{|c|c|c|c|c|c|c|c|c|c|c|c|}
\hline \multicolumn{12}{|c|}{ 5-Axis } \\
\hline Programmer & $\$ \quad 42.90$ & & & & & & & & & & \\
\hline Raw Materials & $\$ \quad 0.72$ & & & & & & & & & & \\
\hline CNC Machine & $\$ 200.20$ & & & & & & & & & & \\
\hline Cutting Tools & $\$ \quad 7.50$ & & & & & & & & & & \\
\hline Machining Total & $\$ 251.32$ & & & & & & & & & & \\
\hline Scrap & $\$ 261.37$ & & & & & & & & & & \\
\hline \multirow{8}{*}{\begin{tabular}{|r|} 
Batch Number \\
1
\end{tabular}} & Batch Size & Str & pment & & & & Phase & & Cost & & Unit \\
\hline & 1 & $\$$ & 40.08 & $\$$ & 22.15 & $\$$ & 62.23 & $\$$ & 323.60 & $\$$ & 161.80 \\
\hline & 2 & $\$$ & 1.25 & $\$$ & 0.65 & $\$$ & 1.90 & $\$$ & 263.27 & $\$$ & 87.76 \\
\hline & 3 & $\$$ & 0.83 & $\$$ & 0.43 & $\$$ & 1.27 & $\$$ & 262.64 & $\$$ & 65.66 \\
\hline & 4 & $\$$ & 0.63 & $\$$ & 0.33 & $\$$ & 0.95 & $\$$ & 262.32 & $\$$ & 52.46 \\
\hline & 5 & $\$$ & 0.50 & $\$$ & 0.26 & $\$$ & 0.76 & $\$$ & 262.13 & $\$$ & 43.69 \\
\hline & 6 & $\$$ & 0.42 & $\$$ & 0.22 & $\$$ & 0.63 & $\$$ & 262.01 & $\$$ & 37.43 \\
\hline & 7 & $\$$ & 0.36 & $\$$ & 0.19 & $\$$ & 0.54 & $\$$ & 261.92 & $\$$ & 32.74 \\
\hline \multirow[t]{7}{*}{2} & 8 & $\$$ & 0.16 & $\$$ & 0.08 & $\$$ & 0.24 & $\$$ & 261.61 & $\$$ & 32.70 \\
\hline & 9 & $\$$ & 0.14 & $\$$ & 0.07 & $\$$ & 0.21 & $\$$ & 261.59 & $\$$ & 29.07 \\
\hline & 10 & $\$$ & 0.13 & $\$$ & 0.07 & $\$$ & 0.19 & $\$$ & 261.56 & $\$$ & 26.16 \\
\hline & 11 & $\$$ & 0.11 & $\$$ & 0.06 & $\$$ & 0.17 & $\$$ & 261.55 & $\$$ & 23.78 \\
\hline & 12 & $\$$ & 0.10 & $\$$ & 0.05 & $\$$ & 0.16 & $\$$ & 261.53 & $\$$ & 21.79 \\
\hline & 13 & $\$$ & 0.10 & $\$$ & 0.05 & $\$$ & 0.15 & $\$$ & 261.52 & $\$$ & 20.12 \\
\hline & 14 & $\$$ & 0.09 & $\$$ & 0.05 & $\$$ & 0.14 & $\$$ & 261.51 & $\$$ & 18.68 \\
\hline
\end{tabular}

Figure 4. 2 Decision support system report for 5-axis.

The reports display the cost of producing each unit. The availability of this information before the selection and execution of machining can be vital. It will aid the manager to set the sale price of the units with the appropriate mark-up. It also allows the manager to estimate how many products must be produced in the production cycle to justify the production.

The reports provide fundamental production information in one coherent place. The cost of the two phases of production data and the cost to manufacture each unit aid in solving three managerial questions posed in this research. The reports are generated for each method and can be instrumental for making the comparison, eliminate methods that generate higher cost and select the one that yield the highest profit and incurs the cost of production in order to achieve cost-effectiveness.

Large data sets and multiple methods can sometime make the evaluation process cumbersome and lengthy. Examining the reports can become complicated, therefore the 
distribution of costs for producing the first unit has been presented in the form of a bar graph in figure 4.3 .

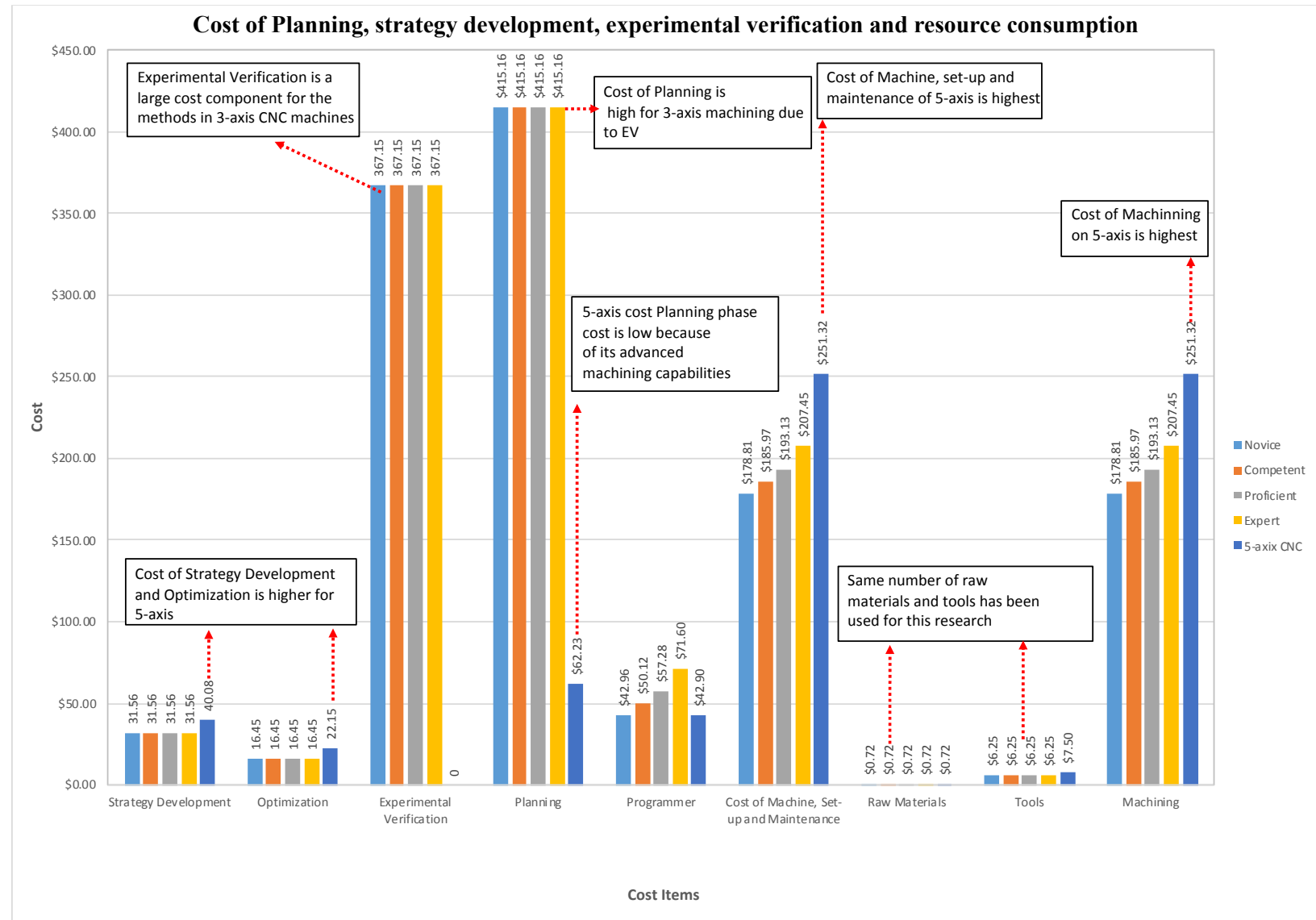

Figure 4. 3 Distribution of costs for first unit.

The display of cost components enables the managers to perform a direct comparison of costs generated from each method. This function is instrumental to quickly analyze the cost items, saves time for the manager and answer the following managerial questions:

MQ 4. What is the costs implication of each resources used to produce the first unit? MQ 5. What is the distribution of cost? 
The bar graph provides an easy to understand break down of costs between the methods. Producing the first unit requires the largest amount of resourced and is the most cost intensive. The graph provides the key information on the cost of resources and the cost of phases that are expected to be utilized. This enables the managers to arrange the capital and resources that will be required for production.

The review of the graph will allow the manager can quickly determine the major cost drivers and identify irregularities in the process for example the graph might display the cost of tool for one method is higher than the other methods, therefore they can change the machining parameters to use a different tool. The graph enables a comparative analysis between the methods and displays the resources being consumed by each method, this information can contribute to controlling costs.

The manager can fine-tune numerous machining parameters to observe any changes to the distribution of cost graph in order to obtain cost-effective production parameters. For instance, by looking at the graph- it can be quickly determined that strategy development and optimization for 3-axis is lower than 5-axis. The application of EV increases the cost of planning for 3-axis but the machining costs in 3-axis are also lower. Therefore, if the structure is simple enough to machine without applying $\mathrm{EV}$, then the 3 -axis machine will be most cost efficient. If the structure is complex and $\mathrm{EV}$ is required than producing large volume of units can balance the added cost of production.

The power learning curve equation presented in section 3.4.1. is integrated into decision support system to accurately calculate the cost arising from activities that involve the 
programmer. When the manager assigns the task to a group of programmers, the cost-saving occurring due to the learning effects are noted and is a major contribution of this research.

The decision support system factors in the cost savings arising from performing a repetitive task and aid the managers in selecting the right programmer's to carryout production in the most cost-effective way. Figure 4.4. presents the graph illustrating the cost-saving implications arising from the power learning curve applied to different groups of programmers and answers the following managerial question:

MQ 6. Which group of programmers should be assigned to complete the task?

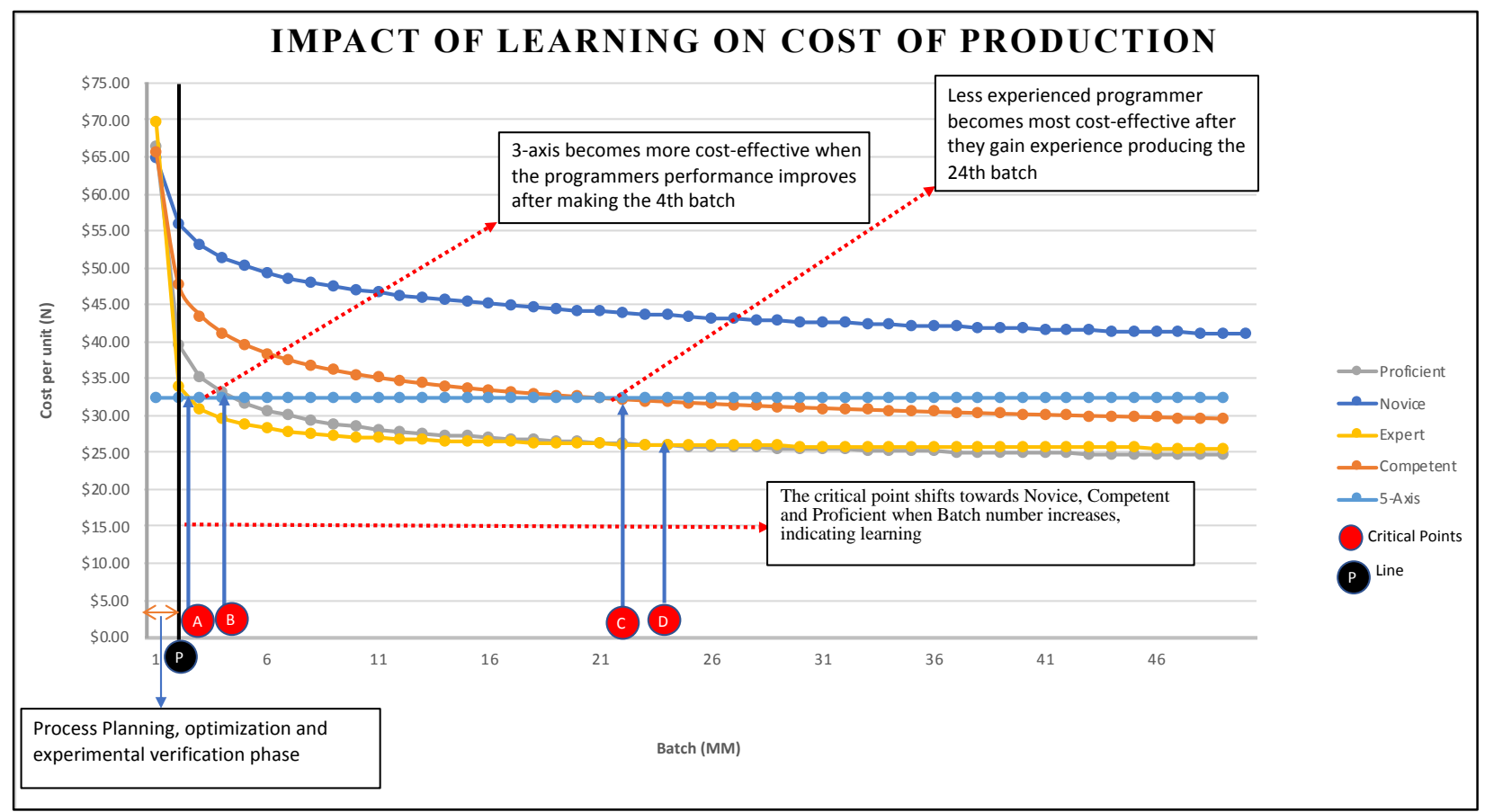

Figure 4. 4 Implication of learning on the cost of production

The data in figure 4.4. is graphical represented the learning effects and conceals the complications arising from the algorithm and the dataset. The y-axis of the graph represents the cost per unit and the $\mathrm{x}$-axis represents the number of batches produced. The graph consists of 
five curves, each representation the different experience levels analysed in this research. (i.e. 3axis novice, 3 -axis proficient, 3 -axis competent, 3 -axis expert and 5-axis programmers). Critical point markers have been placed to indicate the cost-saving implications occurring from learning. 5 -axis is used as the benchmark and given an average rate and $\alpha$ value. Refer to the legends for identification of the curves and critical points. The graph is labeled with arrows and footnotes to explain the information displayed. The section of the graph between the $\mathrm{y}$-axis and the line $\mathrm{P}$ represents the production of the initial batches, for which the cost is substantially higher due to the cost incurred during planning. Furthermore, the cost of producing the initial batches on 3 -axis is higher than 5-axis due to experimental verification. The graph illustrates that 5-axis CNC machines generate the lowest cost to produce the initial batches because of its less complex strategy development and optimization stages.

Each batch (MM) in the production cycle consists of a set number of units $(\mathrm{N})$. Determining the optimal batch size is an essential part of the selection process. Figure 4.5. provide a graphical representation of the best number of units $(\mathrm{N})$ to be produced in each batch and answers the following managerial question:

MQ 7. What is the optimal batch size? 


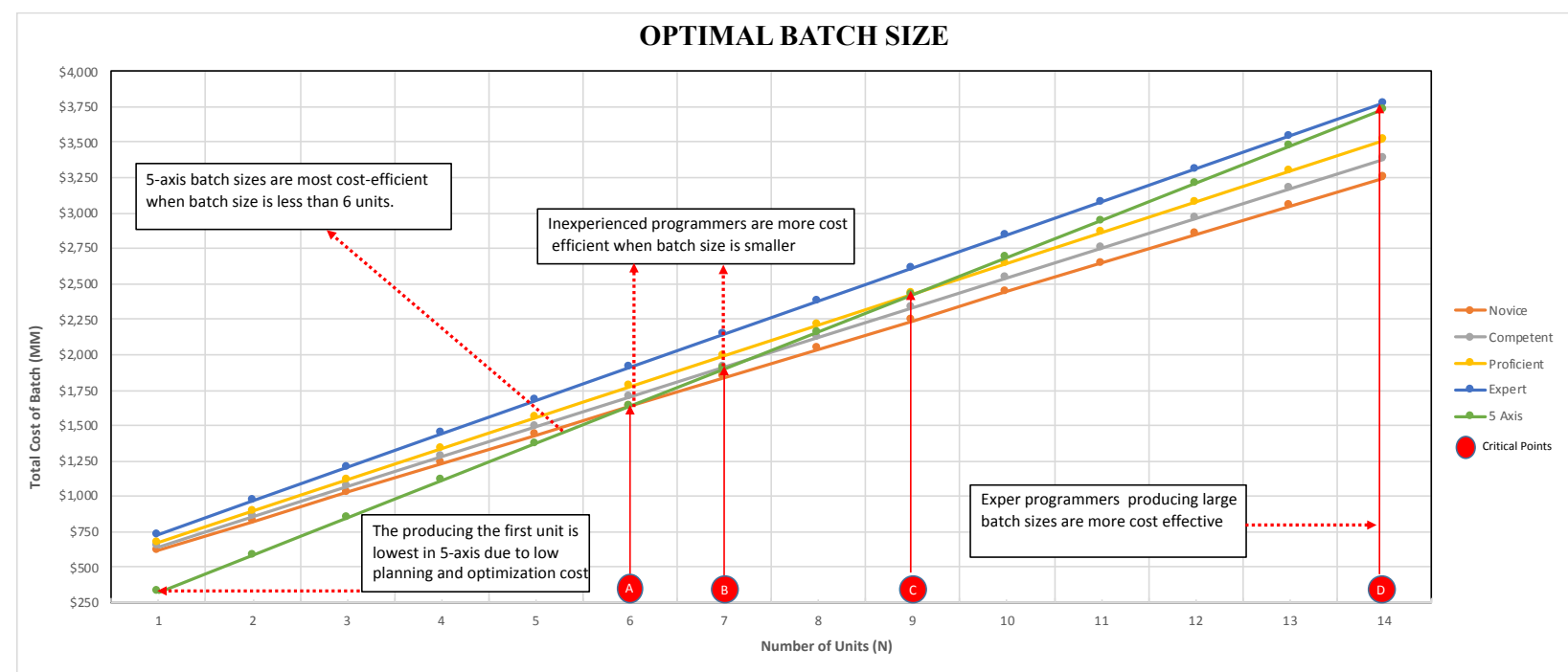

Figure 4. 5 Optimal Batch Size

Finding the optimal batch size enable the managers set the number of units that are needed to be produced per batch, direct resources and schedule the task to programmers. Optimal batch size is determined by performing a direct comparison between the methods being evaluated. The 5-axis uses average programmer rate and provide the benchmark measurements. The comparison is performed by placing all the methods in one graph. The cost of manufacturing the initial units lowest in 5-axis CNC machines in-spite of the high strategy development, optimization and overall machining phase costs. This explains the increased capabilities of the 5axis machines and the reduced time taken for the overall planning phase.

After the manager has assessed the cost of planning, machining, the cost of producing one unit, determining the batch size and assigned the task to a group of programmers. The manager can initiate the machining process. The decision support system has accurately derived and answered key managerial questions posed in this research relating to the selecting costeffective method of production. 


\section{Discussions}

The 5-axis CNC machines are newer technology and contains two additional rotary axes, making it more advanced than 3-axis machines. Zębala \& Plaza, (2014) evaluated the viability of applying enhancements to 3 -axis in order to achieve the same quality of output as 5-axis. They applied an experimental verification (i.e. a material feed-rate and cutting force adjustment algorithm) for the enhancement and enable 3-axis to produce free-form structures. Application of experimental verification successfully increased the capabilities of 3-axis. The resulting structure quality and time required for production was on par with 5-axis machines. However, application of experimental verification, substantially increased cost of planning, resulting in an increase in cost of production. This research builds on their findings and applies the power learning curve to evaluate the cost implications between the two methods.

The 5-axis machines are not optimized with experimental verification because it is more technologically advanced and can machine the structure surface precisely without requiring any enhancements. The application of experimental verification requires additional equipment, which would add to the high cost of acquiring and operating 5-axis machines and increase the overall cost of production. Furthermore, Zębala \& Plaza, (2014) provided evidence that experimental verification does not produce any observable production benefits.

For the purpose of analysis, the learning curve is applied to 3-axis and 5-axis. Two groups of programmers (i.e. novice and expert) are used. Novice programmers assigned with the rate $\$ 12$ per hour, learning curve coefficient of 0.9 and expert programmers assigned with the rate $\$ 20$ per hour, learning curve coefficient of 0.6. The learning curve demonstrated cost 
implications during the planning phase due to labour-intensive tasks like strategy development, optimization and experimental verification.

Expert programmers assigned to perform the task on 5-axis, demonstrated the duration for strategy development is 2 hours and the duration for optimization is 1.04 hours. Therefore, the total time required for planning is 3.04 hours. When novice programmers are assigned to perform the task on 5-axis machines, the resulting duration for strategy development is 3 hours and the duration for optimization is 1.56 hours. Resulting in 4.56 hours dedicated to the planning phase. The time difference is only 1.52 hours. Due to insignificant change in time, the cost implications are observed to be marginal when varying levels of programmers are used for 5axis. Therefore, an average value can be used. This outcome is due to the exclusion of experimental verification and the less complex strategy development and optimization stages.

The same analysis performed for 3-axis. For expert programmer the duration for strategy development resulted in 1.6 hours, the duration for optimization is 0.8 hours and the duration of performing experimental verification is 7 hours. This results in a total of 9.4 hours dedicated to the planning phase. For novice programmers the duration for strategy development is observed to be 2.4 hours, the duration for optimization is 1.2 hours and the duration for performing experimental verification is 19 hours. This results in a total of 22.6 hours dedicated to the planning phase. The difference in time is 13.20 hours. The difference was substantial and an average value cannot be used for 3 -axis.

The calculations demonstrate the validity of the assumption that the learning curve has a greater impact on 3-axis machining than the 5-axis. This is due to 3 -axis machining's more complex strategy development, optimization and the need for experimental verification. Furthermore, the use of average rate and learning curve coefficient to 5-axis enabled the research 
to use the method as a benchmark and observe the learning curve implication displayed by the programmers.

The decision support system developed is able to assist managers in their decision making, enabling them to analyze different methods of production and selecting the most costeffective method quickly and with ease. Furthermore, the research filled in the knowledge gap on how factors, related to $\mathrm{CNC}$ programmer learning in combination with choosing the suitable method of production can impact the businesses cost effectiveness. The system is demonstrated by using actual production data from a repetitive assembly process. Due to the data limitations, this research analysed a particular approach in machining.

The cost model used in this research to support the findings is well supported.

Langmaak, Wiseall, Bru, \& Adkins, (2012) presented the cost model to calculate the per unit cost in a CNC manufacturing process. The use of the cost model enabled them to consider any production uncertainties and measure multifaceted costs arising from the production planning and design phases. Bouaziz, Ben Younes, \& Zghal, (2004) used the cost model to evaluated machining costs in $\mathrm{CNC}$ manufacturing. They first considered planning phase costs items like structure modelling process, use of IT features like CAD followed by machining cost items like machining time, surface finish and scrap rate.

Quintana \& Ciurana, (2011) focused on the machine tool selection and machining cost estimation problem. They applied a multiple regression-based cost model to accurately calculate the machining tool's market cost, which can be a key information for decision makers before the production process starts. Similarly Qian \& Ben-Arieh, (2008) proposed a cost estimation model by combining activity based costing and parametric costs arising during the planning and design phase in CNC machining. This method allowed them to estimate costs early on the production 
phase with more accuracy and also allowed them to compare cost generated from different machining methods. Ben-Arieh \& Qian, (2003) also applied activity-based costing to evaluate cost occurring during the $\mathrm{CNC}$ machining design and development phase.

Asiedu \& Gu, (1998) focused on estimating cost being incurred during the development, machining, utilization and seclusion stages to provide the managers with an accurate cost estimation information during the design phase. Tsai et al., (2015) developed a decision-making model using activity-based costing to maximize companies' profits and promote environmentally friendly manufacturing methods.

\subsection{Interpretations of results}

The reports generated illustrate that the cost of planning for novice is $\$ 418.57$, competent is $\$ 438.57$, proficient is $\$ 458.57$, expert is $\$ 498.57$ and 5 -axis is $\$ 62.23$. This provides an overview of the cost generated during the planning phase. The information shows that planning for 5-axis is substantially lower because of the exclusion of experimental verification and comparatively less complex strategy development and optimization stages. However, the planning phase for novice is relatively low due to the low wage rate.

The cost of machining is for novice is 178.81 , competent is 185.97 , proficient is 193.13 , expert is 207.45 and 5-axis is $\$ 251.32$. As the research predicted the cost of machining is highest for the 5-axis machining. The lowest cost of machining is obtained by novice because of low wage rate, low cost of 3 -axis machines and learning curve implications.

The cost of producing the first unit for novice is $\$ 619.28$, competent is 647.32 , proficient is 675.35 , expert is 731.43 and 5-axis is 161.80 . The 5-axis cost of producing the first unit is 
substantially lower due to the low cost and complexity of strategy development, planning and exclusion of experimental verification. The cost of producing the first unit is lowest for novice because of the low wage rage and learning implications.

The scrap rate is calculated using the scrap percentage in correlation to the cost of machining. 5-axis the scrap cost is $\$ 261.27$, novice is $\$ 200.71$, competent is $\$ 208.75$, proficient is $\$ 216.78$ and expert is $\$ 232.86$. The variation is due to the cost of machining and novice generated the least amount of scrap.

The cost of producing the $7^{\text {th }}$ unit in the first batch for novice is $\$ 28.88$ and the $7^{\text {th }}$ unit in the second batch is $\$ 14.38$. The cost calculation considers all the costs incurred during planning and machining. The scrap rate is also included here. All costs are distributed evenly to the number of units and novice cost of producing each unit most cost-effective.

The cost of producing the $7^{\text {th }}$ unit in the first batch for competent is $\$ 30.02$ and $\$ 14.94$ for the $7^{\text {th }}$ unit in the second batch. Similarly, the cost of producing the $7^{\text {th }}$ unit in the first batch proficient is $\$ 31.17$ and is $\$ 15.50$ for the $7^{\text {th }}$ unit in the second batch. The cost difference is marginal between competent and proficient.

The cost of producing the $7^{\text {th }}$ unit in the first batch for expert is $\$ 33.47$ and is $\$ 16.64$ for the $7^{\text {th }}$ unit in the second batch. Whereas cost of producing the $7^{\text {th }}$ unit in the first batch for 5 -axis is $\$ 32.74$ and is $\$ 18.68$ for the $7^{\text {th }}$ unit in the second batch. 5 -axis cost of producing each unit in first batch is lower than expert but higher than novice, competent and proficient. However, expert producing the $7^{\text {th }}$ unit in the second batch displayed to be more cost effective than 5-axis.

The cost of producing the first unit is lowest for the 5-axis, closely followed by novice. This resulted from the additional time required for planning of novice. However, novice, 
competent, proficient and expert demonstrated to be more cost-effective when multiple batches are produced and when the cost of planning is distributed between a larger number of units.

Figure 4.3. displays the distribution of cost for producing the first unit. The 5-axis cost of strategy development and optimization are comparatively higher, but the overall cost of planning is substantially lower due to the exclusion of experimental verification. 3-axis machining on the other hand incurred high cost of planning due to the inclusion of experimental verification, costs arising from additional equipment for experimental verification, the more complex strategy development and optimization stages. Therefore, it can be concluded that if the production quantity is low, 5 -axis machining is most cost-effective whereas when multiple batches are being produced, 3-axis machining is most cost-effective.

The cost of machines, set-up and maintenance is highest for 5 -axis. The cost varies between novice, competent, proficient and expert using the same machine because of learning curve implications impacting machine set-up time. The 3-axis amortization rates however are much lower than the rate generated from 5-axis. To perform a fair comparison, the same level of raw material and tool cost has been applied. As a result, there was no cost implications. The machining phase cost is highest for 5-axis due to the high machine cost.

Figure 4.4. display the learning curve implications. After the initial batches are produced, the biggest impact of the learning curve is observed where expert programmers producing the fourth batch (MM) are most cost-effective compared to the initially cost-effective 5-axis. The shift in cost-efficiency is indicated by critical point A in graph. After the production of the fifth batch, proficient programmers surpass 5-axis in cost-efficiency but remain less cost-efficient than expert. Therefore, it can be concluded that when the production order consists of at least five batches, it is more cost-effective to select either expert or proficient programmers. 
Proficient programmers surpass 5 -axis in cost-efficiency indicated at critical point $\mathrm{B}$, this occurs after the production of the $5^{\text {th }}$ batch. Furthermore, the method become the most costeffective at critical point $\mathrm{D}$, when producing at least twenty-four batches. This phenomenon highlights learning curve implications and indicates that proficient is the most cost effective when 24 batches are being produced. At graph 4.4. critical point $\mathrm{C}$, competent programmers are observed to become more cost-effective than 5-axis, with producing at least twenty-three batches. Therefore, it can be concluded that when 23 batches or more is being produced, competent programmers using 3 -axis is most cost-efficient. It can be noted that novice, competent, proficient and expert curves display implications arising from learning effects. The time and cost required for the planning phase is substantially reduced after the initial batches are completed and the curves start to flatten out as the programmer becomes more fluent with the production process.

Figure 4.5. aid in determining the optimal batch size. The 5-axis method is used as benchmark due to its advanced capabilities, the application of the average programmer rate and learning curve coefficient. Novice programmers curve intersects 5-axis when six units per batch are being produced indicated with critical point $\mathrm{A}$. Therefore, the ideal batch size for novice should be six units in order for the method to be cost-effective.

The optimal batch size for competent programmers are seven units indicated by critical point B. Similar to novice programmers, this group has a low wage rate and experience level. The graph also suggests that programmers with lower levels of experience should be assigned to tasks with fewer number of units per batch. This will allow the detection of product inaccuracies early on in the production cycle, with the least amount of resources spent. Furthermore, it will enable them to learn faster by performing the task in repetition with frequent interruptions arising 
from batch changes. Applying inexperienced programmers to perform tasks can also have long term benefits for the business, as they will gain experience and knowledge.

The optimal batch size for proficient programmers are nine units, indicated by critical point $\mathrm{C}$. Whereas the optimal batch size for expert programmers is fourteen units or higher indicated by critical point $\mathrm{D}$. This illustrates that programmers with a higher experience level can be assigned to produce large batch sizes. Furthermore, their higher wages are being distributed between a larger number of units. Assigning experienced programmers to complete large batch sizes can also be cost-effective due to the popular belief, that they produce fewer defective products and tend to use less time and resources.

\subsection{Theoretical implications}

The findings of the research matched with studies conducted on decision support systems aiding in managerial decision making Gupta \& Dutta, (2016), Clark et al., (2007), Power, (2008), Mirchandani \& Pakath, (1999) and studies conducted on learning curve implications on repetitive production processes Zębala \& Plaza, (2014a), (Plaza \& Zebala, (2019b), Jaber \& Glock, (2013b), Jaber, (2016), (Logan, 1988). This research contributes to the theory of power learning curve with respect to evaluating and selecting between machining methods with the main criteria to select the most cost-effective method. Through the analysis, it has been discovered that increasing amount of time spent on a task in conjunction to the number of task repetition leads to significant quantifiable performance improvements. This phenomenon is observed when expert programmers performing the task in 3-axis, producing the fourth batch, 
becomes most cost-effective compared to the initially cost-effective 5-axis. Critical point A in graph 4.4. show cost-saving arising from learning effects.

The results corresponded with the theory that performance of programmer with varying levels of experience is lowest, when a new task is introduced i.e. the longest amount of time taken to produce the first batch. However, the decline is quickly reversed after the initial batch is

produced, the programmer is observed to have acquired experience and built-up knowledge. Eventually the programmer requires less time due to cognitive and motor learning. Their production speed increases significant, followed by improvements occurring at a diminishing rate.

The decision support system built with the design science framework simplified managers decision-making process, integrated all the cost items in one coherent place, provided a user interface (UI) that concealed the complications of the model, equation, algorithms, data and aided in solving unstructured selection and assignment problems. The simplified system allowed the managers to select the most cost-effective method using their existing knowledge, experience and without having to learn advanced modelling.

\subsection{Implications for practice}

In practice this research provides a decision support system that can provide numerous merits to the managerial decision-making process in $\mathrm{CNC}$ production and be a cost-effective planning tool. The versatile decision support system can easily be changed, updated and reused for evaluating other methods. It resolved the problem arising from proprietary models provided 
by $\mathrm{CNC}$ machine manufacturers, resulting in a collection of incoherent and customized models available to $\mathrm{CNC}$ machining businesses.

The decision support system aids in minimizing the problem arising from commercial production manuals that contains technical measurement i.e. machine specifications, structure geometry and material properties. These measurements provide base-line parameters that do not derive optimal results therefore frequent adjustments and optimization are needed to achieve cost-efficient, create precision and eliminate discrepancies. The system can instantly display machine specifications, structure geometry and material properties stored in its database. This can drastically reduce costs incurred during planning of production and create cost-efficiency. For every production cycle, multiple machining methods are evaluated. The decision support system can be instrumental in the evaluating different the methods quickly and save managers time.

The decision support system can minimize errors by setting validation rules, which can prevent faulty data entries. For example, fields containing measurements are set in millimetres $(\mathrm{mm})$. Any other form of data is not permitted to be entered into that field, thus minimizing dataentry errors and creating consistency in units throughout the system. Additionally, the system allows users to select predetermined options with drop-down menu options allowing faster accurate entry of data.

The decision support system unified and display all the cost items related to the robust machining process in one coherent place. It enabled the storage of a wide range of machining parameters like feed-rate, spindle rotational speed, depth of cuts, tool-tip, radius of the tool-tip followed by various prospective tool paths. The stored data can be easily retrieved and used for future productions. The functions allow the manager to accurately derive production costs for 
multiple processes, carryout a direct comparison between them and obtain accurate repeatable results. The accurate selection of cost-effective machining can also have broader implication. For instance, the strategies used to select machines can affect the overall businesses flexibility when switching between different products or when making machinery purchase decisions.

It is important to design and perform the machining accurately. Any error made by the programmer can lead to substantial financial losses, cause accidents or injuries. The decision support system addresses the issue by aiding the manager in the work force assignment based on level of experience.

\subsection{Research limitations}

After considering and analyzing as many as possible components of the $\mathrm{CNC}$ production process, there are still a few factors this research could not evaluate. The research analysed one learning curve. However multiple variants of the learning curves can be used to calculate the cost-saving implications. Furthermore, the learning curve did not observe changes in the programmer's performance which can be instrumental in predicting future production cost implications. The programmer's learning coefficients was not confirmed but determined. The coefficients can be confirmed using surveying techniques or by interviewing managers on how they would categorise the programmers.

The production environment was included in the overhead cost calculations, but was not explored in detail. Managing production environment can potentially lead to additional costsaving. In addition, the reports and graphs do not cover all the aspects the manager might be interested in. Lastly the research used data from one case study, multiple case studies from different regions like North America can be used to further enhance the analysis. 


\subsection{Recommendation for future research}

The CNC machining has a wide range of components that can be further evaluated to obtain cost effective methods of production. I propose that anyone, that has benefitted from this research can focus on obtaining confirmed coefficients by testing programmers or by measuring the time taken to complete the task, or by allowing the programmers and managers to complete a survey for performance data analysis. The research can be expanded to compare other methods in machining and include different iterations of the learning and forgetting models to evaluate cost efficiency.

\section{Conclusion}

This paper has implemented the learning theory, design science paradigm and the cost model to create a tool that aims to be a catalyst in the strategic and operational decision-making process to assist managers in selecting cost-effective methods of production, achieve production efficiency and gain a competitive advantage in the market. The tool referred to as the decision support system, it is applied to the $\mathrm{CNC}$ machining process to evaluate feasibility of different machining methods, the business can apply for production.

The first stage of the research was the recognition the components that make up the machining process, followed by the recognition of issues faced by $\mathrm{CNC}$ manufacturers when selecting between various methods. The second stage was to determine the managerial questions, that were needed to be solved to facilitate the selection of cost-effective machining. The third stage was applied to investigate methods and theories that can be applicable to the particular industry in order to achieve cost-efficiency. The fourth stage consists of collecting data on CNC 
machining from a case study. The fifth stage was to apply the data to the decision support system built with the power learning curve and cost model algorithm. The reports and graphs generated from the decision support system solved the managerial questions relating to cost-efficiency. The decision support system has opened the new option for managers for evaluating between machining methods. 


\section{Appendix A}

\begin{tabular}{|c|c|c|c|c|c|c|c|c|c|}
\hline \multicolumn{10}{|c|}{ 3-Axis Competent } \\
\hline Programmer & 50.12 & & & & & & & & \\
\hline Raw Materials & 0.72 & & & & & & & & \\
\hline CNC Machine & 128.88 & & & & & & & & \\
\hline Cutting Tools & 6.25 & & & & & & & & \\
\hline Machining Total & 185.97 & & & & & & & & \\
\hline Scrap & 208.75 & & & & & & & & \\
\hline Batch Number & Batch Size & Strategy Development & & tion & Experimental Verification & Total Cost for Planning Phase & Production Cost & & Unit \\
\hline 1 & 1 & $1 \$ \quad 31.12$ & $\$$ & 15.45 & $\$ \quad 392.00$ & $\$ \quad 438.57$ & $\$ \quad 647.32$ & $\$$ & 647.32 \\
\hline & 2 & 1.00 & $\$$ & 0.50 & 3.50 & 5.00 & 213.75 & $\$$ & 106.87 \\
\hline & 3 & 0.67 & $\$$ & 0.33 & 2.33 & 3.33 & 212.08 & $\$$ & 70.69 \\
\hline & 4 & 0.50 & $\$$ & 0.25 & 1.75 & 2.50 & 211.25 & $\$$ & 52.81 \\
\hline & 5 & 0.40 & $\$$ & 0.20 & 1.40 & 2.00 & 210.75 & $\$$ & 42.15 \\
\hline & 6 & 0.33 & $\$$ & 0.17 & 1.17 & 1.67 & 210.41 & $\$$ & 35.07 \\
\hline & 7 & 0.29 & $\$$ & 0.14 & 1.00 & 1.43 & 210.17 & $\$$ & 30.02 \\
\hline 2 & 8 & 0.15 & $\$$ & 0.08 & 0.53 & 0.75 & 209.50 & $\$$ & 26.19 \\
\hline & 9 & 0.13 & $\$$ & 0.07 & 0.47 & 0.67 & 209.41 & $\$$ & 23.27 \\
\hline & 10 & 0.12 & $\$$ & 0.06 & 0.42 & 0.60 & 209.35 & $\$$ & 20.93 \\
\hline & 11 & 0.11 & $\$$ & 0.05 & 0.38 & 0.55 & 209.29 & $\$$ & 19.03 \\
\hline & 12 & 0.10 & $\$$ & 0.05 & 0.35 & 0.50 & 209.25 & $\$$ & 17.44 \\
\hline & 13 & 0.09 & $\$$ & 0.05 & 0.32 & 0.46 & 209.21 & $\$$ & 16.09 \\
\hline & 14 & 0.09 & $\$$ & 0.04 & 0.30 & 0.43 & 209.17 & $\$$ & 14.94 \\
\hline
\end{tabular}

Figure A1 Decision support system report for 3-axis competent

\begin{tabular}{|c|c|c|c|c|c|c|c|c|}
\hline \multicolumn{9}{|c|}{ 3-Axis Proficient } \\
\hline Programmer & 57.28 & & & & & & & \\
\hline Raw Materials & 0.72 & & & & & & & \\
\hline CNC Machine & 128.88 & & & & & & & \\
\hline Cutting Tools & 6.25 & & & & & & & \\
\hline Machining Total & 193.13 & & & & & & & \\
\hline Scrap & 216.78 & & & & & & & \\
\hline Batch Number & Batch Size & Strategy Development & & tion & Experimental Verification & Total Cost for Planning Phase & Production Cost & Cost Per Unit \\
\hline 1 & 1 & $1 \$ \quad 35.12$ & $\$$ & 17.45 & $\$ \quad 406.00$ & $\$ \quad 458.57$ & $\$ \quad 675.35$ & $\$ \quad 675.35$ \\
\hline & 2 & 1.00 & $\$$ & 0.50 & 3.50 & 5.00 & 221.78 & 110.89 \\
\hline & 3 & 0.67 & $\$$ & 0.33 & 2.33 & 3.33 & 220.12 & 73.37 \\
\hline & 4 & 0.50 & $\$$ & 0.25 & 1.75 & 2.50 & 219.28 & 54.82 \\
\hline & 5 & 0.40 & $\$$ & 0.20 & 1.40 & 2.00 & 218.78 & 43.76 \\
\hline & 6 & 0.33 & $\$$ & 0.17 & 1.17 & 1.67 & 218.45 & 36.41 \\
\hline & 7 & 0.29 & $\$$ & 0.14 & 1.00 & 1.43 & 218.21 & 31.17 \\
\hline 2 & 8 & 0.10 & $\$$ & 0.05 & 0.35 & 0.50 & 217.28 & 27.16 \\
\hline & 9 & 0.09 & $\$$ & 0.04 & 0.31 & 0.44 & 217.23 & 24.14 \\
\hline & 10 & 0.08 & $\$$ & 0.04 & 0.28 & 0.40 & 217.18 & 21.72 \\
\hline & 11 & 0.07 & $\$$ & 0.04 & 0.25 & 0.36 & 217.15 & 19.74 \\
\hline & 12 & 0.07 & $\$$ & 0.03 & 0.23 & 0.33 & 217.12 & 18.09 \\
\hline & 13 & 0.06 & $\$$ & 0.03 & 0.22 & 0.31 & 217.09 & 16.70 \\
\hline & 14 & 0.06 & $\$$ & 0.03 & 0.20 & 0.29 & 217.07 & 15.50 \\
\hline
\end{tabular}

Figure A2 Decision support system report for 3-axis proficient 


\begin{tabular}{|c|c|c|c|c|c|c|c|c|}
\hline \multicolumn{9}{|c|}{ 3-Axis Expert } \\
\hline Programmer & 71.60 & & & & & & & \\
\hline Raw Materials & 0.72 & & & & & & & \\
\hline CNC Machine & 128.88 & & & & & & & \\
\hline Cutting Tools & 6.25 & & & & & & & \\
\hline Machining Total & 207.45 & & & & & & & \\
\hline Scrap & 232.86 & & & & & & & \\
\hline Batch Number & Batch Size & Strategy Development & & Optimization & Experimental Verification & Total Cost for Planning Phase & Production Cost & Cost Per Unit \\
\hline 1 & 1 & $\$ \quad 43.12$ & $\$$ & 21.45 & $\$ \quad 434.00$ & $\$ \quad 498.57$ & $\$ \quad 731.43$ & $\$ \quad 731.43$ \\
\hline & 2 & 1.00 & $\$$ & 0.50 & 3.50 & 5.00 & 237.86 & 118.93 \\
\hline & 3 & 0.67 & $\$$ & 0.33 & 2.33 & 3.33 & 236.19 & 78.73 \\
\hline & 4 & 0.50 & $\$$ & 0.25 & 1.75 & 2.50 & 235.36 & 58.84 \\
\hline & 5 & 0.40 & $\$$ & 0.20 & 1.40 & 2.00 & 234.86 & 46.97 \\
\hline & 6 & 0.33 & $\$$ & 0.17 & 1.17 & 1.67 & 234.52 & 39.09 \\
\hline & 7 & 0.29 & $\$$ & 0.14 & 1.00 & 1.43 & 234.28 & 33.47 \\
\hline 2 & 8 & 0.05 & $\$$ & 0.03 & 0.18 & 0.25 & 233.11 & 29.14 \\
\hline & 9 & 0.04 & $\$$ & 0.02 & 0.16 & 0.22 & 233.08 & 25.90 \\
\hline & 10 & 0.04 & $\$$ & 0.02 & 0.14 & 0.20 & 233.06 & 23.31 \\
\hline & 11 & 0.04 & $\$$ & 0.02 & 0.13 & 0.18 & 233.04 & 21.19 \\
\hline & 12 & 0.03 & $\$$ & 0.02 & 0.12 & 0.17 & 233.02 & 19.42 \\
\hline & 13 & 0.03 & $\$$ & 0.02 & 0.11 & 0.15 & 233.01 & 17.92 \\
\hline & 14 & 0.03 & $\$$ & 0.01 & 0.10 & 0.14 & 233.00 & 16.64 \\
\hline
\end{tabular}

Figure A3 Decision support system report for 3-axis expert. 


\section{References}

A. A. Aly, \& M. Subramaniam. (1993). Design of an FMS decision support system.

Abdel-Malek, L., \& Resare, L. J. (2000). Algorithm based decision support system for the concerted selection of equipment in machining/assembly cells. International Journal of Production Research, 38(2), 323-339. https://doi.org/10.1080/002075400189437

Abdul Kadir, A., Xu, X., \& Hämmerle, E. (2011). Virtual machine tools and virtual machiningA technological review. Robotics and Computer-Integrated Manufacturing, 27(3), 494508. https://doi.org/10.1016/j.rcim.2010.10.003

Ahmad, R., Tichadou, S., \& Hascoet, J.-Y. (2017). A knowledge-based intelligent decision system for production planning. The International Journal of Advanced Manufacturing Technology, 89(5-8), 1717-1729. https://doi.org/10.1007/s00170-016-9214-z

Al-Ahmari, A. M. A. (2001). Mathematical model for determining machining parameters in multipass turning operations with constraints. International Journal of Production Research, 39(15), 3367-3376. https://doi.org/10.1080/00207540110052562

Alamri, Adel. A., \& Balkhi, Z. T. (2007). The effects of learning and forgetting on the optimal production lot size for deteriorating items with time varying demand and deterioration rates. International Journal of Production Economics, 107(1), 125-138. https://doi.org/10.1016/j.ijpe.2006.08.004

Alberti, M., Ciurana, J., Rodríguez, C. A., \& Özel, T. (2011). Design of a decision support system for machine tool selection based on machine characteristics and performance 
tests. Journal of Intelligent Manufacturing, 22(2), 263-277.

https://doi.org/10.1007/s10845-009-0286-6

Altintaş, Y., \& Budak, E. (1995). Analytical Prediction of Stability Lobes in Milling. CIRP Annals, 44(1), 357-362. https://doi.org/10.1016/S0007-8506(07)62342-7

Antonie Stam, \& Markku Kuula. (1991). Selecting a flexible mamufacturing system using multiple criteria analysis.

Anzanello, M. J., \& Fogliatto, F. S. (2007). Learning curve modelling of work assignment in mass customized assembly lines. International Journal of Production Research, 45(13), 2919-2938. https://doi.org/10.1080/00207540600725010

Anzanello, Michel Jose, \& Fogliatto, F. S. (2011). Learning curve models and applications: Literature review and research directions. International Journal of Industrial Ergonomics, 41(5), 573-583. https://doi.org/10.1016/j.ergon.2011.05.001

Arnott, D., \& Pervan, G. (2014). A Critical Analysis of Decision Support Systems Research Revisited: The Rise of Design Science. Journal of Information Technology, 29(4), 269293. https://doi.org/10.1057/jit.2014.16

Ayă̆, Z., \& Özdemir, R. G. (2011). An intelligent approach to machine tool selection through fuzzy analytic network process. Journal of Intelligent Manufacturing, 22(2), 163-177. https://doi.org/10.1007/s10845-009-0269-7

Ayağ, Zeki, \& Gürcan Özdemir, R. (2012). Evaluating machine tool alternatives through modified TOPSIS and alpha-cut based fuzzy ANP. International Journal of Production Economics, 140(2), 630-636. https://doi.org/10.1016/j.jpe.2012.02.009 
Ayağ, Zeki, \& Özdemir, R. G. (2006). A Fuzzy AHP Approach to Evaluating Machine Tool Alternatives. Journal of Intelligent Manufacturing, 17(2), 179-190. https://doi.org/10.1007/s10845-005-6635-1

Azzouz, A., Ennigrou, M., \& Ben Said, L. (2018). Scheduling problems under learning effects: Classification and cartography. International Journal of Production Research, 56(4), 1642-1661. https://doi.org/10.1080/00207543.2017.1355576

Badrinathan, K. S., \& Karunamoorthy, L. (2014). Study of the Effect of Progressive Feed Rate on the Cutting Force in CNC End Milling of AISI 1045 Steel. International Journal of Engineering and Technology, 5(6), 11.

Baskar, N., Asokan, P., Prabhaharan, G., \& Saravanan, R. (2005). Optimization of Machining Parameters for Milling Operations Using Non-conventional Methods. The International Journal of Advanced Manufacturing Technology, 25(11-12), 1078-1088. https://doi.org/10.1007/s00170-003-1939-9

Baskar, N., Asokan, P., Saravanan, R., \& Prabhaharan, G. (2006). Selection of optimal machining parameters for multi-tool milling operations using a memetic algorithm. Journal of Materials Processing Technology, 174(1-3), 239-249. https://doi.org/10.1016/j.jmatprotec.2005.09.032

Ben-Arieh, D., \& Qian, L. (2003). Activity-based cost management for design and development stage. International Journal of Production Economics, 83(2), 169-183. https://doi.org/10.1016/S0925-5273(02)00323-7

Bill Brookfield. (2005). Management Accounting—Decision Management. 
Biskup, D. (1999). Single-machine scheduling with learning considerations. European Journal of Operational Research, 115(1), 173-178. https://doi.org/10.1016/S0377-2217(98)00246X

Biskup, D. (2008). A state-of-the-art review on scheduling with learning effects. European Journal of Operational Research, 188(2), 315-329.

https://doi.org/10.1016/j.ejor.2007.05.040

Bosetti, P., \& Bertolazzi, E. (2014). Feed-rate and trajectory optimization for CNC machine tools. Robotics and Computer-Integrated Manufacturing, 30(6), 667-677. https://doi.org/10.1016/j.rcim.2014.03.009

Çag`daç Arslan, M., Çatay, B., \& Budak, E. (2004). A decision support system for machine tool selection. Journal of Manufacturing Technology Management, 15(1), 101-109. https://doi.org/10.1108/09576060410512374

Cantamessa, M., \& Valentini, C. (2000). Planning and managing manufacturing capacity when demand is subject to di!usion e!ects. 14.

Carlsson, C., \& Turban, E. (2001). DSS: directions for the next decade.

Castellano, D., Gallo, M., Grassi, A., \& Santillo, L. C. (2019). Batching decisions in multi-item production systems with learning effect. Computers \& Industrial Engineering, 131, 578591. https://doi.org/10.1016/j.cie.2018.12.068

Chan, F. T. S., \& Swarnkar, R. (2006). Ant colony optimization approach to a fuzzy goal programming model for a machine tool selection and operation allocation problem in an FMS. Robotics and Computer-Integrated Manufacturing, 22(4), 353-362. https://doi.org/10.1016/j.rcim.2005.08.001 
Charles D. Bailey. (1989). Forgetting and the Learning Curve: A Laboratory Study. Management Science, 35(3), 340-352.

Chen, W., Xue, J., Tang, D., Chen, H., \& Qu, S. (2009). Deformation prediction and error compensation in multilayer milling processes for thin-walled parts. International Journal of Machine Tools and Manufacture, 49(11), 859-864.

https://doi.org/10.1016/j.ijmachtools.2009.05.006

Choi, Y. (2015). Influence of feed rate on surface integrity and fatigue performance of machined surfaces. International Journal of Fatigue, 78, 46-52. https://doi.org/10.1016/j.jpfatigue.2015.03.028

Çimren, E., Çatay, B., \& Budak, E. (2007). Development of a machine tool selection system using AHP. The International Journal of Advanced Manufacturing Technology, 35(3-4), 363-376. https://doi.org/10.1007/s00170-006-0714-0

Clark, Jones, \& Armstrong. (2007). The Dynamic Structure of Management Support Systems: Theory Development, Research Focus, and Direction. MIS Quarterly, 31(3), 579. https://doi.org/10.2307/25148808

Dardan, S., Busch, D., \& Sward, D. (2006). An application of the learning curve and the nonconstant-growth dividend model: IT investment valuations at Intel ${ }^{\circledR}$ Corporation. Decision Support Systems, 41(4), 688-697. https://doi.org/10.1016/j.dss.2004.10.004

Dar-El, E. M., Ayas, K., \& Gilad, I. (1995). A dual-phase model for the individual learning process in industrial tasks. IIE Transactions, 27(3), 265-271. https://doi.org/10.1080/07408179508936740 
Dépincé, P., \& Hascoët, J.-Y. (2006). Active integration of tool deflection effects in end milling. Part 1. Prediction of milled surfaces. International Journal of Machine Tools and Manufacture, 46(9), 937-944. https://doi.org/10.1016/j.ijmachtools.2005.08.005

Dong, J., Ferreira, P. M., \& Stori, J. A. (2007). Feed-rate optimization with jerk constraints for generating minimum-time trajectories. International Journal of Machine Tools and Manufacture, 47(12-13), 1941-1955. https://doi.org/10.1016/j.ijmachtools.2007.03.006

EY Global Steel 2015-2016. (n.d.). Retrieved from https://www.ey.com/Publication/vwLUAssets/EY-global-steel-2015-2016/\$FILE/EYglobal-steel-2015-2016.pdf

Fontaine, M., Devillez, A., Moufki, A., \& Dudzinski, D. (2006). Predictive force model for ballend milling and experimental validation with a wavelike form machining test. International Journal of Machine Tools and Manufacture, 46(3-4), 367-380. https://doi.org/10.1016/j.ijmachtools.2005.05.011

Fu, G., Fu, J., Shen, H., Yao, X., \& Chen, Z. (2015). NC codes optimization for geometric error compensation of five-axis machine tools with one novel mathematical model. The International Journal of Advanced Manufacturing Technology, 80(9-12), 1879-1894. https://doi.org/10.1007/s00170-015-7162-7

Gagnon, R. J., \& Sheu, C. (2000). The impact of learning, forgetting and capacity pro ${ }^{\circledR} l e s$ on the acquisition of advanced technology. 26.

Ganesan, H., \& Mohankumar, G. (2013a). Optimization of Machining Techniques in CNC Turning Centre Using Genetic Algorithm. Arabian Journal for Science and Engineering, 38(6), 1529-1538. https://doi.org/10.1007/s13369-013-0539-8 
Ganesan, H., \& Mohankumar, G. (2013b). Optimization of Machining Techniques in CNC Turning Centre Using Genetic Algorithm. Arabian Journal for Science and Engineering, 38(6), 1529-1538. https://doi.org/10.1007/s13369-013-0539-8

Gao, W., Zhang, C., Hu, T., \& Ye, Y. (2019). An intelligent CNC controller using cloud knowledge base. The International Journal of Advanced Manufacturing Technology, 102(1-4), 213-223. https://doi.org/10.1007/s00170-018-03222-8

Globerson, S., Levin, N., \& Shtub, A. (1989). The Impact of Breaks on Forgetting When Performing A Repetitive Task. IIE Transactions, 21(4), 376-381. https://doi.org/10.1080/07408178908966244

Gopalakrishnan, B., Yoshii, T., \& Dappili, S. M. (2004). Decision support system for machining center selection. Journal of Manufacturing Technology Management, 15(2), 144-154. https://doi.org/10.1108/09576060410513733

Grabec, I. (1988). Chaotic dynamics of the cutting process. International Journal of Machine Tools and Manufacture, 28(1), 19-32. https://doi.org/10.1016/0890-6955(88)90004-1

Gregor, S., \& Jones, D. (2007). The Anatomy of a Design Theory. 8(5), 25.

Grosse, E. H., \& Glock, C. H. (2013). An experimental investigation of learning effects in order picking systems. Journal of Manufacturing Technology Management, 24(6), 850-872. https://doi.org/10.1108/JMTM-03-2012-0036

Grosse, E. H., Glock, C. H., \& Müller, S. (2015). Production economics and the learning curve: A meta-analysis. International Journal of Production Economics, 170, 401-412. https://doi.org/10.1016/j.jpe.2015.06.021 
Guo, J.-X., \& Fan, Y. (2017). Optimal abatement technology adoption based upon learning-bydoing with spillover effect. Journal of Cleaner Production, 143, 539-548. https://doi.org/10.1016/j.jclepro.2016.12.076

Guo, Z. X., Yang, C., Wang, W., \& Yang, J. (2015). Harmony search-based multi-objective optimization model for multi-site order planning with multiple uncertainties and learning effects. Computers \& Industrial Engineering, 83, 74-90. https://doi.org/10.1016/j.cie.2015.01.023

Gupta, N., \& Dutta, G. (2016). An Optimization Based Decision Support System for Strategic Planning in Process Industries: The Case of a Pharmaceutical Company. In J. Papathanasiou, N. Ploskas, \& I. Linden (Eds.), Real-World Decision Support Systems (Vol. 37, pp. 175-198). https://doi.org/10.1007/978-3-319-43916-7_8

Hajian, M., Razfar, M. R., \& Etefagh, A. H. (2017). Experimental study of tool bending force and feed rate in ECDM milling. The International Journal of Advanced Manufacturing Technology, 91(5-8), 1677-1687. https://doi.org/10.1007/s00170-016-9860-1

Hamade, Ramsey F., Jaber, M. Y., \& Sikström, S. (2009a). Analyzing CAD competence with univariate and multivariate learning curve models. Computers \& Industrial Engineering, 56(4), 1510-1518. https://doi.org/10.1016/j.cie.2008.09.025

Hamade, Ramsey F., Jaber, M. Y., \& Sikström, S. (2009b). Analyzing CAD competence with univariate and multivariate learning curve models. Computers \& Industrial Engineering, 56(4), 1510-1518. https://doi.org/10.1016/j.cie.2008.09.025

Hamade, Ramsey F., Jaber, M. Y., \& Sikström, S. (2009c). Analyzing CAD competence with univariate and multivariate learning curve models. Computers \& Industrial Engineering, 56(4), 1510-1518. https://doi.org/10.1016/j.cie.2008.09.025 
Hamade, R.F., Artail, H. A., \& Jaber, M. Y. (2007). Evaluating the learning process of mechanical CAD students. Computers \& Education, 49(3), 640-661. https://doi.org/10.1016/j.compedu.2005.11.009

Hancock. (1989). Effects of alternate routings under variable lot-size conditions.

Hancock, T. M. (1988). Effects of Adaptive Process Planning on Job Cost and Lateness Measures. International Journal of Operations \& Production Management, 8(4), 34-49. https://doi.org/10.1108/eb054833

Hanna, N. H., \& Tobias, S. A. (1969). The non-linear dynamic behaviour of a machine tool structure. International Journal of Machine Tool Design and Research, 9(3), 293-307. https://doi.org/10.1016/0020-7357(69)90005-5

Harald Gruber. (1998). Learning by Doing and Spillovers: Further Evidence for the Semiconductor Industry. Review of Industrial Organization, 13(6), 697-711. https://doi.org/10.1023/A:1007740416004

Hatcher, B. L. (1980). Learning curve calculation and plotting. Computers \& Industrial Engineering, 4(2), 87-93. https://doi.org/10.1016/0360-8352(80)90026-1

Hatchuel, A., Le Masson, P., Reich, Y., \& Subrahmanian, E. (2018). Design theory: A foundation of a new paradigm for design science and engineering. Research in Engineering Design, 29(1), 5-21. https://doi.org/10.1007/s00163-017-0275-2

Heathcote, A., Brown, S., \& Mewhort, D. J. K. (2000). The power law repealed: The case for an exponential law of practice. Psychonomic Bulletin \& Review, 7(2), 185-207. https://doi.org/10.3758/BF03212979

Hevner, R. A., March, S. T., Park, J., \& Ram, S. (2004). Design Science in Information Systems Research. 32. 
I, L., A, S., K.-H, L., Hj, G., \& A, K. (2012). Needs of ergonomic design at control units in production industries. Work, (Supplement 1), 1594-1598. https://doi.org/10.3233/WOR2012-0358-1594

Ibrahim, M. R., Sreedharan, T., Fadhlul Hadi, N. A., Mustapa, M. S., Ismail, A. E., Hassan, M. F., \& Tajul Arifin, A. M. (2017). The Effect of Cutting Speed and Feed Rate on Surface Roughness and Tool Wear when Machining Machining D2 Steel. Materials Science Forum, 909, 80-85. https://doi.org/10.4028/www.scientific.net/MSF.909.80

Isam Abdul Qader, \& Abdul Rahman Elbadawi. (2019). Selection of the optimal manufacturing process of $C A D / C A M / C N C$ and conventional machining through engineering workshop experimentation. 17.

ISO 6983-1:2009. (n.d.). ISO 6983-1:2009. Retrieved May 9, 2019, from ISO website: http://www.iso.org/cms/render/live/en/sites/isoorg/contents/data/standard/03/46/34608.ht $\mathrm{ml}$

Jaber, M. Y. (2016). Learning curves: Theory, models, and applications. CRC Press.

Jaber, M. Y., \& Glock, C. H. (2013a). A learning curve for tasks with cognitive and motor elements. Computers \& Industrial Engineering, 64(3), 866-871. https://doi.org/10.1016/j.cie.2012.12.005

Jaber, M. Y., \& Glock, C. H. (2013b). A learning curve for tasks with cognitive and motor elements. Computers \& Industrial Engineering, 64(3), 866-871. https://doi.org/10.1016/j.cie.2012.12.005

Jaber, M. Y., \& Sikström, S. (2004). A numerical comparison of three potential learning and forgetting models. International Journal of Production Economics, 92(3), 281-294. https://doi.org/10.1016/j.ijpe.2003.10.019 
Jennings, M. G., \& Shah, N. (2014). Workforce planning and technology installation optimisation for utilities. Computers \& Industrial Engineering, 67, 72-81. https://doi.org/10.1016/j.cie.2013.10.008

Ji, M., Yao, D., Yang, Q., \& Cheng, T. C. E. (2015). Machine scheduling with DeJong's learning effect. Computers \& Industrial Engineering, 80, 195-200. https://doi.org/10.1016/j.cie.2014.12.009

Jin, H., Thomas, B. W., \& Hewit, M. (2016). Integer programming techniques for makespan minimizing workforce assignment models that recognize human learning. Computers \& Industrial Engineering, 97, 202-211. https://doi.org/10.1016/j.cie.2016.03.027

Joshi, V. K., Desai, K. P., \& Raval, H. K. (2018). Elliptical curve machining with variable feed rate for shape accuracy. Robotics and Computer-Integrated Manufacturing, 50, 37-49. https://doi.org/10.1016/j.rcim.2017.09.001

K. W. Keung, W. H. IP, \& T. C. Lee. (2000). A genetic algorithm approach to the multiple machine tool selection problem. 12.

Kabaldin, Y. G., Shatagin, D. A., \& Kolchin, P. V. (2018). Optimization of control program for CNC machines with regarding dynamic stability of cutting process and optimum modes of treatment in conditions of digital production. MATEC Web of Conferences, 226, 04016. https://doi.org/10.1051/matecconf/201822604016

Karsak, E. E., \& Kuzgunkaya, O. (2002). A fuzzy multiple objective programming approach for the selection of a \#exible manufacturing system. 11.

Karunakaran, K. P., \& Shringi, R. (2008). A solid model-based off-line adaptive controller for feed rate scheduling for milling process. Journal of Materials Processing Tech., 204(13), 384-396. https://doi.org/10.1016/j.jmatprotec.2007.11.092 
Katz, A. (2010). Beginning Microsoft Excel 2010.

Koltai, T., \& Kalló, N. (2017). Analysis of the effect of learning on the throughput-time in simple assembly lines. Computers \& Industrial Engineering, 111, 507-515. https://doi.org/10.1016/j.cie.2017.03.034

Kose, E., Kurt, A., \& Seker, U. (2008). The effects of the feed rate on the cutting tool stresses in machining of Inconel 718. Journal of Materials Processing Tech., 196(1-3), 165-173. https://doi.org/10.1016/j.jmatprotec.2007.05.019

Lamar, B. W., \& Lee, A. (1999). A strategic investment model for phased implementation of -exible manufacturing systems. 14.

Lange, J., Bergs, F., Weigert, G., \& Wolter, K.-J. (2012). Simulation of capacity and cost for the planning of future process chains. International Journal of Production Research, 50(21), 6122-6132. https://doi.org/10.1080/00207543.2012.661889

Lerch, J. F., \& Buck, J. R. (1975). An Exponential Learning Curve Experiment. 7.

Liang, F., Zhao, J., \& Ji, S. (2017). An iterative feed rate scheduling method with confined highorder constraints in parametric interpolation. The International Journal of Advanced Manufacturing Technology, 92(5-8), 2001-2015. https://doi.org/10.1007/s00170-017$0249-6$

Lie Tang, \& Landers, R. G. (2012). Predictive Contour Control With Adaptive Feed Rate. IEEE/ASME Transactions on Mechatronics, 17(4), 669-679. https://doi.org/10.1109/TMECH.2011.2119324

Liu, L., Caldwell, B. S., Wang, H., \& Li, Y. (2014). A knowledge-centric CNC machine tool design and development process management framework. International Journal of 
Production Research, 52(20), 6033-6051.

https://doi.org/10.1080/00207543.2014.906760

Logan, G. D. (1988). Toward an Instance Theory of Automatization.

Małachowski, B., \& Korytkowski, P. (2016). Competence-based performance model of multiskilled workers. Computers \& Industrial Engineering, 91, 165-177. https://doi.org/10.1016/j.cie.2015.11.018

Mao, J., Liu, S., \& Gao, Z. (2011). Three-axis NC milling simulation based on adaptive triangular mesh. Computers \& Industrial Engineering, 60(1), 1-6. https://doi.org/10.1016/j.cie.2010.06.016

March, S. T., \& Smith, G. F. (1995a). Design and natural science research on information tech.

March, S. T., \& Smith, G. F. (1995b). Design and natural science research on information technology. Decision Support Systems, 15(4), 251-266. https://doi.org/10.1016/01679236(94)00041-2

Media, R. (2015, March 23). Alloy Steel | The Four Types of Steel | Metal Supermarkets. Retrieved September 21, 2019, from Metal Supermarkets-Steel, Aluminum, Stainless, Hot-Rolled, Cold-Rolled, Alloy, Carbon, Galvanized, Brass, Bronze, Copper website: https://www.metalsupermarkets.com/alloy-steel-types/

Miao, E., Liu, H., Fan, K., Lv, X., Liu, Y., \& Hu, Y. (2017). Analysis of CNC machining based on characteristics of thermal errors and optimal design of experimental programs during actual cutting process. The International Journal of Advanced Manufacturing Technology, 88(5-8), 1363-1371. https://doi.org/10.1007/s00170-016-8865-0

Mirchandani, D., \& Pakath, R. (1999). Four models for a decision support system. Information \& Management, 35(1), 31-42. https://doi.org/10.1016/S0378-7206(98)00074-3 
Mishra, S., Prakash, Tiwari, M. K., \& Lashkari, R. S. (2006). A fuzzy goal-programming model of machine-tool selection and operation allocation problem in FMS: A quick converging simulated annealing-based approach. International Journal of Production Research, 44(1), 43-76. https://doi.org/10.1080/13528160500245772

Mohamad Y. Jaber, \& Maurice Bonney. (1996). Production breaks and the learning curve The forgetting phenomenon.

Moon, C., Lee, M., Seo, Y., \& Lee, Y. H. (2002). Integrated machine tool selection and operation sequencing with capacity and precedence constraints using genetic algorithmq. Industrial Engineering, 17.

Morgan, J., \& O’Donnell, G. E. (2017). Multi-sensor process analysis and performance characterisation in $\mathrm{CNC}$ turning-A cyber physical system approach. The International Journal of Advanced Manufacturing Technology, 92(1-4), 855-868. https://doi.org/10.1007/s00170-017-0113-8

Myung, I. J., Kim, C., \& Pitt, M. A. (2000). Toward an explanation of the power law artifact: Insights from response surface analysis. Memory \& Cognition, 28(5), 832-840. https://doi.org/10.3758/BF03198418

Nee, C. Y., Saad, M. S., Mohd Nor, A., Zakaria, M. Z., \& Baharudin, M. E. (2018). Optimal process parameters for minimizing the surface roughness in CNC lathe machining of Co28Cr6Mo medical alloy using differential evolution. The International Journal of Advanced Manufacturing Technology, 97(1-4), 1541-1555.

https://doi.org/10.1007/s00170-018-1817-0 
Nembhard, D. A., \& Uzumeri, M. V. (2000). Experiential learning and forgetting for manual and cognitive tasks. International Journal of Industrial Ergonomics, 25(4), 315-326. https://doi.org/10.1016/S0169-8141(99)00021-9

Newell, A., \& Rosenbloom, P. S. (1980). Mechanisms of skill acquisition and the law of practice. 60 .

Newman, S. T., Nassehi, A., Imani-Asrai, R., \& Dhokia, V. (2012). Energy efficient process planning for CNC machining. CIRP Journal of Manufacturing Science and Technology, 5(2), 127-136. https://doi.org/10.1016/j.cirpj.2012.03.007

Ngai, E. W. T., \& Cheng, T. C. E. (2001). A knowledge-based system for supporting performance measurement of AMT projects: A research agenda. International Journal of Operations \& Production Management, 21(1/2), 223-233. https://doi.org/10.1108/01443570110358558

Ngwenyama, O., Guergachi, A., \& McLaren, T. (2007). Using the learning curve to maximize IT productivity: A decision analysis model for timing software upgrades. International Journal of Production Economics, 105(2), 524-535. https://doi.org/10.1016/j.ijpe.2006.02.013

Norsworthy, J. R., \& Tsai, D. H. (2012). Macroeconomic Policy as Implicit Industrial Policy: Its Industry and Enterprise Effects. Springer Science \& Business Media.

Oliveira, J. F. G., Ferraz Júnior, F., Coelho, R. T., \& Silva, E. J. (2008). Architecture for machining process and production monitoring based in open computer numerical control. Proceedings of the Institution of Mechanical Engineers, Part B: Journal of Engineering Manufacture, 222(12), 1605-1612. https://doi.org/10.1243/09544054JEM1156 
Önüt, S., Soner Kara, S., \& Efendigil, T. (2008). A hybrid fuzzy MCDM approach to machine tool selection. Journal of Intelligent Manufacturing, 19(4), 443-453. https://doi.org/10.1007/s10845-008-0095-3

Oral, A., Cakir, M. C., Gonen, D., \& Karaoglan, A. D. (2016). Experimental investigation of a novel machining strategy for rough turning using variable feed rate. The International Journal of Advanced Manufacturing Technology, 87(1-4), 779-787. https://doi.org/10.1007/s00170-016-8521-8

Peffers, K., Tuunanen, T., Rothenberger, M. A., \& Chatterjee, S. (2007). A Design Science Research Methodology for Information Systems Research. Journal of Management Information Systems, 24(3), 45-77. https://doi.org/10.2753/MIS0742-1222240302

Persson, I. (1991). Developing a Manufacturing Strategy within a Capital-Investment Process A Case Study. International Journal of Operations \& Production Management, 11(3), 32-42. https://doi.org/10.1108/01443579110141595

Petroff, A. (2018, March 2). The global steel industry by the numbers. Retrieved April 2, 2019, from CNNMoney website: https://money.cnn.com/2018/03/02/news/economy/steelindustry-statistics-us-china-canada/index.html

Plaza, M. (2016a). Balancing the costs of human resources on an ERP project. Omega, 59, 171183. https://doi.org/10.1016/j.omega.2015.06.005

Plaza, M. (2016b). Balancing the costs of human resources on an ERP project. Omega, 59, 171183. https://doi.org/10.1016/j.omega.2015.06.005

Plaza, M., \& Rohlf, K. (2008). Learning and performance in ERP implementation projects: A learning-curve model for analyzing and managing consulting costs. International Journal of Production Economics, 115(1), 72-85. https://doi.org/10.1016/j.ijpe.2008.05.005 
Plaza, M., \& Zebala, W. (2019a). A decision model for investment analysis in CNC centers and CAM technology. Computers \& Industrial Engineering, 131, 565-577. https://doi.org/10.1016/j.cie.2019.03.028

Plaza, M., \& Zebala, W. (2019b). A decision model for investment analysis in CNC centers and CAM technology. Computers \& Industrial Engineering, 131, 565-577. https://doi.org/10.1016/j.cie.2019.03.028

Plaza, M., Zębala, W., \& Matras, A. (2019). Decision system supporting optimization of machining strategy. Computers \& Industrial Engineering, 127, 21-38. https://doi.org/10.1016/j.cie.2018.11.034

Power, D. J. (2008). Decision Support Systems: A Historical Overview. In F. Burstein \& C. W. Holsapple (Eds.), Handbook on Decision Support Systems 1: Basic Themes (pp. 121140). https://doi.org/10.1007/978-3-540-48713-5_7

Power, D. J. (2016). Computerized Decision Support Case Study Research: Concepts and Suggestions. In J. Papathanasiou, N. Ploskas, \& I. Linden (Eds.), Real-World Decision Support Systems (Vol. 37, pp. 1-13). https://doi.org/10.1007/978-3-319-43916-7_1

R. Venkata Rao. (2007). Introduction to Decision Making in the Manufacturing Environment. In Decision Making in the Manufacturing Environment (pp. 3-6). https://doi.org/10.1007/978-1-84628-819-7_1

Rai, J. K., \& Xirouchakis, P. (2008). Finite element method based machining simulation environment for analyzing part errors induced during milling of thin-walled components. International Journal of Machine Tools and Manufacture, 48(6), 629-643. https://doi.org/10.1016/j.ijmachtools.2007.11.004 
Rai, R., Kameshwaran, S., \& Tiwari, M. K. (2002). Machine-tool selection and operation allocation in FMS: Solving a fuzzy goal-programming model using a genetic algorithm. International Journal of Production Research, 40(3), 641-665. https://doi.org/10.1080/00207540110081515

Ramsey F.Hamade, Mohamad Y. Jaber, \& Sverker Sikstrom. (2009, September 15). Analyzing CAD competence with univariate and multivariat.pdf. Elsevier.

Ratava, J., \& Lohtander, M. (2018a). Fuzzy feed rate and cutting speed optimization in turning. The International Journal of Advanced Manufacturing Technology, 99(9-12), 20812092. https://doi.org/10.1007/s00170-018-1845-9

Ratava, J., \& Lohtander, M. (2018b). Fuzzy feed rate and cutting speed optimization in turning. The International Journal of Advanced Manufacturing Technology, 99(9-12), 20812092. https://doi.org/10.1007/s00170-018-1845-9

Ratchev, S., Liu, S., Huang, W., \& Becker, A. A. (2004). A flexible force model for end milling of low-rigidity parts. Journal of Materials Processing Technology, 153-154, 134-138. https://doi.org/10.1016/j.jmatprotec.2004.04.300

Razak, N. H., Chen, Z. W., \& Pasang, T. (2017). Effects of Increasing Feed Rate on Tool Deterioration and Cutting Force during End Milling of 718Plus Superalloy Using Cemented Tungsten Carbide Tool. Metals; Basel, 7(10), 441. http://dx.doi.org.ezproxy.lib.ryerson.ca/10.3390/met7100441

Ridwan, F., \& Xu, X. (2013). Advanced CNC system with in-process feed-rate optimisation. Robotics and Computer-Integrated Manufacturing, 29(3), 12-20. https://doi.org/10.1016/j.rcim.2012.04.008 
Ridwan, F., Xu, X., \& Ho, F. (2012a). Adaptive execution of an NC program with feed rate optimization. The International Journal of Advanced Manufacturing Technology, 63(912), 1117-1130. https://doi.org/10.1007/s00170-012-3959-9

Ridwan, F., Xu, X., \& Ho, F. C. L. (2012b). Adaptive execution of an NC program with feed rate optimization. The International Journal of Advanced Manufacturing Technology, 63(912), 1117-1130. https://doi.org/10.1007/s00170-012-3959-9

Roman, A., Bedi, S., \& Ismail, F. (2006). Three-half and half-axis patch-by-patch NC machining of sculptured surfaces. The International Journal of Advanced Manufacturing Technology, 29(5), 524-531. https://doi.org/10.1007/s00170-005-2553-9

Schmidt, J. R., De Houwer, J., \& Rothermund, K. (2016). The Parallel Episodic Processing (PEP) model 2.0: A single computational model of stimulus-response binding, contingency learning, power curves, and mixing costs. Cognitive Psychology, 91, 82108. https://doi.org/10.1016/j.cogpsych.2016.10.004

Seo, Y., \& Egbelu, P. J. (1996). Process plan selection based on product mix and production volume. International Journal of Production Research, 34(9), 2639-2655. https://doi.org/10.1080/00207549608905049

Smunt, T. L. (1999). Log-linear and non-log-linear learning curve models for production research and cost estimation. International Journal of Production Research, 37(17), 3901-3911. https://doi.org/10.1080/002075499189826

Srinivasan, H., Harrysson, O. L. A., \& Wysk, R. A. (2015). Automatic part localization in a CNC machine coordinate system by means of 3D scans. The International Journal of Advanced Manufacturing Technology, 81(5-8), 1127-1138. https://doi.org/10.1007/s00170-015-7178-z 
Stading, G., Flores, B., \& Olson, D. (2001). Understanding managerial preferences in selecting equipment. Journal of Operations Management, 19(1), 23-37. https://doi.org/10.1016/S0272-6963(00)00047-4

Sun, B., Chen, H., Du, L., \& Fang, Y. (2008). Machine Tools Selection Technology for Networked Manufacturing. 2008 Second International Symposium on Intelligent Information Technology Application, 530-534. https://doi.org/10.1109/IITA.2008.421

Taha, Z., \& Rostam, S. (2012). A hybrid fuzzy AHP-PROMETHEE decision support system for machine tool selection in flexible manufacturing cell. Journal of Intelligent Manufacturing, 23(6), 2137-2149. https://doi.org/10.1007/s10845-011-0560-2

Tansel, I. N., Ozcelik, B., Bao, W. Y., Chen, P., Rincon, D., Yang, S. Y., \& Yenilmez, A. (2006). Selection of optimal cutting conditions by using GONNS. International Journal of Machine Tools and Manufacture, 46(1), 26-35. https://doi.org/10.1016/j.ijmachtools.2005.04.012

Thakur, D. G., Ramamoorthy, B., \& Vijayaraghavan, L. (2009). Machinability investigation of Inconel 718 in high-speed turning. The International Journal of Advanced Manufacturing Technology, 45(5-6), 421-429. https://doi.org/10.1007/s00170-009-1987-x

Thomas L. Saaty. (1980). Marketing Applications of the Analytic Hierarchy Process.

Tolouei-Rad, M., \& Bidhendi, M. (1996). I. INTRODUCTION Establishment of efficient machining parameters has been a problem that has confronted. 16.

Vichare, P., Nassehi, A., \& Newman, S. T. (2011). Unified representation of fixtures: Clamping, locating and supporting elements in CNC manufacture. International Journal of Production Research, 49(16), 5017-5032.

https://doi.org/10.1080/00207543.2010.518992 
Wan, M., Zhang, W. H., Tan, G., \& Qin, G. H. (2008). Systematic simulation procedure of peripheral milling process of thin-walled workpiece. Journal of Materials Processing Technology, 197(1-3), 122-131. https://doi.org/10.1016/j.jmatprotec.2007.06.005

Wang, T.-Y., Shaw, C.-F., \& Chen, Y.-L. (2000). Machine selection in flexible manufacturing cell: A fuzzy multiple attribute decision-making approach. International Journal of Production Research, 38(9), 2079-2097. https://doi.org/10.1080/002075400188519

Wright, T. P. (1936). Factors Affecting the Cost of Airplanes. Journal of the Aeronautical Sciences, 3(4), 122-128. https://doi.org/10.2514/8.155

Xiong, Y., Wu, J., Deng, C., \& Wang, Y. (2016). Machining process parameters optimization for heavy-duty $\mathrm{CNC}$ machine tools in sustainable manufacturing. The International Journal of Advanced Manufacturing Technology, 87(5-8), 1237-1246. https://doi.org/10.1007/s00170-013-4881-5

$\mathrm{Xu}, \mathrm{K}$. , \& Tang, K. (2014). Five-axis tool path and feed rate optimization based on the cutting force-area quotient potential field. The International Journal of Advanced Manufacturing Technology, 75(9-12), 1661-1679. https://doi.org/10.1007/s00170-014-6221-9

Yan, R., Tang, X., Peng, F. Y., Wang, Y., \& Qiu, F. (2016). The effect of variable cutting depth and thickness on milling stability for orthogonal turn-milling. The International Journal of Advanced Manufacturing Technology, 82(1-4), 765-777. https://doi.org/10.1007/s00170-015-7418-2

Yang, L., Wang, Y.-R., \& Pai, S. (2009). On-line SPC with consideration of learning curve. Computers \& Industrial Engineering, 57(3), 1089-1095. https://doi.org/10.1016/j.cie.2009.04.015 
Yeh, S.-S., \& Su, H.-C. (2009). Implementation of online NURBS curve fitting process on CNC machines. The International Journal of Advanced Manufacturing Technology, 40(5-6), 531-540. https://doi.org/10.1007/s00170-007-1361-9

Yildiz, A. R. (2013). Optimization of cutting parameters in multi-pass turning using artificial bee colony-based approach. Information Sciences, 220, 399-407. https://doi.org/10.1016/j.ins.2012.07.012

Yin, Z. (2004). Rough and finish tool-path generation for NC machining of freeform surfaces based on a multiresolution method. Computer-Aided Design, 36(12), 1231-1239. https://doi.org/10.1016/j.cad.2004.01.003

Yurdakul, M., \& İç, Y. T. (2009). Analysis of the benefit generated by using fuzzy numbers in a TOPSIS model developed for machine tool selection problems. Journal of Materials Processing Technology, 209(1), 310-317. https://doi.org/10.1016/j.jmatprotec.2008.02.006

Zębala, W., \& Plaza, M. (2014a). Comparative study of 3- and 5-axis CNC centers for free-form machining of difficult-to-cut material. International Journal of Production Economics, 158, 345-358. https://doi.org/10.1016/j.jpe.2014.08.006

Zębala, W., \& Plaza, M. (2014b). Comparative study of 3- and 5-axis CNC centers for free-form machining of difficult-to-cut material. International Journal of Production Economics, 158, 345-358. https://doi.org/10.1016/j.ijpe.2014.08.006

Zhang, Z., Luo, M., Zhang, D., \& Wu, B. (2018). A force-measuring-based approach for feed rate optimization considering the stochasticity of machining allowance. The International Journal of Advanced Manufacturing Technology, 97(5-8), 2545-2556.

https://doi.org/10.1007/s00170-018-2127-2 
Zhao, R., Li, C., \& Tian, X. (2017). A novel industrial multimedia: Rough set based fault diagnosis system used in $\mathrm{CNC}$ grinding machine. Multimedia Tools and Applications, 76(19), 19913-19926. https://doi.org/10.1007/s11042-016-3878-0

Zhiwei, L., Hongyao, S., Wenfeng, G., \& Jianzhong, F. (2012). Approximate tool posture collision-free area generation for five-axis $\mathrm{CNC}$ finishing process using admissible area interpolation. The International Journal of Advanced Manufacturing Technology, 62(912), 1191-1203. https://doi.org/10.1007/s00170-011-3851-z

Zhou, H., Lang, M., Hu, P., Su, Z., \& Chen, J. (2019). The modeling, analysis, and application of the in-process machining data for $\mathrm{CNC}$ machining. The International Journal of Advanced Manufacturing Technology, 102(5-8), 1051-1066. https://doi.org/10.1007/s00170-018-2963-0

Zulkafli, Z., Perez, K., Vitolo, C., Buytaert, W., Karpouzoglou, T., Dewulf, A., ... Shaheed, S. (2017). User-driven design of decision support systems for polycentric environmental resources management. Environmental Modelling \& Software, 88, 58-73. https://doi.org/10.1016/j.envsoft.2016.10.012

Asiedu, Y., \& Gu, P. (1998). Product life cycle cost analysis: State of the art review. International Journal of Production Research, 36(4), 883-908. https://doi.org/10.1080/002075498193444

Ben-Arieh, D., \& Qian, L. (2003). Activity-based cost management for design and development stage. International Journal of Production Economics, 83(2), 169-183. https://doi.org/10.1016/S0925-5273(02)00323-7 
Bouaziz, Z., Ben Younes, J., \& Zghal, A. (2004). Methodology of machining costs evaluation for die and mould manufacturing. Journal of Materials Processing Technology, 152(2), 237245. https://doi.org/10.1016/j.jmatprotec.2004.04.242

Langmaak, S., Wiseall, S., Bru, C., \& Adkins, R. (2012). An activity based parametric hybrid cost model to estimate the unit cost of a novel gas turbine component.

Qian, L., \& Ben-Arieh, D. (2008). Parametric cost estimation based on activity-based costing: A case study for design and development of rotational parts. International Journal of Production Economics, 113(2), 805-818. https://doi.org/10.1016/j.ijpe.2007.08.010

Quintana, G., \& Ciurana, J. (2011). Cost estimation support tool for vertical high speed machines based on product characteristics and productivity requirements. International Journal of Production Economics, 134(1), 188-195. https://doi.org/10.1016/j.ijpe.2011.06.013

Tsai, W.-H., Tsaur, T.-S., Chou, Y.-W., Liu, J.-Y., Hsu, J.-L., \& Hsieh, C.-L. (2015). Integrating the activity-based costing system and life-cycle assessment into green decision-making. International Journal of Production Research, 53(2), 451-465. https://doi.org/10.1080/00207543.2014.951089 